$$
\begin{aligned}
& \text { Universidade de São Paulo } \\
& \text { Instituto de Física de São Carlos }
\end{aligned}
$$

Thiago Schiavo Mosqueiro

\title{
Processamento de informação em redes neurais sensoriais
}



Thiago Schiavo Mosqueiro

\section{Processamento de informação em redes neurais sensoriais}

Tese apresentada ao Programa de PósGraduação em Física do Instituto de Física de São Carlos da Universidade de São Paulo, para obtenção do título de doutor em Ciências.

Área de Concentração: Física Básica

Orientador: Prof. Dr. Leonardo Paulo Maia

Versão Corrigida

(Versão original disponível na Unidade que aloja o Programa)

São Carlos 
AUTORIZO A REPRODUÇÃO E DIVULGAÇÃO TOTAL OU PARCIAL DESTE TRABALHO, POR QUALQUER MEIO CONVENCIONAL OU ELETRÔNICO, PARA FINS DE ESTUDO E PESQUISA, DESDE QUE CITADA A FONTE.

Ficha catalográfica elaborada pelo Serviço de Biblioteca e Informação do IFSC, com os dados fornecidos pelo autor

Mosqueiro, Thiago Schiavo

Processamento de informação em redes neurais sensoriais / Thiago Schiavo Mosqueiro; orientador Leonardo Paula Maia - versão corrigida - São Carlos, 2015. $131 \mathrm{p}$.

Tese (Douroado - Programa de Pós-Graduação em Física Básica) - - Instituto de Física de São Carlos, Universidade de São Paulo, 2015.

1. Neurociência computacional. 2. Fenômenos críticos. 3. Leis de potência. 4. Olfato em insetos. 5. Aprendizagem de máquina. I. Maia, Leonado Paulo, orient. II. Título. 




\section{Agradecimentos}

Serei breve nos agradecimentos, porque seriam muito longos.

Começo agradecendo à minha família, por todo o suporte e paciência.

Agradeço demais a todos os amigos que fiz ao longo de toda a tese, a todos com quem compartilhei as experiências que me ajudaram a crescer e amadurecer ao longo de meu doutorado.

Agradeço a todo o pessoal do IFSC, em especial serviço de pós graduação e biblioteca, com quem tive o grande prazer de trabalhar.

Agradeço ao grupo Neurobiofísica do IFSC e ao meu orientador, que me acolheram e me ensinaram muito sobre física, vida e muito mais...

Por fim, agradeço a todo futuro leitor. Se levei esta tese até o fim, foi por acreditar que esta tese poderia ser útil. 



\section{RESUMO}

MOSQUEIRO, T. S. Processamento de informação em redes neurais sensoriais. 2015. 131 p. Tese de Doutorado - Instituto de Física de São Carlos, Universidade de São Paulo, São Carlos, 2015.

Com os avanços em eletrônica analógica e digital dos últimos 50 anos, a neurociência ganhou grande momentum e nasceu uma de suas áreas que atualmente mais recebe financiamento: neurociência computacional. Estudos nessa área, ainda considerada recente, vão desde estudos moleculares de trocas iônicas por canais iônicos (escala nanométrica), até influências de populações neurais no comportamento de grandes mamíferos (escala de até metros). O coração da neurociência computacional compreende técnicas inter- e multidisciplinares, envolvendo biologia de sistemas, bioquímica, modelagem matemática, estatística, termodinâmica, física estatística, etc. O impacto em áreas de grande interesse, como o desenvolvimento de fármacos e dispositivos militares, é a grande força motriz desta área. Especificamente para este último, a compreensão do código neural e como informação sensorial é trabalhada por populações de neurônios é essencial. E ainda estamos num estágio muito inicial de desvendar todo o funcionamento de muitos dos sistemas sensoriais mais complexos. Um exemplo é de um dos sentidos que parece existir desde as formas mais primitivas de vida: o olfato. Em mamíferos, o número de estudos parece sempre crescer com os anos. Ainda estamos, no entanto, longe de um consenso sobre o funcionamento de muitos dos mecanismos básicos do olfato. A literatura é extensa em termos bioquímicos e comportamental, mas reunir tudo em um único modelo é talvez o grande desafio atual. Nesta tese discuto, em duas partes, sistemas sensoriais seguindo uma linha bastante ligada ao sistema olfativo. Na primeira parte, um modelo formal que lembra o bulbo olfativo (de mamíferos) é considerado para investigar a relação entre a performance da codificacção neural e a existência de uma dinâmica crítica. Em especial, discuto sobre últimos experimentos baseados em observações de leis de potência 
como evidências da existência de criticalidade e ótima performance em populações neurais. Mostro que, apesar de a performance das redes estar, sim, ligada ao ponto crítico do sistema, a existência de leis de potência não está ligada nem com tal ponto crítico, nem com a ótima performance. Experimentos recentes confirmam estas observações. Na segunda parte, discuto e proponho uma modelagem inicial para o órgão central do sentido olfativo em insetos: o Corpo Cogumelar. A novidade deste modelo está na integração temporal, além de conseguir tanto fazer reconhecimento de padrões (qual odor) e estimativa de concentrações de odores. Com este modelo, proponho uma explicação para uma recente observação de antecipação neural no Corpo Cogumelar, em que sua última camada paradoxalmente parece antecipar a primeira camada. Proponho a existência de um balanço entre agilidade do código neural contra acurácia no reconhecimento de padrões. Este balanço pode ser empiricamente testado. Também proponho a existência de um controle de ganho no Corpo Cogumelar que seria responsável pela manutenção dos ingredientes principais para reconhecimneto de padrões e aprendizado. Ambas estas partes contribuem para o compreendimento de como sistemas sensoriais operam e quais os mecanismos fundamentais que os fornecem performance invejável.

PALAVRAS-CHAVE: Neurociência computacional. Fenômenos críticos. Leis de potência. Olfato em insetos. Aprendizagem de máquina 


\section{ABSTRACT}

MOSQUEIRO, T. S. Information processing in sensory neural networks. 2015. 131 p. Tese de Doutorado - Instituto de Física de São Carlos, Universidade de São Paulo, São Carlos, 2015.

With the advances in digital and analogical electronics in the last 50 years, neuroscience gained great momentum and one of its most well-financed sub-areas was born: computational neuroscience. Studies in this area, still considered recent by many, range from the ionic balance in the molecular level (scale of few nanometers), up to how neural populations influence behavior of large mammalians (scale of meters). The computational neuroscience core is highly based on inter- and multi-disciplinary techniques, involving systems biology, biochemistry, mathematical modeling, thermodynamics, statistical physics, etc. The impact in areas of current great interest, like in pharmaceutical drugs development and military devices, is its major flagship. Specifically for the later, deep understanding of neural code and how sensory information is filtered by neural populations is essential. And we are still grasping at the surface of really understanding many of the complex sensory systems we know. An example of such sensory modality that coexisted among all kinds of life forms is olfaction. In mammalians, the number of studies in this area seems to be growing steadily. However, we are still far from a complete agreement on how the basic mechanisms in olfaction work. There is a large literature of biochemical and behavioral studies, yet there is not a single model that comprises all this information and reproduces any olfactory system completely. In this thesis, I discuss in two parts sensory systems following a general line of argument based on olfaction. In the first part, a formal model that resembles the olfactory bulb (mammalians) is considered to investigate the relationship between performance in information coding and the existence of a critical dynamics. I show that, while the performance of neural networks may be intrinsically linked 
to a critical point, power laws are not exactly linked to neither critical points or performance optimization. Recent experiments corroborate this observation. In the second part, I discuss and propose a first dynamical model to the central organ responsible for olfactory learning in insects: the Mushroom Bodies. The novelty in this model is in the time integration, besides being able of pattern recognition (which odor) and concentration estimation at the same time. With this model, I propose an explanation for a seemingly paradoxical observation of coding anticipation in the Mushroom Bodies, where the last neural layer seems to trail the input layer. I propose the existence of a balance between accuracy and speed of pattern recognition in the Mushroom Bodies based on its fundamental morphological structure. I also propose the existence of a robust gain-control structure that sustain the key ingredients for pattern recognition and learning. This balance can be empirically tested. Both parts contribute to the understanding of the basic mechanisms behind sensory systems.

KEYwords: Computational neuroscience. Critical phenomena. Power laws. Olfaction in insects. Machine learning 


\section{Lista de Figuras}

Figura 1.1 - (a): Famosos desenhos de Ramon \& Cajal (A) duas células de Purkinje e (B) algumas células granulares. O ponto mais escuro $(A, B)$ são os corpos celulares, enquanto a estrutura superior é a árvore dendrítica dessas células e a inferior são os axônios. Via de regra, os potenciais de ação se propagam do axônio do neurônio pressináptico para o dendrito pos-sináptico. O ponto de ligação entre ambos é chamado de sinapse. (b): Forma estereotipada dos potenciais de ação apresentada pela grande maioria dos neurônios. Este gráfico foi obtido simulando um neurônio de Hodgkin-Huxley com uma corrente constante. . . . . . . . . . . . . . . 28

Figura 1.2 - Perspectiva qualitativa em microscópio de um neurônio isolado do gânglio estomatogástrico de um siri azul, sendo tocado por um eletrodo de tunstênio. Note que os neurônios deste gânglio são considerados muito grandes (maiores que $1 \mu \mathrm{m}$ ). Com menos foco, é possível ver suas ramificações dendríticas. . . . . . . . . . . . . . . . . . . . . . 31

Figura 2.1 - Sequência de quadros representando uma avalanche. Detecção de disparos em um dado eletrodo é identificado com uma marca vermelha. A escala de tempo entre um quadro e outro é sempre da ordem de $1 \mathrm{~ms}$. 
Figura 3.1 - Forma estereotipada do potencial de ação extraído de uma simulação usando o modelo de Hodgkin-Huxley (ver texto). (a): Série temporal do potencial de membrana de um neurônio disparando num passo fixo, regime conhecido como de disparos tônicos. Muitas vezes, este regime é atingido como resposta a uma corrente elétrica fixa, embora possa ser resultado também da dinâmica intrínseca do neurônio. (b): Uma visão simplificada dos diferentes estágios pelos quais o neurônio passa. Note que essa nomenclatura leva em consideração somente o potencial de membrana, e apesar de útil trata-se de uma descrição superficial e incompleta. No entanto estas são as principais características necessárias para estudar os experimentos de avalanches.

Figura 3.2 - Identificação das transições de cada autômato (representados pelas caixas, dentro das quais o número é o estado momentâneo do autômato) do modelo GH. O estímulo externo aparece como a probabilidade $\lambda$ (flecha azul), dirigido pela taxa $r$ por meio de $\lambda=1-e^{-r \Delta t}$, e só pode se manifestar sobre os neurônios excitáveis. Dado que um neurônio $j$ esteja excitável (caixa central em vermelho com estado 0), um de seus vizinhos excitados (caixa com estado 1 , em verde) pode excitá-lo com probabilidade dada pelo peso de sua conexão (no caso, $p_{2 j}$ ). Já um vizinho não excitado (autômatos em azul) não pode excitá-lo.

Figura 3.3 - Esquema com a construção do UCM. Em (a), a criação de arestas com ponta aberta. O número de arestas em cada nó deve seguir a distribuição desejada $p_{d}(k)$. Em (b), conexão das pontas das arestas uniformemente marcadas em verde, evitando dupla conexão. 
Figura 3.4 - (a) Transição de fase no modelo GH demonstrada por meio do parâmetro de ordem $F(r \rightarrow 0)$ (atividade neural espontânea). (b) Curvas estímuloresposta geradas por este modelo. A dinâmica é crítica quando $\sigma=1$, caso destacado em vermelho no gráfico. (c) Como resultado da transição de fase, a faixa dinâmica quando o modelo está ajustado em seu ponto crítico é ótima. Para todos os casos (a-b-c), as linhas são apenas guias para os olhos. . . . . . . . . . . . . . . . . . . . . . . 48

Figura 4.1 - Probabilidade de morte eventual. No ERM, temos o resultado numérico e analítico concordando. Mostro também resultados numéricos em outras redes. Apesar de o formalismo de processos de ramificação parecer não se encaixar nestas redes, ainda assim elas apresentam resultados similares. 55

Figura 4.2 - Taxa de ramificação crítica em função do expoente $\gamma$ da distribuição de graus no UCM, com $m=5, N=10^{4}$ e $K=10$. Como a taxa de ramificação crítica indica o mínimo peso sináptico médio para que haja possibilidade de atividade autossustentada, fica claro que a rede influencia profundamente a dinâmica macroscópica.

Figura 4.3 - Distribuições de tamanho e duração das avalanches no ERM. As únicas leis de potência são nos casos críticos $(\sigma=1)$. As linhas cheias são previsões do processo de ramificação. Os expoentes críticos são $-3 / 2$ para tamanho e -2 para duração de avalanches, concordando com os experimentos mais antigos. . . . . . . . . . . . . . . . 58 
Figura 4.4 - Distribuições de tamanho e duração das avalanches no BAM. O caso crítico $(\sigma=0.4)$ não apresenta leis de potência, assim como casos subcríticos apresentam leis de potência $(\sigma \sim 0.36)$. No caso crítico, após um regime inicial similar a uma lei de potência, segue uma anomalia que chamarei de bump, um excesso de massa probabilística concentrada em eventos do extremo da distribuição. Esses bumps representam ganhos em comparação ao que se esperaria de uma lei de potência pura, o que significa que avalanches de duração e tamanho maiores são relativamente mais prováveis. Os expoentes do regime de lei de potência (que dura apenas duas décadas) são -2.5 para tamanho e -3 para duração. . . . . 58

Figura 4.5 - Colapso das distribuições cumulativas de tempos de avalanches para ERM (a) e BAM (b). No canto inferior, apresento funções de escala encontradas numericamente em sistemas colocados em casos críticos (da equação 4.3.2). 60

Figura 4.6 - Diferença entre as entropias em redes de (a) ERM e (b) BAM. Em ambos os casos, a entropia de duração de avalanches (bolas azuis) se otimiza no mesmo ponto em que a faixa dinâmica (pentágonos verdes), i.e., no ponto crítico do sistema. Já a entropia de tamanhos de avalanches (quadrados laranjas) pode não otimizar no ponto crítico em algumas topologias. Em (b), o inset mostra que o ponto crítico de fato ocorre em $\sigma \approx 0.4$ no BAM. 63

Figura 4.7 - Exemplo de realizações diferentes de formas de avalanche resultantes da dinâmica GH. Superior: diferentes realizações de avalanches de durações diferentes (10, 20 e 40 passos temporais). Inferior: diferentes realizações de formas de avalanches, todas com duração 40 passos temporais. . . . . 64

Figura 4.8 - Formas médias de avalanches. Esquerda: exemplos extraídos de um conjunto crítico e um subcrítico. É importante notar que os resultados do caso crítico seguem uma forma parabólica bastante suave. Direita: Colapso das formas médias de avalanches usando a função de escala proposta 
Figura 5.1 - Microscopia eletrônica de uma antena de vespa (Vespula vulgaris), mostrando cílios comuns a diversos insetos e as células receptoras olfativas (estrutura rugosa e elíptica). Essas células têm proteínas específicas que se ligam a certos odorantes e desencadeiam um potencial de ação. Este potencial de ação sinaliza a detecção daquele odorante. . . . . . . . . . . . 68

Figura 5.2 - Microscopia do Corpo Cogumelar (CG) usando barra de escala de $100 \mu \mathrm{m}$. Os eixos d e I na figura indicam, respectivamente, o eixo dorsoventral e lateral mediano. Em outras palavras: o olhos composto direito da abelha estaria à direita da figura. As legendas mostram o mapeamento das áreas CG, das quais as mais importantes para o presente propósito são (de cima pra baixo): LC (Cálice Lateral), Pe (Pêdunculo), MC (Cálice Médio), a-L (lóbulo $\alpha$ ) e $\mathrm{AL}($ Lóbulo Antenal). . . . . . . . . . . . . . . . . . . . . 70

Figura 5.3 - Microscopia eletrônica tridimensional do Corpo Cogumelar de uma abelha de mel (Apis mellifera). Esta imagem evidencia bem o formato dos cálices lateral e médio e dos lóbulos $\alpha$ e $\beta$. Compare com a representação pictórica na figura $5.4 \ldots \ldots . \ldots . \ldots . \ldots 71$

Figura 5.4 - Visão cartunesca do Corpo Cogumelar, evidenciando as populações neurais centrais para o presente estudo: (i) Lóbulo Antenal (AL); (ii) Células Kenyon (KC) presentes nos Cálices lateral (ICa) e médio ( $\mathrm{mCa}$ ); (iii) o lóbulo $\alpha$, com neurônios extrínsecos (EN); e (iv) o Trato Protocalical (PCT). Para referência, estão também presentes os lóbulos ópticos. Compare a região verde com figura 5.3. LO e ME são regiões ligadas com a visão e servem para facilitar a logalização das outras áreas. Compare com a visão computacional dos CGs na figura 6.1, em que ficam evidentes os padrões de conexão são e o sentido do fluxo de informação olfativa. 
Figura 5.5 - Propriedades do Corpo Cogumelar na aprendizagem de odores baseados em séries realísticas. (a): Resposta de um sensor químico a monóxido de carbono (CO). Dados disponíveis no UCI Machine Learning Repository. ${ }^{(1)}$ (b): Série captada por um sensor químico semelhante em um campo aberto, evidenciando a complexidade de um sinal olfativo. ${ }^{(2)} \ldots 75$

Figura 5.6 - Medidas eletrofisiológicas em abelhas (Apis mellifera) de ambos Neurônios de Projeção (PNs) e Neurônios Extrínsecos (ENs). Embora os PNs estejam na primeira camada neural que recebe informação olfativa, estas medidas foram utilizadas por Strube-Bloss e colaboradores $^{(3)}$ para demonstrar a antecipação dos ENs em reconhecimento de odores. À esquerda, medidas reais e respectivos raster plots. À direita, resultados usando o modelo introduzido no capítulo 6 para diferentes experimentos.

Figura 6.1 - Visão computacional do funcionamento do Corpo Cogumelar (CG) para reconhecimento de padrões olfativos. São retratadas qualitativamente a maioria das características que tornam o CG um excelente dispositivo de reconhecimento de padrões em olfato. As características estão resumidas na seção 6.1. Setas indicam sinapses excitatórias, enquanto bolas indicam inibitórias. Os tamanhos relativos de cada populção neural também está qualitativamente indicado: as KCs representam a maior parcela do CG; os ENs são mais numerosos que os ENs (em abelhas de mel, aproximadamente de quatro a cinco vezes maiores); os PCTs formam o menor grupo.

Figura 6.2 - Propriedades do Corpo Cogumelar na aprendizagem de odores baseados em séries realísticas 
Figura 6.3 - Exemplo de uma simulação usando um neurônio Integra-e-Dispara com Vazamento (LIF, de Leaky Integrate-and-Figre). A curva em verde mostra a corrente em função do tempo e a curva azul, o potencial de membrana. Sempre que o neurônio atinge $-50 \mathrm{mV}$, o programa assume que houve um disparo e retorna para $V_{r}=-65 \mathrm{mV}$. Após um período refratário $t_{r e f}=20 \mathrm{~ms}$, o neurônio volta a evoluir no tempo. Nesta simulação, uso $t_{r e f}$ propositalmente longo para torná-lo mais visível na figura, em geral este parâmetro varia de 1 a $10 \mathrm{~ms}$. Note que apenas a partir de um certo valor de corrente, o neurônio passa a disparar. Também mostro o relaxamento que ocorre quando na ausência de corrente (últimos 100ms de simulação). Compare com o resultado de um modelo mais realístico na figura $1.1 b . \ldots \ldots \ldots \ldots \ldots$

Figura 6.4 - Sobreajuste gerado pela ignorância na camada das KCs, evidenciado pela região circular em azul escuro. Todos os conjuntos de parâmetros nesta região são candidatos em pé de igualdade, no que se refere à função perda definida para este algoritmo. Este resultado demorou em torno de um dia para ser calculado por completo.

Figura 6.5 - Simulação com exemplo da abordagem fuzzy. Neste caso, foram realizadas $N_{r}=100$ cópias do modelo, que foram simuladas de forma independente. Curvas azuis são as atividades individuais de cada cópia, enquanto as curvas pretas indicam, para cada tempo $t$, os maior e menor valores da atividade dos ENs dentre todas as cópias. Por fim, a curva azul escura (central) é a média da atividade dentre todas as $N_{r}$ observações. Note que as curvas azuis ocupam praticamente todo o espaço entre as curvas pretas. 
Figura 6.6 - Ajuste dos parâmetros livres usando o algoritmo baseado em uma Cadeia de Markov Monte Carlo. Em comparação ao sum dia inteiro de computação do algoritmo guloso, este método leva cerca de uma hora para obter resultados similares ou melhores. (a): definição gráfica de cada contribuição da função perda $\mathcal{E}$ (veja equação 6.4 .2 e o texto para detaIhes). (b): Exemplo de resultado do ajuste de parâmetros contra um dos possíveis experimentos. Vale comentar que a presença dos PCTs pode gerar uma diminuição próxima de $30 \%$ no valor final de $\mathcal{E}$. . . . . . . . . 96

Figura 7.1 - Estudo do tempo de respota dos ENs usando o modelo. (a): Registro experimental da atividade dos PNs e ENs. (b): Atividade do modelo com os parâmetros ajustados, em resposta à atividade registrada dos PNs. (c): Tempo de reação dos PNs e ENs: em todos os experimentos ocorre a antecipação. Os resultados mostrados acima são para 1-hexanol. A ordem dos experimentos foi escolhida de forma a ordenar decrescentemente a diferença entre os tempos de reação. A diferença é estatisticamente significativa (segundo teste de Mann-Whitney) com $p$-valor menor que

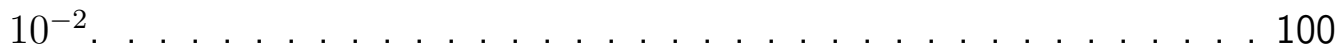

Figura 7.2 - Protocolo de estimulação artificial para testar de forma mais controlada a resposta do Corpo Cogumelar (CG). Este protocolo consiste em estímular os Neurônios de Projeção (PNs), iniciando em $t=2 \mathrm{~s}$ e evoluindo linearmente de 0 a $r_{\max }$ com derivada (i.e., inclinação) $\Delta$. (a): Atvidade dos PNs em resposta para diversos valores de $\Delta$, mantendo fixo $r_{\max }=150 \mathrm{~Hz}$. (b): Lado a lado, atividade dos PNs e dos Neurônios Extrínsecos (ENs). De forma qualitativa, vemos que os ENs tendem a ultrapassar os PNs. . . . . . . . . . . . . . . . . . . . . . . . . . 102 
Figura 7.3 - Tempos de resposta dos Neurônios Extrínsecos (ENs) ao protocolo de estimulação artificial. Todos os tempos foram medidos com respeito ao tempo de resposta dos neurônios de projeção, e por isso tempos negativos indicam que ENs responderam mais rapidamente que PNs. (a): Mantendo fixo $\Delta$, vario $r_{\max }$. Fica claro que para baixos $r_{\max }(<90 \mathrm{~Hz})$, os PNs respondem mais rapidamente. Este efeito era esperado: Nesse intervalo, a frequência de disparo induzida nos PNs é muito baixa e completamente incompatível com experimentos ou estímulos reais. (b): Fixando $r_{\max }=150 \mathrm{~Hz}$, o que induz nos PNs uma taxa de disparo de aproximadamente $23 \mathrm{~Hz}$ (veja figura 7.2 ), vario $\Delta$. Para todos os valores testados, os ENs sempre ultrapassam os PNs. Note que com altas inclinações $\Delta$, ENs chegam a avançar em $40 \mathrm{~ms}$, compatível com os dados experimentais que temos usado. . . . . . . . . . . . . . . . . . . . . . . 102

Figura 7.4 - Durante a estimulação da rede (entre 1 e 3 segundos), a variância cai significativamente, indicando alta fidelidade com o código neural. (a): Quanto maior o número $n$ de Células Kenyon (KCs), maior o ruído induzido. Isto indica amplificação (indesejada) de ruído vindo dos PNs. Observe à direita que esta variância espúria cresce superlinearmente (linha é apenas um guia para os olhos). (b): Queda abrupta da variância no início da estimulação olfativa.

Figura 7.5 - Resposta das Células Kenyon (KCs) para uma atividade dos Neurônios de Projeção (PNs) que cresce linearmente. A explosão de atividade não apenas indica falta de controle de ganho, como certamente atrapalharia no processo de aprendizagem e reconhecimento de padrões (como argumentado nas seções 5.3 e 6.1). 
Figura 7.6 - Controle de ganho na camada das células Kenyon (KCs). (a): Com os neurônios do Trato Protocerébro Calical (PCT), é possível ajustar o ganho da camada de KCs de forma que com o aumento da intensidade do sinal dos Neurônios de Projeção (PNs) não atrapalhe a esparsividade do código, consequentemente não danificando o processo de reconhecimento de padrões no sinal olfativo.

Figura 7.7 - Efeito do tamanho da camada de Células Kenyon (KCs) no tempo de reação dos Neurônios Extínsecos (ENs). Existe um tamanho ótimo de KCs que torna o tempo de reação o menor possível. A diferença entre o caso ótimo e casos subótimos é de quase $30 \mathrm{~ms}$, uma diferneça de tempo muito maior que a soma dos delays sinápticos e da ordem do tempo de reação total em moscas já treinadas. Adicionalmente, este tempo é próximo do tempo de reação de outras modalidades sensoriais (visão, por exemplo).

Figura 8.1 - Analogia com o processamento de informação no bulbo olfatório, em que existe um canal de comunicação entre o bulbo e o córtex olfatório. Espécies químicas associadas ao estímulo olfativo chegam a receptores químicos usualmente posicionados nas narinas de animais ou em partes específicas de insetos (antenas, por exemplo). Estes receptores químicos, ao se ligarem com as partículas dos odorantes, enviam disparos de potencial de ação ao bulbo olfatório, que é composto por camadas de células especializadas e que comunicam-se com o cortex olfatório. A entropia de duração de avalanches está ligada com a capacidade de codificação deste canal. . . . . . . . . . . . . . . . . . . . . 117 


\section{Lista de Tabelas}

Tabela 6.1 - Tabela com os intervalos de valores utilizados para os atrasos sinápticos de cada populção. Veja o texto para detalhes sobre considerções feitas para estas estimativas. . . . . . . . . . . . . . . . . 89

Tabela 6.2 - Tabela com os valores utilizados para os pesos de cada uma das contribuições na função perda. Pequenas variações não causam qualquer efeito perceptível no algoritmo. O fator mais crítico é manter $\zeta$ ao menos uma ordem de grandeza menor que os outros parâmetros.

Tabela 6.3 - Tabela com os intervalos utilizados para atualizar cada uma das categorias de parâmetros usados no modelo. 



\section{Sumário}

Capítulo 1 Introdução . . . . . . . . . . . . . . . . . . . 27

1.1 Neurociência . . . . . . . . . . . . . . . . . . . . . . . 27

1.2 Código neural . . . . . . . . . . . . . . . . . . 30

1.3 Como esta tese está organizada . . . . . . . . . . . . . . 32

Capítulo 2 Avalanches neurais e faixa dinâmica . . . . . . . 35

2.1 Avalanches neurais . . . . . . . . . . . . . . . . . 36

2.2 Criticalidade fora do equilíbrio . . . . . . . . . . . 37

2.3 Faixa dinâmica e leis de potência . . . . . . . . . . . . . . . 38

2.4 Novos experimentos e a questão central . . . . . . . . . . . . . . 39

Capítulo 3 Metodologia: Modelo probabilístico . . . . . . . . . 41

3.1 Dinâmica do modelo . . . . . . . . . . . . . . . . . . 41

3.2 Modelos de grafos aleatórios . . . . . . . . . . . . . . . . . . 44

3.2.1 Grafo de Erdős-Rényi . . . . . . . . . . . . . . . . . . . . . 45

3.2.2 Modelo de configuração descorrelacionado . . . . . . . . . . . . . 46

3.2.3 Modelo de Barabási-Álbert . . . . . . . . . . . . . . . . . . . 47

3.3 Taxa de disparo e faixa dinâmica . . . . . . . . . . . . . . . 47 
3.4 Medidas de avalanches . . . . . . . . . . . . . . . . . . . . . 49

3.5 Entropia de avalanches . . . . . . . . . . . . . . . 50

3.6 Modelo de criticalidade fora-do-equilíbrio . . . . . . . . . . . . . 51

3.7 Implementações deste modelo . . . . . . . . . . . . . . . . . . . 52

Capítulo 4 Resultados: Avalanches críticas e leis de potências 53

4.1 Morte eventual . . . . . . . . . . . . . . . . . . . . . . . 53

4.2 Excitabilidade resultante da rede . . . . . . . . . . . . . . . 56

4.3 Avalanches críticas sem leis de potência . . . . . . . . . . . . . . 57

4.3.1 Subamostragem da população neural . . . . . . . . . . . . . . 60

4.3.2 Expoentes do regime livre de escala inicial . . . . . . . . . . . . . 62

4.4 Entropia de tamanhos e tempos de avalanches . . . . . . . . . . . . 62

4.5 Última medida de criticalidade: colapso do perfil de avalanches . . . . . 63

Capítulo 5 Olfato em insetos e antecipação de informação . . . 67

5.1 Das antenas ao Corpo Cogumelar . . . . . . . . . . . . . . . . 67

5.2 Anatomia e fisiologia do Corpo Cogumelar . . . . . . . . . . . . . . . 69

5.2 .1 Balanço das populações . . . . . . . . . . . . . . . . . 72

5.2 .2 Inibição recorrente . . . . . . . . . . . . . . . . . . . . . . 72

5.2 .3 Resumo da morfologia . . . . . . . . . . . . . . . . . . . 73

5.3 Corpo cogumelar e aprendizagem . . . . . . . . . . . . . . . . 74

5.4 Antecipação na deteç̧ão de odores . . . . . . . . . . . . . . . 76

Capítulo 6 Metodologia: Modelo do Corpo Cogumelar . . . . . 79

6.1 Fundamentos computacionais . . . . . . . . . . . . . . . . 79 
6.1 .1 Classificando odores realísticos . . . . . . . . . . . . . . . . 81

6.1 .2 Ligação com Máquinas de Vetor Suporte . . . . . . . . . . . . . . . . 83

6.2 Modelo com dinâmica temporal . . . . . . . . . . . . . . . . 84

6.2 .1 Modelo Integra-e-Dispara . . . . . . . . . . . . . . . . . . 84

6.2.2 Modelos baseados em condutâncias variáveis . . . . . . . . . . . . 86

6.3 Modelo de conectividade . . . . . . . . . . . . . . . . . . . 87

6.3.1 Conectividade no Corpo Cogumelar . . . . . . . . . . . . . . . . 88

6.3 .2 Estimando o atraso sináptico . . . . . . . . . . . . . . . 89

6.4 Ajuste de parâmetros . . . . . . . . . . . . . . . . . . . 90

6.4 .1 Ajuste guloso . . . . . . . . . . . . . . . . . . . . . . . 90 90

6.4 .2 Metodologia Fuzzy . . . . . . . . . . . . . . . . . . . . . . 92

6.4 .3 Função perda . . . . . . . . . . . . . . . . . . . . . . 93

6.4 .4 Cadeias de Markov Monte Carlo . . . . . . . . . . . . . . . . . . . . 96

Capítulo 7 Resultados: Balanço entre performance e agilidade 99

7.1 Reprodução da antecipação dos ENs . . . . . . . . . . . . . . . 99

7.1 .1 Estimulação artificial . . . . . . . . . . . . . . . . . . . 101

7.2 Fidelidade da atividade neural e tamanho da rede . . . . . . . . . . 103

7.3 Controle robusto de ganho . . . . . . . . . . . . . . . . . . . 104

7.3.1 Análise de estabilidade dos pontos fixos . . . . . . . . . . . . 107

7.3.2 Condição suficiente para controle de ganho . . . . . . . . . . . . . 109

7.3.3 Verificando numericamente controle de ganho . . . . . . . . . . . 110

7.4 Ótimo tamanho de rede para antecipação da tomada de decisão . . . . 112 
7.5 Balanço entre Performance e Agilidade no Reconhecimento de Odores . 114

Capítulo 8 Conclusões . . . . . . . . . . . . . . . . . . . 115

8.1 Processamento de informação, criticalidade e leis de potência . . . . . 115

8.2 Antecipação no reconhecimento de odores . . . . . . . . . . . . . 117

Referências . . . . . . . . . . . . . . . . . . . 120 


\section{Capítulo 1}

\section{Introdução}

Neste capítulo, inicio esta tese com uma breve introdução à neurociência e explico como esta tese está organizada, reunindo os resultados e conclusões principais que demonstrarei ao longo do texto.

Como este tema é intrinsecamente multidisciplinar, este capítulo serve especialmente para homogeneizar a linguagem desta tese e reunir referências que podem ser úteis para possíveis leitores com bagagens distintas.

\subsection{Neurociência}

Neurociência trata-se de um campo extremamente vasto de pesquisa inter- e multidisciplinar cujo objetivo final é o entendimento de como o cérebro funciona. Nossa percepção do mundo, raciocínio, capacidade de aprender, e capacidade motora estão todos baseados fortemente no cérebro e no sistema nervoso. Embora questões relacionadas ao cérebro e a mente, este segundo como um ente mais abstrato, datam de muito cedo na história humana, a natureza de seu funcionamento e as ferramentas necessárias para um estudo mais aprofundado só começaram a surgir no último século. Um dos campos científicos ligados ao estudo da neurocência datam de Século XIX, em que pesquisadores acreditavam ser possível ligar características de uma pessoa, como caráter, personalidade, e grau de periculosidade criminal, utilizando o formato do crânio - i.e., observando caroços e protuberâncias. Essa visão, apesar de atualmente descartada, já mostra que a curiosidade humana em conectar cérebro e mente sempre esteve 
(a)

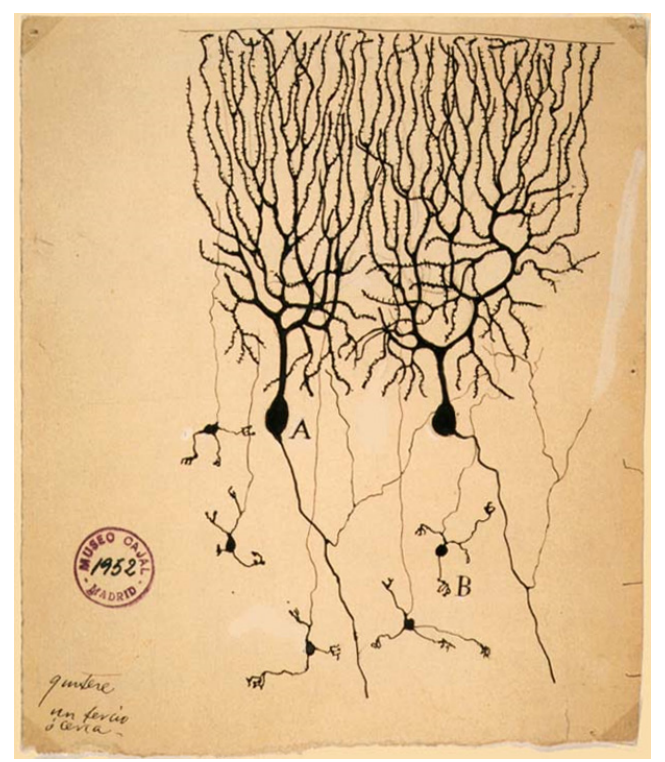

(b)

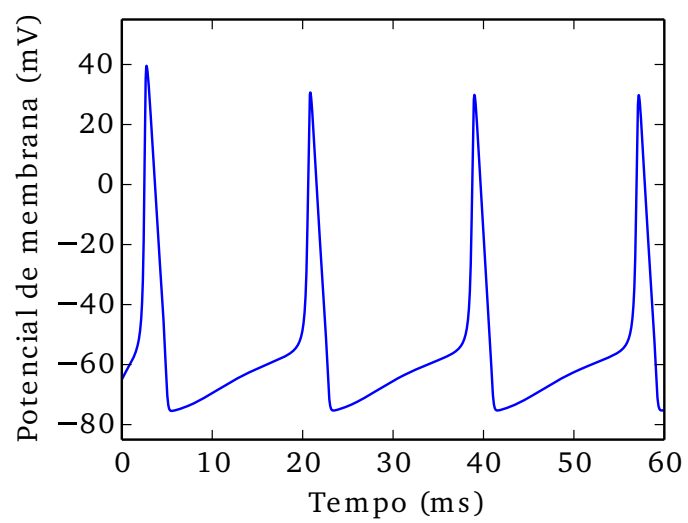

Figura 1.1- (a): Famosos desenhos de Ramon \& Cajal (A) duas células de Purkinje e (B) algumas células granulares. O ponto mais escuro $(A, B)$ são os corpos celulares, enquanto a estrutura superior é a árvore dendrítica dessas células e a inferior são os axônios. Via de regra, os potenciais de ação se propagam do axônio do neurônio pressináptico para o dendrito pos-sináptico. O ponto de ligação entre ambos é chamado de sinapse. (b): Forma estereotipada dos potenciais de ação apresentada pela grande maioria dos neurônios. Este gráfico foi obtido simulando um neurônio de Hodgkin-Huxley com uma corrente constante.

Fonte: (a) RAMÓN \& CAJAL '1899. (b) Elaborada pelo autor.

presente.

Os primeiros passos na compreensão do funcionamento do cérebro vêm com a identificação das unidades "mais básicas" que o constituem: os neurônios. São de Ramón \& Cajal e Golgi as primeiras especulações em nível celular sobre o funcionamento do cérebro. Eles retrataram e analisaram extensivamente diversos tecidos neurais, o que lhes rendeu o Nobel de 1906. Em especial, Ramón \& Cajal foi o primeiro a observar filamentos organizados que crescem por quimiotaxia - direcionados por concentrações químicas específicas -, hoje conhecidos como axônios. Ambos estes pesquisadores, com visões filosoficamente divergentes, contribuiram de forma ímpar para o avanço de estudos fisiológicos e anatômicos em neurociência. Na figura 1.1a reproduzo uma fotografia de um dos desenhos mais famosos de Ramón \& Cajal: células de Purkinje e células granulares, observadas no cerebelo de pombos.

Simultaneamente, conduziam-se diversos estudos sobre o papel de certas correntes elétricas no sistema nervoso, que culminaram na descoberta do potencial de ação por Emil du 
Bois-Reymond: uma velocíssima inversão da ordem de $100 \mathrm{mV}$ na diferença de potencial elétrico entre o meio extra- e intracelular (potencial de membrana) que se propaga através dos axônios para outros neurônios e grande responsável pela propagação da informação por todo o sistema nervoso. ${ }^{(4)}$ Por esse caráter de iniciar uma reação nos outros neurônios, dizemos que o neurônio disparou (to spike). Todas estas observações foram o berço da crença atual de que o cérebro deve ser encarado como um gigantesco sistema dinâmico formado por unidades altamente não lineares, acopladas pelos axônios e dendritos. ${ }^{(5)}$ Hoje em dia, há um grande apelo tanto pelo entendimento dos mecanismos celulares microscópicos que geram a atividade neural como pela forma na qual estes neurônios se agrupam e acoplam. Somente com estes dois ingredientes será possível chegarmos perto de responder como somos capazes de realizar tarefas computacionalmente tão complexas e de forma tão eficiente.

Neurônios, unidades de processamento do sistema nervoso central, são células fisiologicamente especializadas para gerar pulsos eletroquímicos com notável precisão espaço-temporal. Apesar de apresentarem formas e funções bastante variadas, são comuns a todos três divisões físicas $^{(4,6)}$ : (i) o corpo celular, estrutura central também chamada de soma; (ii) projeções alongadas do corpo celular, conhecidas como dendritos; e (iii) os axônios, fibras nervosas responsáveis pela propagação de tais pulsos eletroquímicos - também conhecidos como potenciais de ação (ou simplesmente spikes). Por último, as "sinapses" são estruturas celulares responsáveis pela comunicação eletroquímica entre um neurônio e outro. Durante o spike a diferença de potencial elétrico propaga-se pelo axônio de um neurônio - chamado de pressináptico - e viaja, através da sinapse, até o dendrito de outro neurônio - pós-sináptico ${ }^{(4,5)}$. Nesse momento, uma troca de íons entre o meio externo e o neurônio pós-sináptico induz mudanças que podem inclusive gerar um novo pulso. Via de regra, os spikes constituem a base da comunicação entre neurônios. Os mecanismos biofísicos que geram os spikes têm como modelo primário o modelo de Hodgkin-Huxley. ${ }^{(7)}$ Embora como base qualitativa funcione muito bem, mesmo este modelo não se aplica tão bem a toda a diversidade de neurônios existentes $^{(8)}$, principalmente porque foi concebido para explicar os axônios gigantes de lulas. 


\subsection{Código neural}

A comunicação neural pode ser desencadeada por um sistema periférico (como um nervo nos membros de um animal) que gera um sinal inicial e propagada até o sistema nervoso central. Ao longo de todo esse caminho, o sinal original passa por diversas transformações (o sinal pode ser filtrado, atenuado, amplificado, comparado com sinais advindos de outras populações neurais, etc). Nesses processos, nosso sistema está realizando computações para compreender o que significa o sinal inicial e decidir como respondê-lo. Este processo de compreensão é usualmente identificado como "(De)Codificação Neural", já o processo de decisão subdivide-se em muitas e muitas áreas da neurociência. Acredita-se hoje que grande parte do funcionamento dos seres vivos decorre de mecanismos assim, extremamente intrincados e interconectados de forma a conseguir resolver problemas diversos e complexos. ${ }^{(4,5,9,10)}$ Um exemplo: com erro bastante aceitável, somos capazes de olhar para a foto de uma pessoa e descobrir seu sexo. Mesmo nos dias atuais, este ainda é um desafio razoável dentro de inteligência artificial ${ }^{(9)}$. Estima-se hoje a existência de quase uma centena de bilhões de neurônios no cérebro humano ${ }^{(11,12)}$ e há fortes indícios de que todas as três partições físicas de cada um destes quase trilhões de neurônios são utilizadas para computar "algo", $(13,14)$ o que torna o desafio de descobrir como funciona a codificação neural um dos problemas científicos mais complexos (e desejados por aplicações) deste século.

Atualmente, contamos com tecnologia suficiente para acessar quantitativamente diversas propriedades neurais eletroquímicas. A eletrofisiologia tornou possível investigações diversas sobre como neurônios individuais ou em grupos se comportam em diversos contextos e sob a ação dos mais variados cenários. Para medir sinais neurais, as principais técnicas baseiamse em eletrodos (finas pontas de prova) que podem ser introduzidos dentro (intracelular) ou muito próximo (extracelular) do corpo celular ou ramificações. Na figura 1.2 vemos um neurônio do gânglio estomatogástrico de um siri azul e um eletrodo de tungstênio introduzido dentro do corpo celular. Exceto técnicas ópticas que surgiram nos últimos 10 anos, grande parte dos estudos de eletrofisiologia usa tecnologias baseadas em aquisição rápida (escala de submilissegundos) de sinais elétricos. ${ }^{(15)}$

Técnicas especializadas também foram se desenvolvendo para responder questões relacio- 


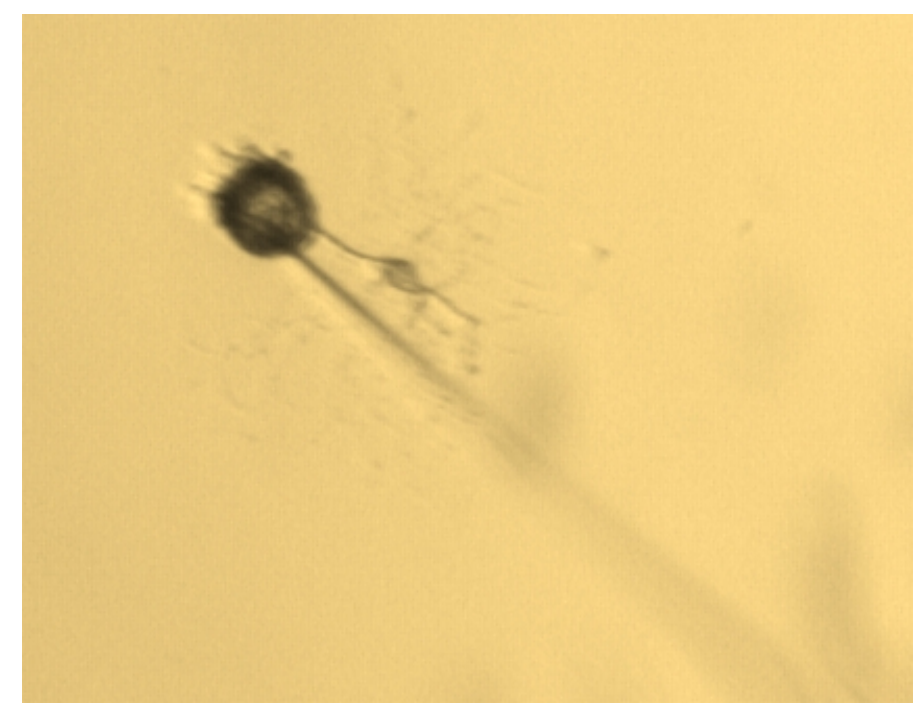

Figura 1.2- Perspectiva qualitativa em microscópio de um neurônio isolado do gânglio estomatogástrico de um siri azul, sendo tocado por um eletrodo de tunstênio. Note que os neurônios deste gânglio são considerados muito grandes (maiores que $1 \mu \mathrm{m})$. Com menos foco, é possível ver suas ramificações dendríticas.

Fonte: Cortesia de RAFAEL VIEGAS (2009).

nadas ao como neurônios são capazes de codificar, armazenar e processar informação. ${ }^{(16)}$ Esta área, conhecida como Teoria da Informação em âmbito mais geral, foi o grande carro chefe no repertório dos eletrofisiologistas nas últimas décadas.

Dentro deste enorme sistema, os sistemas sensoriais são populações de neurônios que codificam, num primeiro nível, informações sobre o ambiente externo para um ser vivo. A forma como essa codificação é realizada depende do sistema específico e do tipo de informação que se quer codificar. Informações captadas por sistemas sensoriais podem ser reunidas para uma resposta rápida (promovida por interneurônios conectados a neurônios motores, por exemplo) ou podem ser propagadas até um centro nervoso, como o cérebro, para uma póscomputação de tarefas mais complexas (e, consequentemente, mais lentas). Uma parte expressiva dos esforços de pesquisa atuais na neurociência tenta entender como este código funciona, principalmente porque grande parte de nossas respostas "comportamentais" a um ambiente baseiam-se em como tais sistemas trabalham. Esse conhecimento não apenas nos ajudaria a compreender o cérebro como um todo, mas também geraria tecnologia (e.g., interfaces cérebro-máquina) e novas terapias para doenças do sistema nervoso. A ciência que investiga estas respostas comportamentais e cognitivas a ambientes diversos - de forma minimamente quantitativa - é a psicofísica. 


\subsection{Como esta tese está organizada}

Esta tese concentra-se em questões relativas aos mecanismos fundamentais para a codificação neural. Em especial, para sistemas sensoriais. Há duas partes distintas, embora bem correlacionadas, nesta tese: (i) transições e fenômenos críticos em sistemas sensoriais, compreendendo os capítulos 2, 3 e 4, e (ii) olfato em insetos, compreendendo os capítulos 5, 6 e 7. Brevemente, explico a seguir qual o principal objetivo de cada uma destas partes e como o conteúdo está dividido.

Há quase uma década, indícios fortes de que fenômenos críticos estariam envolvidos na dinâmica neural e poderiam ser fundamentais para o funcionamento do cérebro como um todo agitou a comunidade científica. Muitas das observações neste sentido baseiam-se na ligação íntima que existe entre leis de potência e fenômenos críticos. No entanto, distribuições de leis de potência são objetos estatísticos especialmente complexos, e sua frequente observação na natureza, sem o devido cuidado metodológico, vem sendo criticada por muitos pesquisadores. Outra crítica ataca a própria ligação entre leis de potência e fenômenos críticos, dado que populações neurais não podem ser encaradas como sistemas em equilíbrio (caso no qual é possível fazer esta ligação). Uma revisão bibliográfica e explicação mais aprofundada deste tópico é apresentada no capítulo 2.

Para contribuir nesta área, propus o uso de um modelo neural simplificado e que permite a investigação da ligação de leis de potência com ambos fenômenos críticos e performance da população neural. ${ }^{(17)}$ Modelos simplificados similares são comumente utilizados para estudar sincronização de grupos de neurônios. ${ }^{(18,19)}$ Explico o modelo e a metodologia no capítulo 3, e no capítulo 4 exponho meus resultados. Em especial, aponto que a performance da rede parece não estar ligada exatamente com a existência de leis de potência, mas com a otimização de uma entropia do sistema. ${ }^{(20)}$ Esta otimização sempre parece ocorrer no ponto crítico, embora nem sempre em conjunto com leis de potência. ${ }^{(21)}$

Na segunda parte desta tese, passo a estudar olfato em insetos, onde ocorre um efeito quase paradoxal: a última camada neural relacionada com reconhecimento de odores parece antecipar a primeira camada que recebe a informação olfativa. Este fenômeno, apontado experimentalmente, traz diversas perguntas que, se respondidas satisfatoriamente, podem levar 
à construção de dispositivos eletroquímicos mais eficientes. Em especial em abelhas, o sentido do olfato não apenas é extremamente aguçado, como também é pelo menos uma ordem de grandeza mais rápido que qualquer dispositivo hoje construído. Por esse motivo, e para gerar um texto autocontido e que traz uma revisão bibliográfica sobre olfato em insetos do ponto de vista computacional, reuno no capítulo 5 todas as informações necessárias para construir um modelo capaz de testar hipóteses com respeito à essa antecipação do código neural. Este capítulo pode ser pulado sem grandes prejuízos para o entendimento dos capítulos seguintes, com exceção da seção 5.4, onde o fenômeno é explicado(22).

No capítulo 6 introduzo o modelo que será então usado no capítulo 7 para resolver esta questão. Neste capítulo utilizo modelos realísticos, baseados em condutividades sinápticas e sistemas de equações diferenciais não lineares. ${ }^{(22,23)}$ Adianto que obtive indicações de que a estrutura morfológica, que se baseia em uma forte divergência do sinal seguida de uma convergência, parece ser a maior responsável pela antecipação do sinal olfativo. Mais ainda, esta estrutura parece induzir um balanço entre quão rápido e quão bem o inseto é capaz de reconhecer odores. Todas estas observações levantam questões novas e predições que poderão ser experimentalmente testadas no futuro.

Todo código desenvolvido para esta tese será publicado como software livre. Publico todos os códigos sob licenças bastante permissivas, para que qualquer um possa ser beneficiado da forma mais fácil possível. Além disso, a reprodutibilidade desta tese deve ser imediata a partir dos códigos. A primeira parte desta tese, referente aos capítulos 2-4 já está disponibilizado por completo pelo serviço Github. ${ }^{(24)}$ O código fonte para gerar esta tese também será disponível em breve no mesmo serviço. O código fonte referente aos capítulos 5-7 está em fase de revisão para ser publicado em breve.

Por fim, eu fiz de fato a escolha de escrever em primeira pessoa do singular (eu). Esta escolha é consciente (baseado que há apenas um autor), e segue coerente ao longo da tese. Isso não implica que eu não trabalhei com outras pessoas, e as citações que faço indicam e dão créditos ao imenso grupo de pessoas que me ajudou e com quem colaborei ao longo de meu doutorado. O leitor encontrará, no entanto, alguns trechos em que mudo para o plural. Nestes momentos, me refiro a autor e leitor como um grupo (por exemplo, vimos no capítulo 
anterior que ...). 


\section{Capítulo 2}

\section{Avalanches neurais e faixa dinâmica}

Há uma década, Beggs e Plenz ${ }^{(25)}$ perceberam que a atividade neural gravada por matrizes de eletrodos apresenta indícios fortes de que, por trás da rica gama de padrões de disparo apresentados por populações de neurônios talvez não tão pequenas, pode existir um fenômeno crítico. Devido à semelhança desses padrões com as avalanches estudadas por Bak, Tang e Wiesenfeld, ${ }^{(26)}$ Beggs e Plenz cunharam o nome avalanches neurais. Essas observações tomaram força no cenário mundial, e muitos experimentos foram realizados, tanto in vitro como in vivo, para ressaltar uma possível universalidade deste comportamento em um amplo espectro de animais, sistemas e populações. Assim criou-se uma jovem ramificação da neurociência que, unida às técnicas da física estatística de não equilíbrio, passou a buscar uma razão para tal tipo de comportamento.

Isso levou Shew e colaboradores ${ }^{(27)}$ a observar que esses padrões de atividade crítica, quando ligadas a certos tipos de computação, podem estar correlacionadas ao ótimo funcionamento de redes sensoriais, quantificadas pela faixa dinâmica de curvas estímulo-resposta. Vou discutir nas seções seguintes essas observações e, por fim, chamar a atenção do leitor para experimentos realizados em 2012 que demonstram discrepâncias deste cenário que não podem ser ignoradas. Essas discrepâncias nos levarão à questão fundamental de meu trabalho: qual a relação entre a faixa ótima dinâmica e as avalanches neurais? Em poucas palavras, eu vou buscar o mecanismo microscópico realmente responsável pela maximização da faixa dinâmica destes sistemas. Nos próximos capítulos vou responder tal pergunta e ligar nossas descobertas com os experimentos aqui discutidos. 


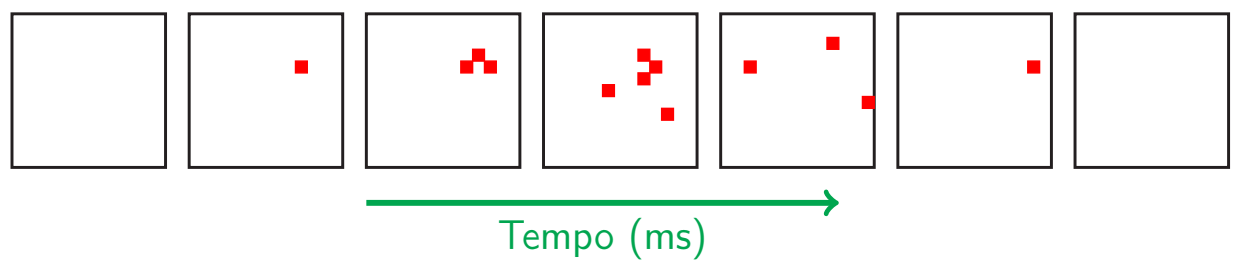

Figura 2.1- Sequência de quadros representando uma avalanche. Detecção de disparos em um dado eletrodo é identificado com uma marca vermelha. A escala de tempo entre um quadro e outro é sempre da ordem de $1 \mathrm{~ms}$.

Fonte: Elaborada pelo autor.

\subsection{Avalanches neurais}

Os sistemas sensoriais são populações de neurônios que codificam, num primeiro nível, informações sobre o ambiente externo para um ser vivo. ${ }^{(13)}$ A forma como essa codificação é realizada depende do sistema específico e do tipo de informação que se quer codificar. Informações captadas por sistemas sensoriais podem ser reunidas para uma resposta rápida (promovida por interneurons conectados a neurônios motores, por exemplo) ou podem ser propagadas até um centro nervoso, como o cérebro, para uma póscomputação de tarefas mais complexas (e, consequentemente, mais lentas). Uma parte expressiva dos esforços de pesquisa atuais na neurociência tenta entender como este código funciona, principalmente porque grande parte de nossas respostas "comportamentais" a um ambiente baseiam-se em como tais sistemas trabalham. ${ }^{(28)}$ A ciência que investiga estas respostas comportamentais e cognitivas a ambientes diversos - de forma minimamente quantitativa - é a psicofísica.

Nesse contexto, uma avalanche neural é uma sequência de disparos iniciada por um (às vezes por um pequeno grupo de) neurônio e que se propaga pela rede neural através das sinapses. A figura 2.1 mostra de forma pictórica essa ideia de avalanches neurais. Nos experimentos, uma matriz de eletrodos mede o potencial de membrana de uma população de neurônios ao longo do tempo ${ }^{(25,29-32)}$. Usando esta série temporal, são detectados e registrados apenas os instantes de ocorrência dos spikes. Assim, da fig. 2.1 ficam claras as definições de duração (tempo até a atividade se extinguir) e tamanhos (número de eletrodos envolvidos na sequência de atividades) de avalanches.

O fato surpreendente nisso tudo está nas distribuições de probabilidade de duração e tamanho de avalanches: ambas apresentam leis de potência, ou seja, suas distribuições têm 
forma $p(x) \sim x^{-\gamma}$, em que $\gamma$ é seu expoente. Estas leis são especialmente importantes em sistemas físicos, e podem revelar possíveis mecanismos microscópicos. ${ }^{(36)}$ Note que, se a operação $x \mapsto \alpha x$, com $\alpha \in \mathbb{R}$, então a razão

$$
\frac{p(\alpha x)}{p(x)} \sim \frac{\alpha^{-\gamma} x^{-\gamma}}{x^{-\gamma}}=\alpha^{-\gamma}
$$

independe de $x$, indicando que a razão a probabilidade relativa entre dois eventos $x=x_{1} \mathrm{e}$ $x=x_{2}$ invaria se o eixo $x$ for re-escalado pelo real $\alpha$. Costuma-se chamar esta propriedade de invariância de escala.

Por fim, não apenas o fato de ser uma lei de escala, mas conhecer qual o valor do expoente desta lei pode ajudar a entender mais aprofundadamente a dinâmica microscópica do sistema. ${ }^{(36)}$ Em específico, diversos exprimentos com populações neurais razoavelmente grandes, tanto in vitro como in vivo, mostram os expoentes $-3 / 2$ para tamanho e -2 para duração de avalanches. ${ }^{(29,30,33)}$ Estes são os mesmos expoentes observados no modelo de pilha de areia, modelo base do que se tornou a criticalidade auto-organizada. ${ }^{(34)}$ Isso é um forte indício de que um fenômeno parecido ao da pilha de areia pode subjazer a dinâmica neural. Destas observações não apenas vem a ideia de cunhar o termo avalanche neural, como também a hipótese de criticalidade na dinâmica neural.

\subsection{Criticalidade fora do equilíbrio}

Fenômenos críticos estão presentes em todas as áreas da física, desde em sistemas quânticos à cosmologia, e renderam o prêmio Nobel ao físico americano Kenneth Wilson principalmente pela criação do (semi-) grupo de renormalização. Um exemplo bastante típico desta fenomenologia ocorre em nosso cotidiano: ímãs comuns ("de geladeira") perdem abruptamente sua magnetização natural se aumentarmos muito sua temperatura. Em sentido amplo, a transição da fase ferro- para a paramagnética no modelo de Ising é o modelo padrão para a compreensão desse fenômeno. ${ }^{(35,36)}$ Para um sistema de dipolos magnéticos acoplados a um reservatório térmico (em duas ou mais dimensões), há uma temperatura $T_{C}$ especial a partir da qual a magnetização por dipolo, no equilíbrio, anula-se. Quando a magnetização está nula, dizemos 
que estamos na fase desordenada; quando a magnetizacão não é nula, chamamos de fase ordenada. Por este motivo, $T_{C}$ é chamada de temperatura crítica.

A transição de fase a que Beggs e Plenz se referiam, no entanto, é uma transição um pouco diferente em dois sentidos. Primeiramente, porque ocorre fora do equilíbrio e é bastante similar ao modelo de pilha de areia, ${ }^{(34)}$ que é a base do que chamamos hoje de criticalidade autoorganizada. Além disso, não foi dada uma explicação precisa de que fases estavam envolvidas nesta transição. Nos seis anos seguintes a esta primeira publicação, novos estudos apontaram para a ligação destas observações com processos de ramificação e demonstraram que existem duas fases bem distintas ${ }^{(37-39)}$ : (i) uma fase em que a atividade iniciada por um estímulo rapidamente morre sem quase se propagar (fase ordenada); (ii) outra fase em que a atividade neural se autossustenta (fase desordenada). Chamando de parâmetro de (des)ordem deste fenômeno crítico a atividade neural, descobriu-se logo um parâmetro de controle: a taxa de ramificação da rede ${ }^{(25,37-39)}$. Exatamente no ponto de transição entre estas duas fases (ponto crítico), ocorrem as avalanches livres de escala, ${ }^{(38)}$ bem como a otimização da performance da rede em codificar os estímulos externos. ${ }^{(27,38,40)}$ A última destas grandezas tornou-se central em nossas primeiras investigações: a faixa dinâmica.

\subsection{Faixa dinâmica e leis de potência}

Criticalidade está em geral ligada com a otimização de alguma propriedade do sistema. No caso do modelo de Ising, o comprimento de correlação diverge no ponto crítico. No modelo de pilha de areia, avalanches tanto de tamanho como de tempo muito maiores que a média se tornam bem mais frequentes. Aproximando da discussão a neurociência, diversos mecanismos neurais de resposta necessitam de memória, e modelos (de criticalidade auto-organizada) têm sido aplicados a working memories (memórias que recuperam informações de forma rápida). Em outras palavras, a existência de fenômenos críticos na dinâmica neural pode ser uma possível descrição de como alguns sistemas naturais conseguem trabalhar tão bem.

A partir de 2009, Shew e colaboradores demonstraram que a existência de avalanches neurais está fortemente correlacionada com a otimização de uma quantidade de equilíbrio importante para a psicofísica: a faixa dinâmica. ${ }^{(27)}$ Esta grandeza mede o comprimento da 
região de estímulos que o sistema em estudo é capaz de codificar. Medidas em humanos mostram faixas dinâmicas extremamente largas para sentidos como a audição. Esta conexão entre grandezas fora de e em equilíbrio revelou mais um caso em que a dinâmica crítica pode ser a responsável pela performance ótima do sistema sensorial.

\subsection{Novos experimentos e a questão central}

À luz de todas estas observações, no início do 2012 dois trabalhos mostraram novos resultados que abrem novas discussões não apenas na neurociência, como no âmbito geral de fenômenos críticos. Primeiramente, Friedman e colaboradores demonstraram que, apesar de evidências de criticalidade, as tais leis de potências podem ter sido resultado da baixa resolução espacial dos experimentos anteriores. ${ }^{(41)}$ Neste estudo foram utilizados matrizes de eletrodos espaçados de $60 \mu \mathrm{m}$, o que permite capturar atividade neural de neurônios mais próximos espacialmente e obter dados de potencial local com maior resolução espacial. Os autores alegam que como resultado a distribuição de avalanches deixa de ser uma lei de potência e apresenta "bumps", concentrações inesperadas de massa probabilística em eventos que estariam na cauda da lei de potência (como avalanches muito longas e grandes). Outras técnicas, no entanto, sustentam a hipótese de criticalidade: seguindo análises bastante contextualizadas em outras áreas, Friedman e colaboradores mostraram o colapso das formas de avalanche - uma medida extremamente robusta pelo grande número de graus de liberdade - e a lei de potência na média do tamanho de avalanches em função de suas durações. Em suma, os resultados apontam para uma possível criticalidade sem leis de potência nas distribuições de avalanches.

O segundo trabalho, publicado por Dehghani et al, sugere a completa inexistência de leis de potência na atividade neural ${ }^{(42)}$, sugerindo a inexistência de criticalidade (auto-organizada ou não) nos indivíduos experimentados. Este estudo envolveu, de meu conhecimento, o maior número de animais e espécies diferentes (córtex motor de gatos, córtex motor e prémotor de macacos e córtex temporal de humanos epilépticos), combinando abordagens comportamentais diferentes (animais acordados, sono de onda lenta e sono REM). Embora o resultado seja bastante similar (animais saudáveis sem avalanches críticas), algo interessante de se apontar é o fato de os eletrodos deste grupo distarem de $400 \mu \mathrm{m}$, seis vezes maior que o espaçamento 
de Friedman et al.

Em vista destes novos resultados, existe genuinamente uma falta de mecanismo que explique sem sombra de dúvidas a otimização da faixa dinâmica com detalhes microscópicos da dinâmica neural, sendo ela crítica ou não. Deixe-me listar alguns tópicos pontuais que podemos aprender destes experimentos:

- Sistemas neurais em perfeito estado podem não apresentar distribuições de avalanche seguindo leis de potência.

- Apesar de não serem leis de potência, existe algum tipo de invariância de escala.

- Os animais usados nestes experimentos recentes são os mesmos dos experimentos que ligam avalanches a performances ótimas (Shew e colaboradores).

- O trabalho de Shew e colaboradores não mostra de fato leis de potência perfeitas em todos os experimentos.

Neste presente trabalho, apresento o resultado que foi obtido ao estudar uma versão probabilística do modelo de Greenberg-Hastings (GH) frente a essas novas observações. Com este modelo GH temos uma explicação para a otimização da faixa dinâmica de uma rede neural baseada em uma transição de fases. ${ }^{(37)}$ Mostro então que o modelo $\mathrm{GH}$ pode apresentar não apenas avalanches qualitativamente comparáveis aos dois estudos recentes citados, como também pares de expoentes idênticos. Como fruto disto, identifico como responsável pela otimização da faixa dinâmica não a lei de potêcia das distribuições de avalanches, mas sim a entropia (de Shannon) do tempo de avalanches. Nos capítulos seguintes exponho estes resultados para, em minhas conclusões, ligar definitivamente nossas descobertas com estes experimentos. 


\section{Capítulo 3}

\section{Metodologia: Modelo probabilístico}

No capítulo 2, reuni uma série de observações experimentais sobre as avalanches neurais, que caracterizam em última instância uma primeira tentativa de entender o mecanismo básico por detrás da atividade de uma população grande de neurônios. E para tal, o grau de detalhe que esses estudos podem atingir está bastante limitado, deixando de lado o formato do potencial de ação e outras nuances da atividade neural. Por fim, o neurônio se torna uma unidade binária: ou está excitado (disparando o potencial de ação) ou não está. É natural questionar essa abordagem, mas vamos nos ater a entendê-la como um dos primeiros passos à compreensão da codificação por grandes populações. Tendo dito isso, considerei apenas modelos de neurônios igualmente simples, dos quais escolhi uma versão probabilística do modelo de GreenbergHastings $(\mathrm{GH})$ para subsidiar minhas investigações. Nas seções seguintes, discuto a dinâmica neural, modelos para padrões de conectividade e como fazer medidas de avalanches.

\subsection{Dinâmica do modelo}

Como comento no capítulo anterior, o modelo de Greenberg-Hastings (GH) foi originalmente concebido como um protótipo de modelo em que o desempenho ótimo de um sistema sensorial é resultado de uma transição de fase contínua. Já adiantei que se trata de um modelo bastante simples, sem entrar em pormenores da dinâmica neural (trata-se de um modelo formal). Cada neurônio será visto como um autômato celular a tempo discreto: o estado do $j$-ésimo neurônio no instante $t$ será denotado por $X_{j}(t)$ e assume valores inteiros de 0 a $m-1$. A cada um 
(a)

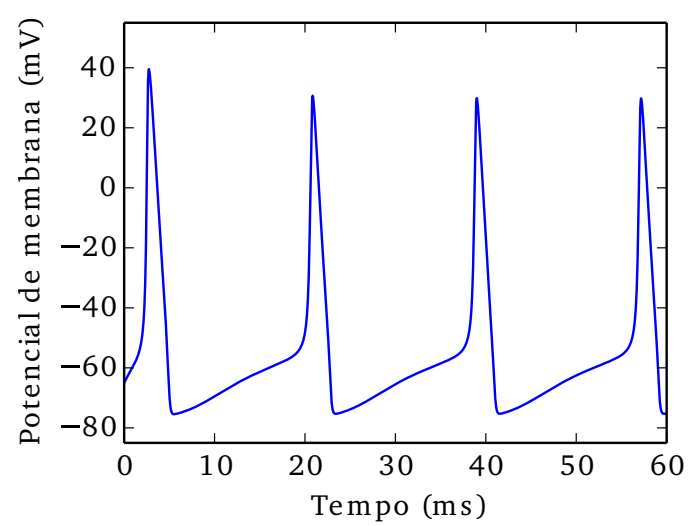

(b)

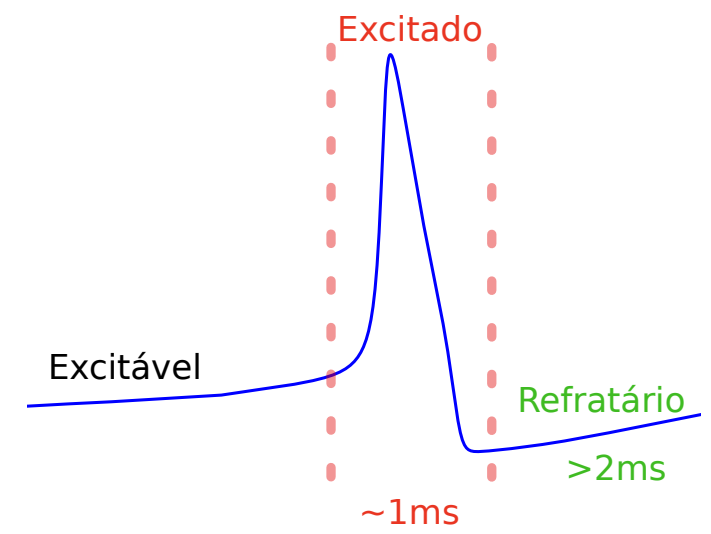

Figura 3.1- Forma estereotipada do potencial de ação extraído de uma simulação usando o modelo de Hodgkin-Huxley (ver texto). (a): Série temporal do potencial de membrana de um neurônio disparando num passo fixo, regime conhecido como de disparos tônicos. Muitas vezes, este regime é atingido como resposta a uma corrente elétrica fixa, embora possa ser resultado também da dinâmica intrínseca do neurônio. (b): Uma visão simplificada dos diferentes estágios pelos quais o neurônio passa. Note que essa nomenclatura leva em consideração somente $o$ potencial de membrana, e apesar de útil trata-se de uma descrição superficial e incompleta. No entanto estas são as principais características necessárias para estudar os experimentos de avalanches.

Fonte: Elaborada pelo autor.

destes inteiros correspondem certos instantes do potencial de ação: ao estado $X_{j}(t)=0$ associamos o estado de repouso do neurônio (comumente em $\sim-60 \mathrm{mV}$ com respeito ao meio extracelular); quando $X_{j}(t)=1$, o neurônio está disparando seu potencial de ação $(\sim 40 \mathrm{mV})$; para todos $X_{j}(t)=k, 1>k>m$, temos o período refratário. Além de sua dinâmica intrínseca, estes neurônios estão acoplados segundo as ligações de um grafo aleatório (detalhes na seção 3.2), entendidas como sinapses entre pares de neurônios. Por simplicidade, as sinapses serão simétricas e sem atraso temporal (similar a sinapses elétricas).

Fica claro que este pode ser encarado como um modelo mínimo que captura as principais características presentes nos experimentos de avalanches neurais. A excitação de um neurônio é a transição do estado 0 para o 1 . Essa transição é estocástica, em oposição às outras transições $(1 \rightarrow 2,2 \rightarrow 3, \ldots, m-1 \rightarrow 0)$ que são todas determinísticas:

$$
X_{j}(t+1)=\left[X_{j}(t)+1 \bmod m\right], \quad X_{j}(t) \geq 1 .
$$

Por esse motivo, uma boa escolha para a duração do passo temporal $\Delta t$ é de $\sim 1 \mathrm{~ms}$, o 

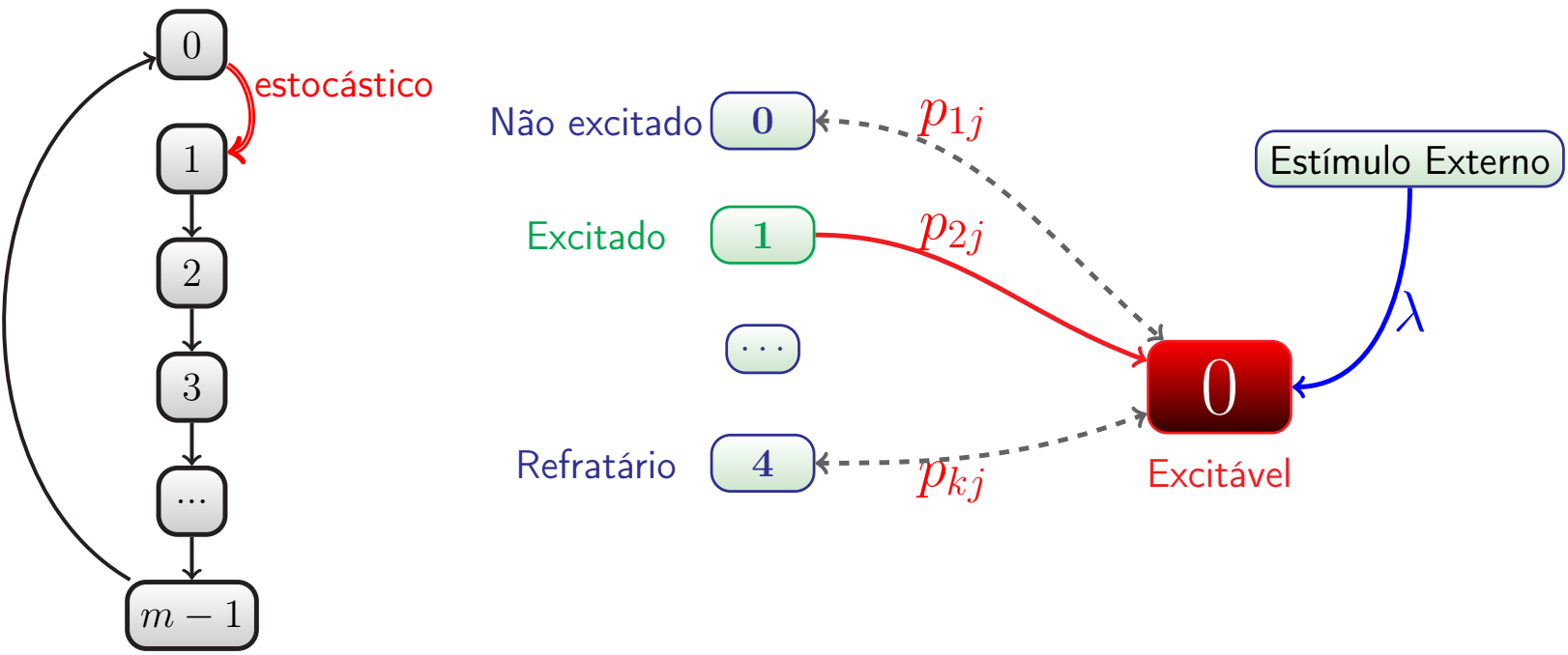

Figura 3.2- Identificação das transições de cada autômato (representados pelas caixas, dentro das quais o número é o estado momentâneo do autômato) do modelo $\mathrm{GH}$. O estímulo externo aparece como a probabilidade $\lambda$ (flecha azul), dirigido pela taxa $r$ por meio de $\lambda=1-e^{-r \Delta t}$, e só pode se manifestar sobre os neurônios excitáveis. Dado que um neurônio $j$ esteja excitável (caixa central em vermelho com estado 0 ), um de seus vizinhos excitados (caixa com estado 1 , em verde) pode excitá-lo com probabilidade dada pelo peso de sua conexão (no caso, $p_{2 j}$ ). Já um vizinho não excitado (autômatos em azul) não pode excitá-lo.

Fonte: Elaborada pelo autor.

que torna o período refratário $(m-2) \Delta t$ da ordem de algumas unidades (até dezenas) de milissegundos. Há duas fontes de excitação $(0 \rightarrow 1)$ : (i) o ambiente externo, caracterizado por uma probabilidade de excitação $\lambda$, e (ii) por meio das sinapses com outros neurônios. Para cada vizinho $k$ do neurônio $j, p_{k j}$ será a probabilidade de que, dado $X_{j}(t)=0$ e $X_{k}(t)=1$, o neurônio $j$ seja excitado por $k$ e, assim, $X_{j}(t+1)=1$. Essas probabilidades não variam no tempo e são geradas segundo uma distribuição uniforme em $\left[0, p_{\max }\right)$.

Dado um neurônio $j$ excitado no instante $t$ e supondo que seus $K_{j}$ vizinhos estejam todos quiescentes, $j$ é capaz de excitar quantos neurônios em média? Como são $K_{j}$ "tentativas" com probabilidades distintas de excitação (leia-se sucesso), a probabilidade de que $j$ excite $n$ de seus vizinhos é uma Poisson-Binomial cuja média vale

$$
\sigma_{j}=\sum_{k=1}^{K_{j}} p_{k j} .
$$


Chama-se $\sigma_{j}$ de taxa de ramificação local de $j$. A média das taxas de ramificação local,

$$
\sigma=\sum_{j=1}^{N} \frac{\sigma_{j}}{N}=\sum_{j=1}^{N} \frac{1}{N} \sum_{k=1}^{K_{j}} p_{k j}
$$

surpreendentemente toma um papel central: Kinouchi e Copelli mostraram que $\sigma$ é o parâmetro de controle de uma transição de fase contínua ${ }^{(37)}$. Chamando a média do número de conexões de $K=\left\langle K_{j}\right\rangle$ e lembrando que $p_{k j}$ são realizações de uma distribuição uniforme em $\left[0, p_{\max }\right)$, então

$$
\sigma=\frac{K p_{\max }}{2}
$$

Note que $\sigma$ é influenciado tanto pela dinâmica do modelo $\mathrm{GH}\left(p_{\max }\right)$ como pelo grafo $(K)$ e é portanto possível utilizar este fato para prever a taxa de ramificação média da rede ao fixar estes dois parâmetros.

Por fim, falta definir como atua o agente externo que o modelo deve codificar: $\lambda$ será uma medida de intensidade de algum estímulo. Em analogia com outros sistemas sensoriais (olfato ou visão), $\lambda$ pode ser proporcional à concentração de algum odorante específico sobre o que o sistema esteja codificando a presença. Para ligar mais facilmente com este tipo de cenário, vou reescrever $\lambda=1-\exp (-r \Delta t)$, em que $\Delta t$ é o passo temporal (1 ms) e $r$ passa a ser a taxa com que o estímulo excita algum dos neurônios. Nenhum dos resultados que mostraremos depende centralmente desta forma específica para o estímulo.

Todas estas possibilidades de transição estão resumidas na visão esquemática apresentada na figura 3.2. A menos que comentado ao contrário, a conectividade média será $K=10$, o número de neurônios $N=10^{5}$ e cada autômato terá $m=5$ estados. A taxa de excitação $r$ varia de $10^{-5}$ a $10^{1}$.

\subsection{Modelos de grafos aleatórios}

Além da dinâmica neural, a forma como os neurônios se comunicam é crucial não apenas para a transmissão da informação, mas também para a computação em si. Investigar os padrões de conectividade presentes em tecidos nervosos se tornou uma área de pesquisa bastante 
promissora, ${ }^{43-47)}$ muito embora estejamos ainda longe de qualquer conhecimento profundo da conectividade mesmo de sistemas simples. Em especial a respeito de redes muito grandes (como o córtex humano), uma grande parte das referências aponta indícios de propriedades de mundo pequeno, ${ }^{(48)}$ distribuições de graus livres de escala ${ }^{(47)}$ e presença de correlação de graus. ${ }^{(49-51)}$

Nesta seção, vou revisar alguns conceitos sobre três modelos de grafos aleatórios que utilizarei nas investigações: grafo de Erdős-Rényi (ERG), ${ }^{(52)}$ o modelo de configuração descorrelacionado $(\mathrm{UCM})^{(53,54)}$ e o modelo de Barabási-Álbert (BAM). ${ }^{(55)}$ Em todo modelo, a associação dos pesos das arestas é feita de forma independente da associação das arestas.

\subsubsection{Grafo de Erdős-Rényi}

O modelo de Erdős-Rényi (Erdōs-RényiModel, ERM) é o mais antigo modelo de grafo aleatório, concebido por Erdős e Rényi para mostrar a emergência de um componente gigante. Há duas formas quase certamente (i.e., assintoticamente) equivalentes deste modelo, e a seguir introduzo a mais intuitiva. Note que, apesar mais intuitiva, não é a que utilizarei em minhas simulações: este algoritmo é bem mais lento que a outra opção. Primeiramente, suponha $N$ nós. Para cada par de nós neste grafo, defino $0 \leq p \leq 1$ como a probabilidade de que haja uma aresta ligando este par. Assim, para cada $p$ os grafos resultantes terão, para $N$ grande o suficiente, conectividade média $K=p(N-1)$ e distribuição de graus (i.e., número de vizinhos de cada nó) bem aproximada por uma Poisson,

$$
p_{d}(n)=\frac{K^{n} e^{-K}}{n !}
$$

em que o subíndice $d$ indica degree (do inglês, grau). Por este motivo, este modelo de grafo aleatório é dito homogêneo. $\mathrm{O}$ modelo $\mathrm{GH}$ foi estudado originalmente em redes regulares (cubos) e neste ERM. 
(a)

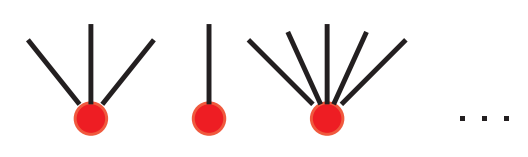

(b)

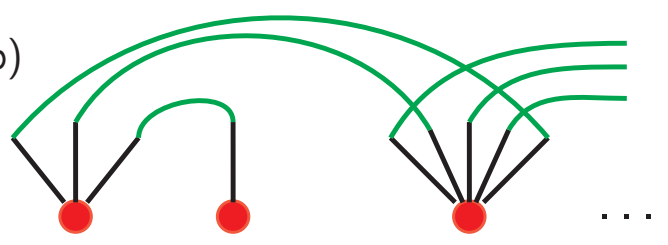

Figura 3.3- Esquema com a construção do UCM. Em (a), a criação de arestas com ponta aberta. O número de arestas em cada nó deve seguir a distribuição desejada $p_{d}(k)$. Em (b), conexão das pontas das arestas uniformemente marcadas em verde, evitando dupla conexão.

Fonte: Elaborada pelo autor.

\subsubsection{Modelo de configuração descorrelacionado}

O modelo de configuração descorrelacionado (Uncorrelated Configuration Model, UCM) é uma extensão natural do ERM para que a distribuição de nós possa ser controlada livremente. Em geral, muitos dos resultados no ERM têm correspondentes no UCM (e.g., a emergência de um componente gigante no UCM foi demonstrado por Molloy e Reed $\left.{ }^{(56)}\right)$. A ideia é simples: considere $N$ nós e associe ao $j$-ésimo nó $k_{j}$ arestas com pontas abertas (veja figura 3.3.a), em que os $k_{j}$ formam uma sequência de variáveis aleatórias idênticas e independentes, distribuídas conforme $p_{d}(k)$ dado. Em seguida, escolha uniformemente pares de pontas abertas das arestas e as ligue (veja figura 3.3.b).

Assim a distribuição de graus será exatamente $p_{d}(k)$, embora possam ocorrer dois efeitos indesejados: (i) dois nós podem conectar-se mais de uma vez (arestas múltiplas) e (ii) a conexão de um nó com ele próprio. Note que apesar de ambas ocorrerem na natureza, não quero introduzir (ao menos por hora) tais efeitos. Para isso, ao associar pares de arestas abertas, precisamos testar estas duas condições. Os grafos resultantes deste modelo em geral apresentam "correlação" de grau - uma vez que o sorteio das pontas abertas não é feito de forma uniforme - e, por isso, costuma-se definir uma versão descorrelacionada deste modelo usando um limiar (cut-off) $N_{C}$ imposto à mão ${ }^{(54)}$. A distribuição de $k_{j}$ passa então a ter o suporte reduzido ao intervalo $0, \ldots, N_{c}$. O nosso maior interesse está em grafos com distribuição livre de escala, e $N_{c}=N^{-1 / 2}$ nesse caso. ${ }^{(57)}$

Em termos de referências que tentam obter informações sobre a conectividade de tecidos neurais, existem algumas observações da presença de correlações nas distribuições de 
grau. ${ }^{(49-51)}$ Optei por testar este modelo de grafos aleatórios por ser cada vez mais comum a solução analítica de modelos com dinâmica razoavelmente complexa em redes UCM. Um dos próximos passos será investigar qual a influência da presença de correlações nesta fenomenologia.

\subsubsection{Modelo de Barabási-Álbert}

Também adiciono um modelo de grafo que envolve o "crescimento" do grafo, ou seja, os nós são adicionados ao longo da construção. O mais famoso deles, e que apresenta uma distribuição livre de escala, é o modelo de Barabási-Álbert (Barabási-ÁlbertModel, BAM), idealizado para servir de mecanismo-exemplo para que um grafo realístico tenha distribuição livre de escala, ${ }^{(55)}$ uma vez que a lei de potência na distribuição de graus não é imposta diretamente. Barabási e Albert descobriram os dois ingredientes essenciais para a distribuição de graus livre de escala: (i) crescimento e (ii) ligação preferencial.

A receita para estes dois ingredientes é como segue: (i) comece com $N_{0}$ nós conectados como preferir (e.g., todos conectados com todos), e fixe o número $m$ como um parâmetro; (ii) acrescente um neurônio e conecte-o a $m$ outros nós de acordo com a probabilidade de conexão $q(k) \propto k$ (assim quanto mais conectado um nó for, maior a chance de o novo nó conectarse com ele); (iii) repita ii até que a rede tenha o número de nós desejado. Desta forma, a distribuição de graus final converge para uma lei de potência com expoente -3 . ${ }^{(58)}$ Para poder controlar este expoente, Dorogovtsev e Mendes propuseram uma modificação mínima na probabilidade de conexão, introduzindo um fator $\mathcal{A}$ real que eles chamaram de atratividade ${ }^{(59)}$. Assim, se $q(k) \propto k+\mathcal{A}$, então a distribuição de graus se torna assintoticamente $k^{-3-\mathcal{A} / m}$. Se $\mathcal{A}<0$, então podemos explorar expoentes na região $(2,3]$, que são os valores empiricamente observados. ${ }^{(45,46)}$

\subsection{Taxa de disparo e faixa dinâmica}

A seguir, vou revisar um pouco do que já foi estudado do modelo $\mathrm{GH}$, especialmente no ERM, e introduzir as grandezas-chave do estudo. A atividade instantânea da rede pode ser definida 
(a)

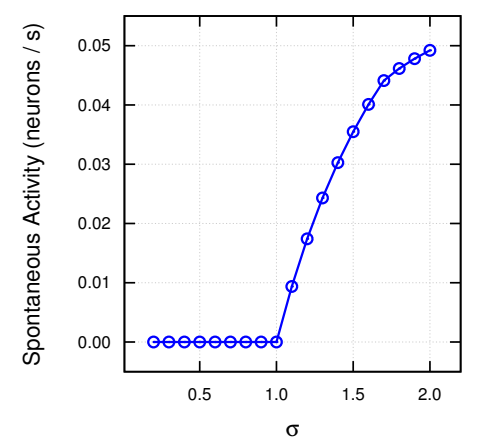

(b)

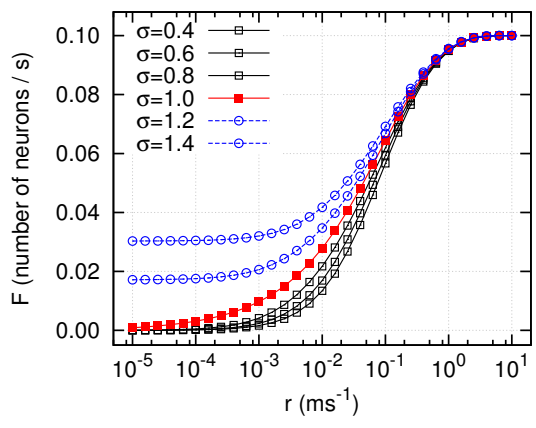

(c)

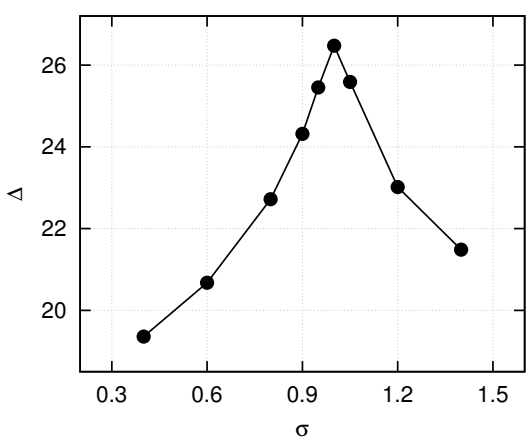

Figura 3.4- (a) Transição de fase no modelo GH demonstrada por meio do parâmetro de ordem $F(r \rightarrow 0)$ (atividade neural espontânea). (b) Curvas estímulo-resposta geradas por este modelo. A dinâmica é crítica quando $\sigma=1$, caso destacado em vermelho no gráfico. (c) Como resultado da transição de fase, a faixa dinâmica quando o modelo está ajustado em seu ponto crítico é ótima. Para todos os casos (a-b-c), as linhas são apenas guias para os olhos.

Fonte: Elaborada pelo autor.

como

$$
\rho(t)=\sum_{j=1}^{N} \delta\left\{X_{j}(t), 1\right\},
$$

em que $\delta$ é a função de delta de Kronecker. A atividade média da rede, ou taxa de disparo, é a média $F$ desta atividade ao longo de uma janela temporal $T(\gg \Delta t)$,

$$
F=\frac{1}{T} \sum_{t=0}^{T} \rho(t)=\frac{1}{T} \sum_{t=0}^{T} \sum_{j=1}^{N} \delta\left\{X_{j}(t), 1\right\} .
$$

Estas duas grandezas, $F$ e $\rho(t)$, dependem da taxa de ramificação média $\sigma$ e do estímulo externo $r$. A transição de fase pode ser vista pela taxa de disparo livre de estímulo $(r \rightarrow 0)$ na figura 3.4a. A taxa de ramificação crítica ocorre em $\sigma_{c}=1$, mas adianto que este valor dependerá da conectividade subjacente. Larremore e colaboradores demonstraram, dentro de uma aproximação razoável (mas que discutirei no capítulo de resultados) que o importante é o maior autovalor da matriz de adjacência (matriz formada pelos pesos sinápticos entre cada neurônio). ${ }^{(60,61)}$

Por fim, observe que a taxa de disparo é função de $r$. As curvas de estímulo resposta (figura 3.4b) apresentam um regime intermediário de alta derivada. Apenas neste regime é possível inverter essa função de $r$ (decodificação neural) e, por isso, esta é a região em que 
este sistema pode funcionar. A faixa dinâmica mede o quão grande este regime se manifesta, e pode ser definida como

$$
\Delta=-10 \log \left(\frac{r_{0.9}}{r_{0.1}}\right)
$$

em que $r_{x}$ é solução única da equação $F\left(r_{x}\right)=F(0)+x(F(\infty)-F(0))$ com $x \in\{0,1\}$. Assim, $\Delta$ mede em decibeis o tamanho da região entre $10 \%$ e $90 \%$ do total de atividade da rede. Na figura 3.4c, vemos que $\Delta$ é máximo quando $\sigma=\sigma_{c}$. Isso foi observado por Kinouchi e Copelli no $\operatorname{ERM}^{(37)}$, em redes regulares ${ }^{(62,63)}$ e no BAM por Copelli e Campos ${ }^{(64)}$. Note que no BAM, o valor de $\sigma_{c}$ é menor $(\sim 0.4)$ conforme adiantei na seção 3.1. ${ }^{(60)}$

\subsection{Medidas de avalanches}

Nesta seção vou explicar rapidamente como simulei as avalanches geradas pelo modelo $\mathrm{GH}$ para, no capítulo 4, então mostrar os resultados destas simulações e qual sua conexão com os experimentos comentados no capítulo 2 .

Para gerar as avalanches, utilizei a seguinte prescrição: com a rede construída e fixando todos os neurônios no estado quiescente, sorteio uniformemente um nó para torná-lo excitado. Após a atividade cessar (dentro de um período $T \sim 2 \times 10^{4}$ ), gravo o número de neurônios que foram eventualmente excitados (tamanho) e o tempo de duração desta atividade. Estas duas definições estão de acordo com os experimentos do capítulo 2.1 (reveja figura 2.1). Repito esse procedimento $M>10^{6}$ vezes, de forma que em média cada neurônio dá início a mais de dez avalanches. Com estes dados, infiro por máxima verossimilhança - i.e., contando a frequência dos eventos - a distribuição de tamanhos e durações de avalanches.

Em um sistema de fato infinito, pode existir uma chance de que a atividade se propague indefinidamente. No capítulo 4, entenderemos este fenômeno melhor, mas posso adiantar que ele está ligado com a fase supercrítica (veja figura 3.4a), em que há atividade autossustentada. Assim, quanto maior $\sigma$, as avalanches tendem a ter com maior frequência maiores durações e por isso as simulações são mais lentas. Em meus experimentos, sempre que uma avalanche se estende até o período $T$ limitante, eu a interrompo e marco sua duração como $T$. Em redes supercríticas, a distribuição de tempos apresenta um pequeno pico em $T$ (limite do suporte 
dessa distribuição inferida).

Caso ocorra alguma lei de potência, é interessante estimar o expoente. Eu segui três diferentes metodologias para esta tarefa. A mais óbvia é graficar a distribuição em eixos $\log -\log$ e fitar o coeficiente angular da reta resultante. Esta metodologia está sujeita a diversos erros/vícios, principalmente com respeito à escolha do bin utilizado para a construção da distribuição. Por este motivo, e considerando que a distribuição cumulativa de uma lei de potência de expoente $\gamma$ também é uma lei de potência mas com expoente $\gamma-1$, uso também a distribuição cumulativa e ajusto o coeficiente angular da reta. ${ }^{(65)}$ Por fim, o último método é utilizando o estimador de máxima verossimilhança para o expoente de uma lei de potência. ${ }^{(65,66)}$ Explicar os detalhes envolvidos neste estimador foge ao escopo desta monografia, mas é importante ressaltar que este método utiliza os dados nus, sem se basear em construções gráficas e ajustes de parâmetros. Ele próprio é o ajuste que maximiza as chances de a lei de potência com o expoente resultante ser a que descreve meus dados (princíprio dos métodos de verossimilhança). Cada um destes métodos têm seus defeitos, mas são complementares e coincidem razoavelmente. Não vou mostrar seus resultados de forma separada simplesmente porque ambos concordam muito bem e, por isso, não acrescenta muito à presente discussão.

\subsection{Entropia de avalanches}

Para compreender mais profundamente a relação entre as propriedades das avalanches críticas e a otimização da faixa dinâmica, utilizarei a entropia de Shannon. ${ }^{(67)}$ Dada uma variável aleatória $X$, que pode ser no presente contexto a duração ou o tamanho de uma avalanche neural, e sua distribuição $p_{X}(x)$, a entropia de Shannon $H(X)$ desta variável $X$ é definida como

$$
H(X)=\sum_{\forall x} p_{X}(x) \log \left[p_{X}(x)\right]
$$

Chamarei daqui em diante de $H_{t}$ a entropia da duração de avalanches e $H_{s}$, a de tamanho de avalanches.

De acordo com o que apresentei na seção 3.4, as distribuições de avalanches são inferidas a partir das simulações. A equação 3.5 .1 será usada para calcular numericamente $H_{s}$ e $H_{t}$. 
Como ambas são variáveis discretas, não há necessidade de se preocupar com tamanho de bins. No entanto é preciso salientar que dada à amostragem finita das avalanches, muitos $p_{X}(x)$ são nulos simplesmente por não haver observações de $x$. Por esse motivo, é usual impor a condição $p_{X}(x) \log \left[p_{X}(x)\right]=0$, com $p_{X}(x)=0$.

\subsection{Modelo de criticalidade fora-do-equilíbrio}

Nesta última seção explicando a metodologia, apresento uma forma clara de como compreender a transição de fase fora do equilíbrio e que será, no capítulo seguinte, ligada com o modelo GH. Trata-se de um modelo de brinquedo conhecido como processo de ramificação. ${ }^{68,69)}$ Naturalmente surgirá uma grandeza acessível em experimentos (e que medi em minhas simulações): probabilidade de morte eventual. Sem recorrer a definições matemáticas, imagine que haja um indivíduo capaz de dar origem a um número aleatório $Z_{1}$ de novos indivíduos idênticos a ele. Então, $Z_{1}$ é o número de indivíduos na "primeira geração". A distribuição de probabilidade $\mathbb{P}\left(Z_{1}=z\right)=P(z)$ é dada e às vezes é chamada de distribuição de prole. Cada um de seus novos filhos pode dar origem independentemente a novos filhos, cada um com mesma distribuição. Vamos denotar a soma de todos os novos filhos (netos do indivíduo original) por $Z_{2}$, ou seja, o número de indivíduos na segunda geração. Induzindo essas definições, $Z_{n}$ é a variável aleatória número de indivíduos na $n$-ésima geração. Por fim, a média de filhos de cada indivíduo desse modelo mantem-se fixa em $m=\sum_{z=0}^{\infty} P(z) z$. Vale comentar que, da definição, as variáveis $Z_{n}$ não contabilizam os indivíduos $Z_{n-1}$ (ou seja, os pais): nestas variáveis estão apenas a prole da geração anterior.

A partir de $P(z)$, é possível descobrir a distribuição de $Z_{n}$ usando funções geradoras ${ }^{(70)}$. Como conhecemos a distribuição de $Z_{1}$, sua função geradora é definida como

$$
\phi(x)=\sum_{j=0}^{\infty} P(z) x^{z} .
$$

O que se demonstra é que a função geradora $\phi_{n}(x)$ de $Z_{n}$ é a $n$-ésima iterada de $\phi(x)$ - que é conhecida! -

$$
\phi_{n}(x)=\phi(\phi(\phi(\ldots x)))
$$


Naturalmente, $\phi_{0}(x)=x, \phi_{1}(x)=\phi(x), \phi_{2}(x)=\phi(\phi(x))$ e assim por diante. Essa é uma afirmação bastante forte, e a distribuição de $Z_{n}$ fica completamente determinada com ${ }^{(70)}$

$$
\mathbb{P}\left(Z_{n}=z\right)=\frac{1}{z !} \frac{d^{z} \phi_{n}}{d x^{z}}(0)
$$

De forma inesperada, este modelo apresenta uma transição de fase: sendo $q$ a probabilidade de que, em algum momento, a população se extinga -ou seja, $\exists t>0: Z_{t}=0$-, então é possível provar que (i) $q=1$ se $m \leq 1$; (ii) $q<1$ caso contrário. Isso significa que, a menos que a média do número de filhos seja maior que a unidade, a extinção da população é certa. Por completeza, este modelo é comumente aplicado a dados reais (nomes de famílias inglesas ${ }^{(68)}$ e japonesas) e também é bastante aplicado à biologia (infectologia). Há também versões deste modelo com uma dinâmica para a média $m$ da distribuição de prole para gerar criticalidade auto-organizada. ${ }^{(71)}$

\subsection{Implementações deste modelo}

Minha implementação deste modelo está disponíveis como software livre sob uma licença bastante permissiva. ${ }^{(24)}$ Todo e qualquer estudante e pesquisador que tenha qualquer interesse em utilizá-lo para quaisquer fins pode fazê-lo, dada atribuição apropriada.

Nesta implementação, disponibilizo também um programa exemplo para facilitar o aprendizado. O código está escrito em Fortran 95, e conta com diversas otimizações para tempo de execução. Vale comentar que o código não usa ainda o melhor algoritmo possível em termos de consumo de memória, mas tenho uma versão já em fase de testes que deve ser disponibilizada em breve. 


\section{Capítulo 4}

\section{Resultados: Avalanches críticas e leis de potências}

Neste capítulo, farei uma exposição de meus resultados principais, discutindo brevemente a ligação com as questões levantadas no primeiro capítulo e quais as novidades que estes resultados trazem. No capítulo 8 , discutirei em maior profundidade estas novidades e resumirei a contribuição dada à área de pesquisa.

\subsection{Morte eventual}

Na seção 3.6, apresentei o famoso processo de ramificação clássico. Em seguida utilizarei este modelo para compreender melhor a transição de fase que ocorre no modelo probabilístico de Greenberg-Hastings (GH). Para tornar o problema tratável analiticamente, vamos associar a toda aresta o peso fixo $p_{j k}=\sigma / K$ nesta presente seção. Quando se inicia uma avalanche, um único neurônio excitado passa adiante o sinal, excitando subsequentemente outros neurônios. A comparação é simples: cada indivíduo do processo de ramificação será encarado como um neurônio excitado. Ao evento de gerar um descendente no processo de ramificação, entenda como um neurônio excitando um de seus vizinhos. Ou seja, a prole de um indivíduo é o conjunto de neurônios que este indivíduo excitou no passo temporal seguinte. Com esta 
conexão, a distribuição de prole pode ser calculada como

$$
P(m)=\sum_{j=m}^{\infty}\left(\begin{array}{c}
j \\
m
\end{array}\right)\left(\frac{\sigma}{K}\right)^{m}\left(1-\frac{\sigma}{K}\right)^{j-m} p_{d}(j)
$$

em que $p_{d}(j)$ é a distribuição de graus (número de vizinhos). Antes de prosseguir, gostaria de chamar a atenção para o que representa a equação (4.1.1). A posteriori, sabemos que essa análise só funciona para o ERM, e esse fato pode ser explicado de acordo com a seguinte argumentação: essa comparação parece razoável enquanto não houver colisões entre avalanches, uma vez que cada indivíduo gera filhos de forma independente. O ERM, assintoticamente, é constituído de árvores com ramos independentes, o que elimina as colisões e faz com que esse modelo funcione bem. Já em outros modelos de grafos, como BAM, cuja conectividade é dita mais heterogênea, esta abordagem (e qualquer outra conhecida na atualidade) não reproduz quantitativamente os resultados, embora a noção básica de criticalidade fora do equilíbrio pareça ainda bastante similar (como mostrarei usando a distribuição de morte eventual).

Tendo dito isto, vou usar a distribuição de graus referente à ERM (equação 3.2.1) na 4.1.1, simplificando para

$$
P(m)=\frac{\sigma^{m} e^{-\sigma}}{m !}
$$

ou seja, uma distribuição de Poisson. Este resultado não é bonito apenas por sua simplicidade, mas tamém porque reflete diretamente a criticalidade originalmente observada no modelo: a média da distribuição de prole é $\sigma$, a taxa de ramificação. Assim, retornando à discussão 3.6, quando $\sigma \leq 1$, com probabilidade 1 a atividade neural será extinta. Já para $\sigma>1$, existe uma chance de que a atividade torne-se autossustentada.

Sabendo a distribuição de prole, é possível calcular a probabilidade de extinção do sinal. Definindo a função geradora de 4.1.2,

$$
\phi(x)=\sum_{m=0}^{\infty} P(m) x^{m}=e^{\sigma(x-1)} .
$$




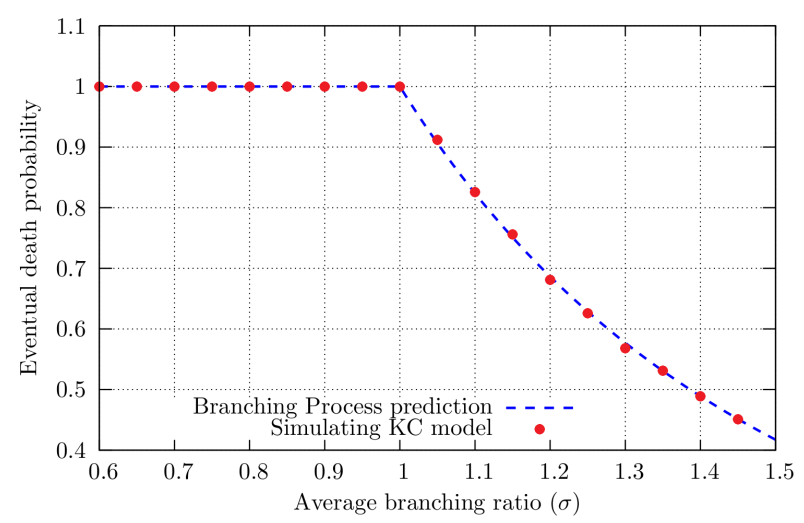

Figura 4.1- Probabilidade de morte eventual. No ERM, temos o resultado numérico e analítico concordando. Mostro também resultados numéricos em outras redes. Apesar de o formalismo de processos de ramificação parecer não se encaixar nestas redes, ainda assim elas apresentam resultados similares.

Fonte: Elaborada pelo autor.

A probabilidade $q(\sigma)=q$ de extinção do sinal é o ponto fixo de $\phi(x),{ }^{(69)}$

$$
\phi(q)=q
$$

Embora esta última equação transcenda nossas habilidades matemáticas polinomiais, sua solução numérica é bastante simples. Até primeira ordem em $1 / \sigma$, é possível ver duas soluções analiticamente: $q(\sigma)=1$ para $\sigma \leq 1 \mathrm{e}$

$$
q(\sigma)=1-\frac{3 \sigma-\sqrt{-15 \sigma^{2}+24 \sigma}}{2 \sigma^{2}}
$$

para $\sigma>1$. Note que com $\sigma=1$ em 4.1.5, vemos que há uma descontinuidade apenas na derivada de $q(\sigma)$ (evidente na figura 4.1). Essa é uma assinatura de criticalidade numa grandeza fora do equilíbrio que podemos testar nas simulações. Na figura 4.1, apresento a comparação desta solução com simulações no ERM.

A figura 4.1 nos mostra que, apesar de os elementos que introduzi não capturarem por completo a dinâmica em outras redes, ainda assim o modelo de ramificação parece um bom protótipo para o entendimento da dinâmica. Utilizar $q$ em vez da atividade livre de estímulo, como feito na seção 3.3, pode ser vantajoso, principalmente porque $q$ é uma grandeza dinâmica (em oposição à atividade da rede, que é uma grandeza de equilíbrio). 


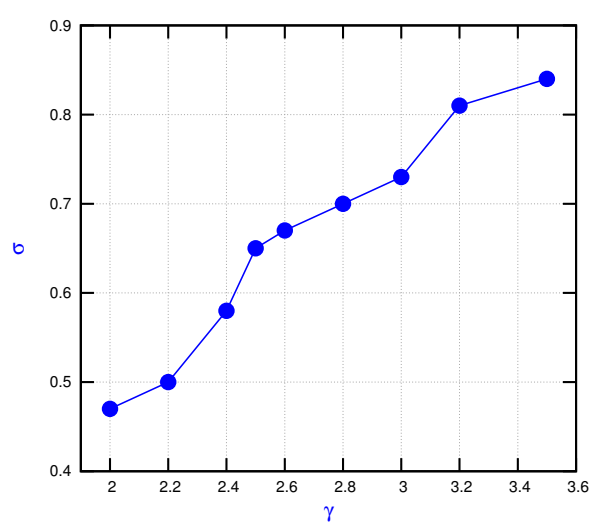

Figura 4.2- Taxa de ramificação crítica em função do expoente $\gamma$ da distribuição de graus no UCM, com $m=5, N=10^{4}$ e $K=10$. Como a taxa de ramificação crítica indica o mínimo peso sináptico médio para que haja possibilidade de atividade autossustentada, fica claro que a rede influencia profundamente a dinâmica macroscópica.

Fonte: Elaborada pelo autor.

Antes de abordarmos avalanches emergentes desta dinâmica, vou explorar um pouco mais qual a influência da rede na dinâmica, investigando os efeitos que escapam da análise de processo de ramificação.

\subsection{Excitabilidade resultante da rede}

Na última seção, vimos um modelo pra compreender melhor a transição de fase que ocorre no modelo GH. No entanto, algo que este modelo não foi capaz de captar, embora já explicado utilizando matrizes aleatórias, ${ }^{(60)}$ é a mudança da taxa de ramificação crítica $\sigma_{c}$. Note que não se trata apenas de compreender o ponto crítico de uma transição de fase, $\sigma_{c}$ é o acoplamento mínimo (médio) para que exista a possibilidade de a atividade neural se autossustentar, e por isso podemos usá-lo para entender o quão "fácil", em algum sentido, a atividade consegue sobreviver na rede. Com estas novas observações, vamos entender como a topologia influencia o que podemos chamar de excitabilidade da rede.

Na figura 4.2, vemos $\sigma_{c}$ em função do expoente $\gamma$ da distribuição de graus de UCM. Podemos ver que quanto maior este expoente, caso em que os eventos extremos se tornam cada vez menos prováveis, $\sigma_{c}$ também cresce. Na região mais realística, $(2,2.2],{ }^{(47)}$ a taxa de ramificação crítica é menor que a metade de $\sigma_{c}$ no ERM. 


\subsection{Avalanches críticas sem leis de potência}

Nesta seção, passo a estudar as avalanches neurais propriamente ditas. Ao final desta seção, apresento alguns resultados complementares que investigamos que podem ajudar na compreensão da conexão de alguns dos resultados com os experimentos.

Voltando ao processo de ramificação definido na seção 3.6, é possível derivar uma forma fechada - também em primeira ordem de $\sigma$ - para as distribuições de tamanho e tempo de avalanches. Como resultado (apenas para ERM), surgem leis de potência com expoentes $-3 / 2$ para tamanho e -2 para duração de avalanches. Esses resultados concordam com os resultados experimentais originais. ${ }^{(25,30,33)}$ Mais recentemente, Larremore e colaboradores também derivaram este resultado usando matrizes aleatórias para quaisquer redes. ${ }^{(72)}$

$\mathrm{Na}$ figura 4.3, apresento numericamente a emergência de leis de potência no ERM no ponto crítico da rede. ${ }^{(17,20)}$ Fazendo as medidas indicadas na seção 3.4 , os expoentes medidos das avalanches críticas foram $-1.5 \pm 0.1$ para tamanhos e $-2.0 \pm 0.1$ para tempos, concordando com a maioria dos experimentos. Além disso, note que estes dois expoentes são exatamente os mesmos que os esperados para uma dinâmica auto-organizada mais clássica (modelo de pilha de areia), embora não haja auto-organização neste modelo, apenas um ponto crítico que pode ser controlado.

No entanto, ao observar BAM e UCM na figura 4.4 fica claro que estas distribuições distanciam-se consideravelmente de puras leis de potência. Não se trata apenas de diferentes expoentes associados às leis de potência, mas algo ainda mais inesperado ocorre: a falta de uma lei de potência verdadeira e o surgimento de um acréscimo anômalo (bump) em avalanches com duração e tamanho próximos aos limites do suporte da distribuição. Note que não apenas avalanches críticas não são distribuídas conforme leis de potência, como também há a ocorrência de leis de potência em sistemas subcríticos.

Estas observações levantam diversas questões ligadas ao coração da fenomenologia de transições de fase fora do equilíbrio, principalmente pelo conflito com a crença de que leis de potência consistem uma das assinaturas mais confiáveis de transições de fase. No entanto, note que a transição de fase não é, por definição, a ocorrência ou não de leis de potência, mas sim algum tipo de comportamento anômalo (como descontinuidades ou não-analiticidades) em 
(a) Tamanho

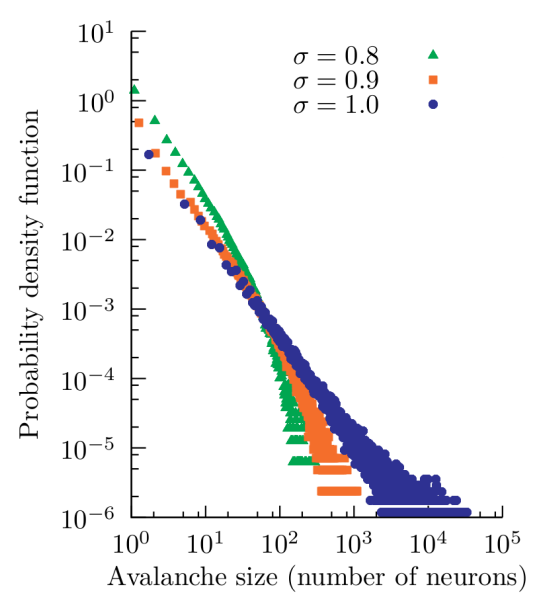

(b) Duração

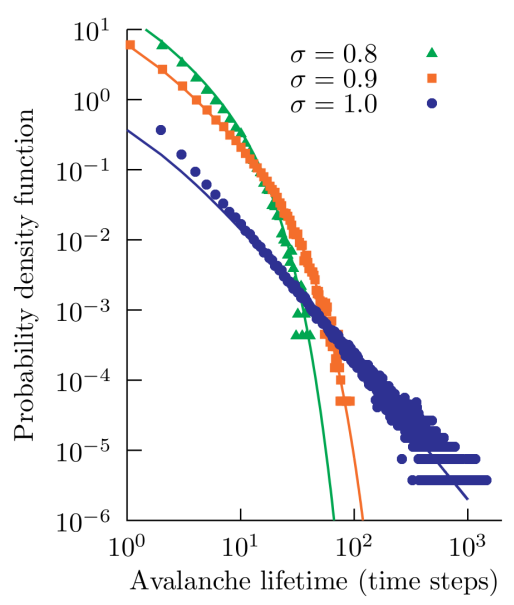

Figura 4.3- Distribuições de tamanho e duração das avalanches no ERM. As únicas leis de potência são nos casos críticos $(\sigma=1)$. As linhas cheias são previsões do processo de ramificação. Os expoentes críticos são $-3 / 2$ para tamanho e -2 para duração de avalanches, concordando com os experimentos mais antigos.

Fonte: Elaborada pelo autor.

(a) Tamanho

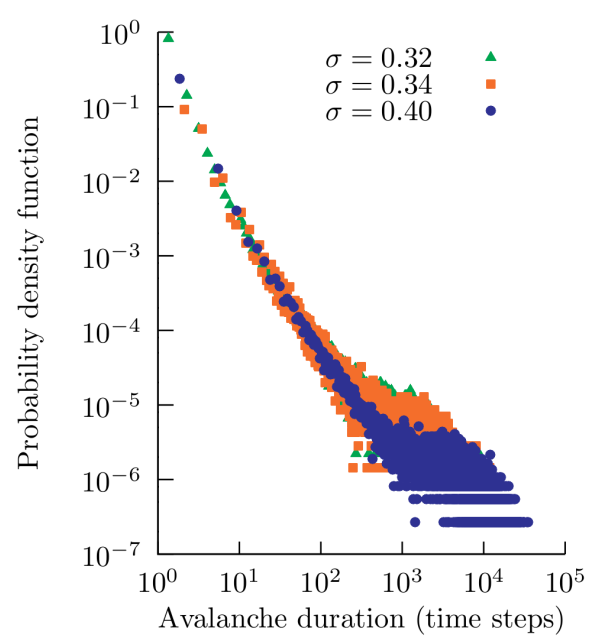

(b) Duração

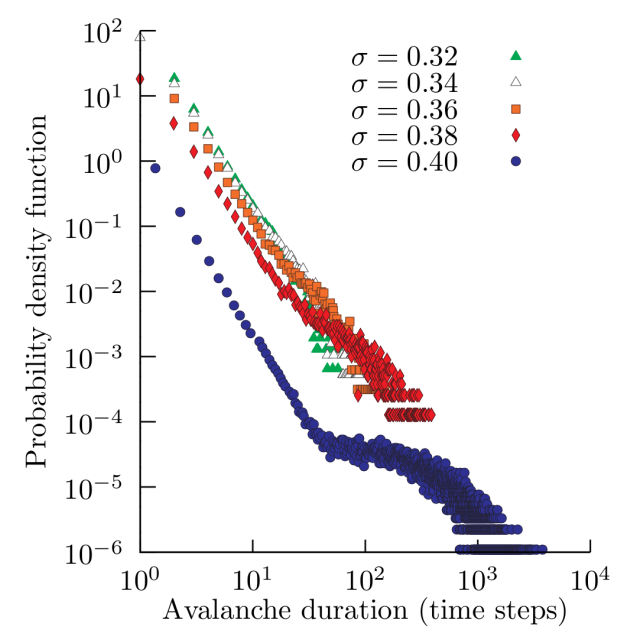

Figura 4.4- Distribuições de tamanho e duração das avalanches no BAM. O caso crítico ( $\sigma=$ 0.4) não apresenta leis de potência, assim como casos subcríticos apresentam leis de potência $(\sigma \sim 0.36)$. No caso crítico, após um regime inicial similar a uma lei de potência, segue uma anomalia que chamarei de bump, um excesso de massa probabilística concentrada em eventos do extremo da distribuição. Esses bumps representam ganhos em comparação ao que se esperaria de uma lei de potência pura, o que significa que avalanches de duração e tamanho maiores são relativamente mais prováveis. Os expoentes do regime de lei de potência (que dura apenas duas décadas) são -2.5 para tamanho e -3 para duração.

Fonte: Elaborada pelo autor. 
alguma função de interesse que demarque duas fases (ao menos qualitativamente) distintas. A ocorrência de leis de potência nestes pontos em que a anomalia ocorre (pontos críticos) parece sempre estar presente nas dinâmicas até hoje contempladas, muito embora nunca tenha sido demonstrada rigorosamente qualquer relação mais íntima. Portanto, em última análise, não há nenhuma contradição lógica nestes resultados.

Existem, no entanto, outros indicadores de fenômenos críticos que podem ser calculados neste presente contexto. Um deles é a análise de tamanho finito, usualmente utilizada não apenas para demonstrar a existência de uma função de escala que torna a lei estudada livre de escala, como também para estimar os pontos críticos e, em caso de lei de potência, os expoentes. Na parte superior da figura 4.5 vemos as distribuições cumulativas $\rho_{N}(t)$ para ambas ERM (a) e BAM (b) variando o número $N$ de neurônios. Fica claro que quanto maior $N$, maiores durações de avalanches tendem a ser observadas nas simulações, e portanto o domínio das distribuições (ou suporte) tendem a se alargar. Assim, é desejável encontrar uma função de escala $\mathcal{F}$ que relacione tais distribuições a $N$ diferentes.

Pensando em uma lei de potência, como é o caso das distribuições da figura 4.3, é natural esperar que essa função de escala seja definida segundo(36)

$$
\rho_{N}(t)=t^{-\gamma} \mathcal{F}\left(\frac{t}{N^{D}}\right)
$$

em que $N^{D}$ está relacionado com o corte das $\rho_{N}(t)$ (veja parte superior da figura 4.5) e $-\gamma$ é o expoente da lei de potência. Dessa forma,

$$
\mathcal{F}\left(\frac{t}{N^{D}}\right)=\rho_{N}(t) t^{\gamma}
$$

Note que $\mathcal{F}(\tau)$ independe de $N$ e essa é a característica que a torna tão útil: se graficarmos candidatas à função escala em função de $\tau$, variando $N$, então todas as curvas para diferentes $N$ devem colapsar em uma única curva/função - conhecido como "colapso de dados". Quando a lei em questão é livre de escala, então podemos usar este fato para descobrir o expoente da distribuição de avalanches. Heuristicamente, vou aplicar exatamente o mesmo método e esperar encontrar uma função de escala que, no entanto, estará também ligada a um expoente 
(a)
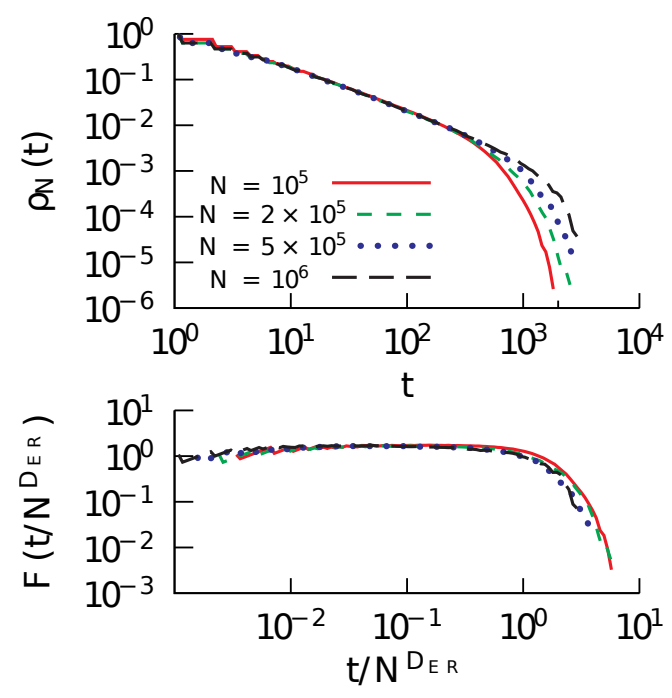

(b)
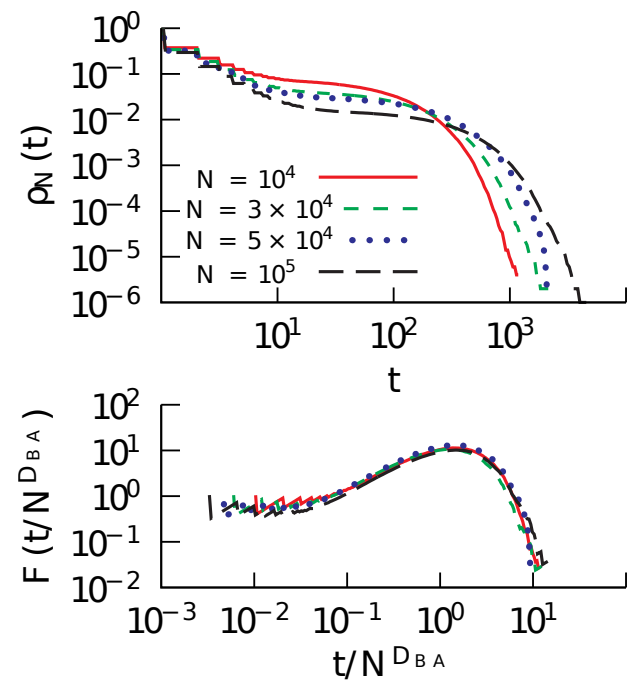

Figura 4.5- Colapso das distribuições cumulativas de tempos de avalanches para ERM (a) e BAM (b). No canto inferior, apresento funções de escala encontradas numericamente em sistemas colocados em casos críticos (da equação 4.3.2).

Fonte: Elaborada pelo autor.

$-\gamma$ que não fará necessariamente sentido com respeito à distribuição original. Ainda assim será uma função de escala.

Esses resultados estão na parte inferior da figura 4.5. Particularmente, na figura 4.5a os expoentes $\gamma$ e $D_{E R}$ que fazem com que os dados colapsem são $\gamma=2$ (o que concorda com as outras medidas do expoente da lei da figura 4.3.b) e $D_{E R}=1 / 2$, o que significa que o corte devido ao tamanho finito escala com a raiz do tamanho do sistema. Já para figura 4.5b, os expoentes são $\gamma=2$ e $D_{B A}=1$. Este é, portanto, um indício forte de criticalidade que posso oferecer. Note que apesar de as distribuições não serem leis de potência em um sentido ainda obscuro, existe algum tipo de invariância de escala, o que pode significar que uma lei "livre de escala" seja mais do que apenas leis de potência.

\subsubsection{Subamostragem da população neural}

No capítulo 2 mostro como os experimentos são realizados e que as vezes pode ocorrer que uma subamostragem da população neural leve a distribuições que se assemelham a exponenciais em vez de leis de potência. Gostaria de responder outra pergunta: seriam as leis de potência possíveis subamostragens de distribuições como as da figura 4.4? Realizei dois experimentos 
neste sentido, e vou discuti-los a seguir.

No entanto, é importante ressaltar uma diferença sutil e importante nestes próximos argumentos. Não defendo a ideia, em hipótese alguma, de que todas as distribuições já estudadas por Beggs, ${ }^{(25)}$ Plenz ${ }^{(41)}$ e toda esta comunidade científica sofrem efeitos de subamostragem e que seus resultados podem ser artefatos gerados pela forma de medida. Este pode sim ser o caso em algum estudo, mas não é este o resultado que temos das últimas seções. Dado que ERM demonstrou leis de potência (assim como outros modelos de grafo aleatório), então existe uma origem "topológica" que determina as distribuições de avalanches. Sendo assim, populações neurais distintas podem a priori gerar distribuições completamente diferentes. Portanto, leis de potências não são resultados lógicos de subamostragem, mas podem estar ligados intimamente com detalhes específicos da conectividade/dinâmica neural de populações específicas. ${ }^{(21)}$

Tendo dito isso, seguem os experimentos para testar a hipótese de subamostragem. Primeiramente, escolho uniformemente uma parte da população neural e realizo a contagem de duração e tamanho das avalanches neurais geradas apenas por essa porção da rede. Naturalmente, uma avalanche que momentaneamente não se manifesta em nenhum dos neurônios escolhidos para a amostragem é considerada terminada. Para assegurar consistência, se esta mesma avalanche continuasse e passasse a excitar os neurônios dentre a população escolhida, a consideramos como uma nova avalanche. Com isso, é possível ver que com uma subamostragem de $\sim 95 \%$, leis de potência reaparecem quando as distribuições completas são as da figura 4.4. Além de a forma da distribuição modificar-se (os bumps desaparecem), o valor numérico dos expoentes também pode variar bastante. Com subamostragens menores $(0 \%-$ $80 \%$ ), o suporte da distribuição passa a diminuir significativamente, muito embora a forma da distribuição se mantém bastante distinta de uma lei de potência pura.

A segunda abordagem tratou de imitar efeitos de picos negativos nos potenciais locais. Associo a cada neurônio uma probabilidade $p$ de não detectar seu sinal. Medindo de forma semelhante à primeira abordagem, quando $p \sim 0.05$ as leis de potência reaparecem. Veja que estas duas abordagens apresentam resultados equivalentes, uma vez que $p \sim 0.05$ é equivalente a subamostrar os spikes em $\sim 95 \%$ das detecções. 


\subsubsection{Expoentes do regime livre de escala inicial}

Apesar de as distribuições de avalanches em BAM e UCM fugirem do comportamento clássico de lei de potência (figura 4.4), o regime inicial - referente à primeira uma década e meia parece seguir uma lei de potência razoavelmente bem, assim como nos experimentos mais recentes de Friedman e colaboradores. Como eles apresentam expoentes desse regime inicial, testei quais resultados emergem do modelo $\mathrm{GH}$ e se há alguma possível comparação mais quantitativa que podemos fazer com o experimento.

Usando BAM, os expoentes são bem maiores: -2.5 para tamanho e -2.9 para duração de avalanches e parece mais complicado controlar este expoente, mesmo controlando o expoente da distribuição de graus usando attractiveness. Já com o UCM, é possível controlar este expoente da parte inicial da distribuição de avalanches - embora não de forma independente para duração e tamanho - usando o expoente da distribuição de graus, nominalmente $-\alpha$. Com $\alpha=3.5$, o expoente de tamanhos se torna -1.7 e de duração, -1.9 , em completa concordância com Friedman e colaboradores. ${ }^{(41)}$

\subsection{Entropia de tamanhos e tempos de avalanches}

Até o momento os resultados indicam que o fato de a distribuição de tamanhos e durações de avalanches serem leis de potência não é necessário nem suficiente para otimização da faixa dinâmica. O que as figuras 4.3 e 4.4 nos mostram de fato é que tão mais próximo as redes estão de apresentarem uma faixa dinâmica máxima, mais frequentes são avalanches de tamanhos e durações gigantescos. Essa tendência pode ser capturada por uma medida que interessa muito aos neurocientistas: a entropia. A entropia de uma variável aleatória é muitas vezes associada à uma medida de sua variabilidade, no entanto em sentido mais estrito é uma medida do domínio (ou suporte) em que a distribuição de probabilidades (ou densidade) apresenta valores apreciáveis. Como os bumps representam um acúmulo anormal de massa probabilística em eventos "extremos" (avalanches muito longas ou envolvendo grande parte da população neural), é natural esperar que a entropia dessas avalanches cresça conforme o sistema caminha para a criticalidade. Mais ainda, num sistema supercrítico, uma parte 
(a) Erdős-Rényi

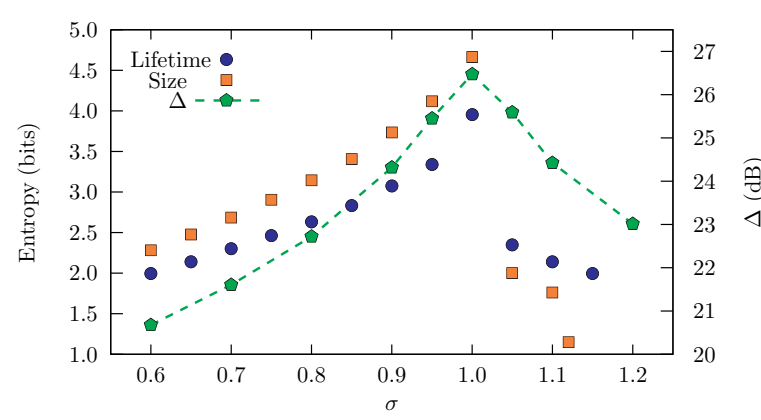

(b) BAM

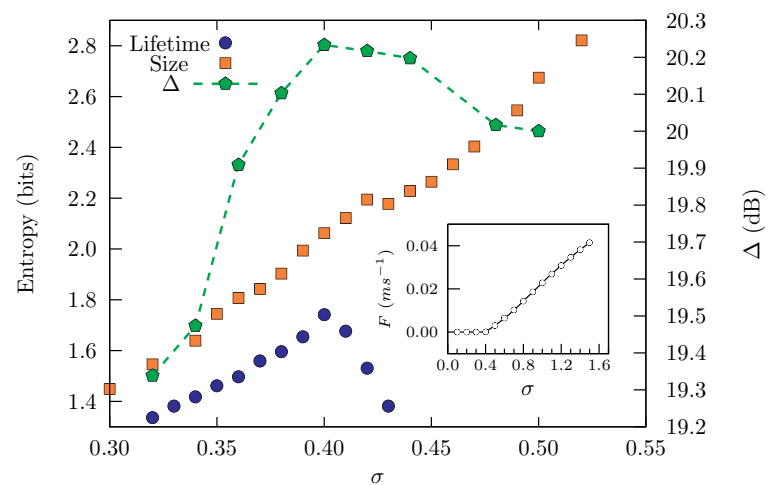

Figura 4.6- Diferença entre as entropias em redes de (a) ERM e (b) BAM. Em ambos os casos, a entropia de duração de avalanches (bolas azuis) se otimiza no mesmo ponto em que a faixa dinâmica (pentágonos verdes), i.e., no ponto crítico do sistema. Já a entropia de tamanhos de avalanches (quadrados laranjas) pode não otimizar no ponto crítico em algumas topologias. Em (b), o inset mostra que o ponto crítico de fato ocorre em $\sigma \approx 0.4$ no BAM.

Fonte: Elaborada pelo autor.

da massa probabilística perde-se dado que avalanches de duração e tamanho indeterminados passam a ser prossíveis. Em especial, para um sistema finito, a probabilidade de uma avalanche infinita é sempre nula. No limite "termodinâmico", estes eventos se tornam possíveis.

Calculando as entropias de tamanhos e durações de avalanches seguindo a receita da seção 3.5, a figura 4.6 mostra que de fato há uma otimização concomitante com a faixa dinâmica, no entanto não com ambas as entropias, mas apenas com a entropia de durações de avalanches. Isso significa que existe algum tipo de privilégio com o balanço temporal da atividade neural: o importante é um maior vocabulário nas durações de avalanches para a otimização da faixa dinâmica.

\section{5 Última medida de criticalidade: colapso do perfil de avalanches}

Apesar de a definição de um ponto crítico envolver apenas a não-analiticidade de uma função de interesse, é bastante comum a ocorrência de efeitos estranhos em tal condição. Uma delas já foi exposta anteriormente - colapso das distribuições cumulativas de avalanche. Como 

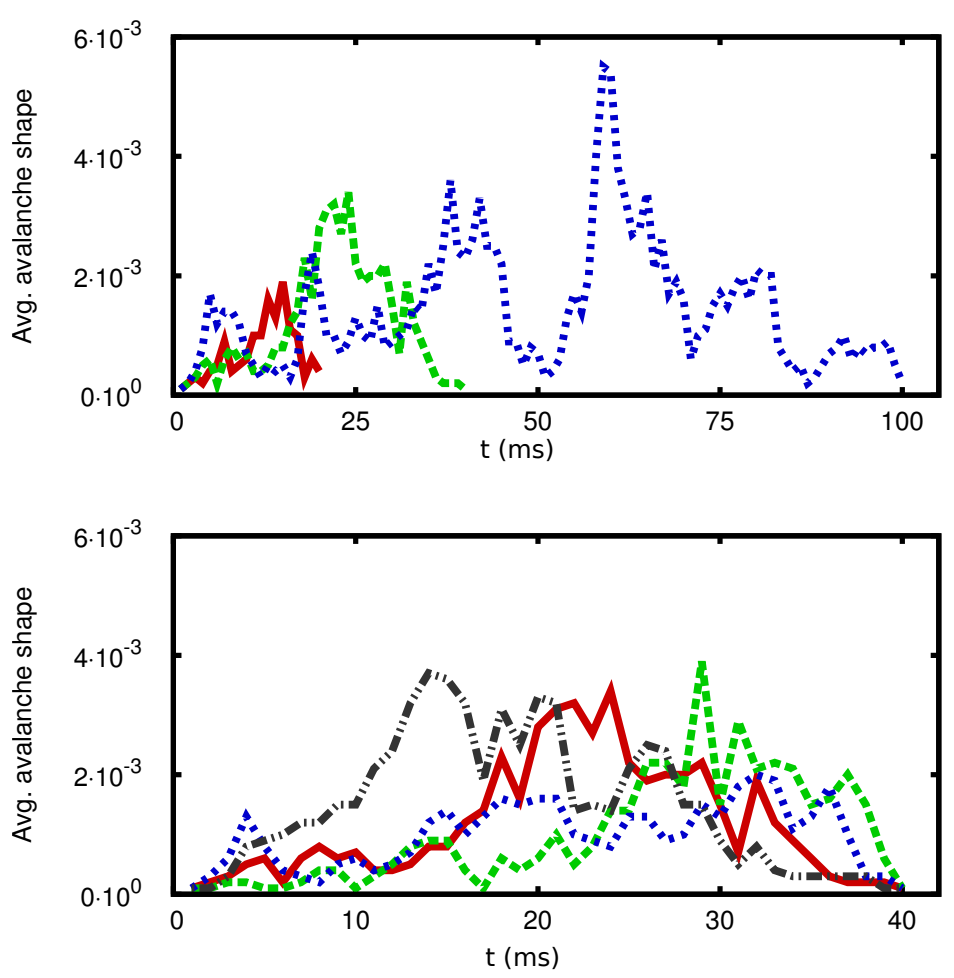

Figura 4.7- Exemplo de realizações diferentes de formas de avalanche resultantes da dinâmica GH. Superior: diferentes realizações de avalanches de durações diferentes (10, 20 e 40 passos temporais). Inferior: diferentes realizações de formas de avalanches, todas com duração 40 passos temporais.

Fonte: Elaborada pelo autor.

consequência, dizemos que existe uma lei que rege todas as escalas de tamanho do sistema, uma lei universal. A seguir, exploro outra possível lei bem mais robusta e complexa, uma que rege a forma das avalanches. Este método é bastante aceito e utilizado em outros sistemas e contexto. ${ }^{(73-76)}$

Em vez de registrar apenas o tamanho e a duração das avalanches, marco todo o histórico da atividade neural. Na figura 4.7 (topo) vemos três realizações exemplos de atividade em função do tempo, todas iniciadas com apenas um único "neurônio gatilho". Qualquer uma delas pode ocorrer, embora com diferentes probabilidades. Chamaremos esta evolução de perfil da avalanche e denotaremos a atividade no instante $t$, dado que o perfil dura um tempo $T$, de $f_{T}(t)$. Claramente, $f_{T}(t)$ define uma família de variáveis aleatórias correlacionadas de uma forma bastante intrincada. Na figura 4.7 (inferior) vemos quatro realizações diferentes de $f_{T}(t) \operatorname{com} T=40 \mathrm{~ms}$. 

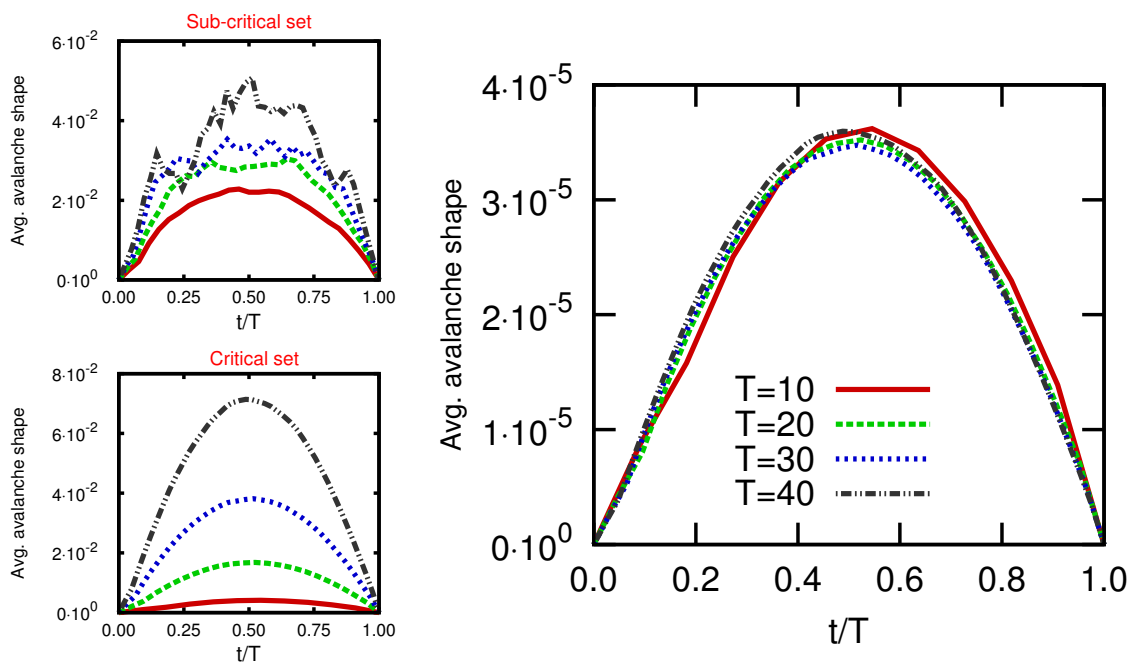

Figura 4.8- Formas médias de avalanches. Esquerda: exemplos extraídos de um conjunto crítico e um subcrítico. É importante notar que os resultados do caso crítico seguem uma forma parabólica bastante suave. Direita: Colapso das formas médias de avalanches usando a função de escala proposta.

Fonte: Elaborada pelo autor.

O interessante é que a média destes perfis, denotada por $\left\langle f_{T}(t)\right\rangle$, também costumam seguir uma lei universal no ponto crítico independente de $T$ ou qualquer outra característica específica destes perfis. Ao reescalar o eixo temporal para $t / T$, todos os perfis começam e acabam nos mesmos pontos. Já para o colapso de fato, perfis relacionados a diferentes durações $T$ devem escalar de uma forma bastante especial: $T^{1 / \mu}$. De fato, fora do ponto crítico, não é possível encontrar $\mu$ de forma que os perfis colapsam. Como função de escala, uso

$$
\mathcal{G}\left(\frac{t}{T}\right)=T^{1 / \mu}\left\langle f_{T}\left(\frac{t}{T}\right)\right\rangle
$$

Note que um perfil $T$ tem em geral $T-1$ graus de liberdade e o colapso dos perfis implica em uma correlação extremamente não trivial. Na figura 4.8, é possível ver os perfis colapsando no ponto crítico.

Existem ainda muitos outros indicativos de fenômenos críticos que podem ser testados, dos quais alguns já foram testados com sucesso. No entanto, fogem um pouco do escopo desta tese e portanto serão apresentados no futuro. Apesar disso, acredito que o essencial destes testes pode ser resumido no colapso dos perfis de avalanches como apresentado aqui. 



\section{Capítulo 5}

\section{Olfato em insetos e antecipação de}

\section{informação}

Neste capítulo, reviso um pouco sobre o conhecimento da principal estrutura envolvida no olfato de insetos, o Corpo Cogumelar. O principal objetivo desta revisão é reunir os diversos artigos e informações que usei para construir meus modelos e servir como base para os que quiserem ingressar nessa área. Ao final deste capítulo, introduzo a questão científica que abordei em meu trabalho: quais as propriedades dos Corpos Cogumelar são responsáveis pela rapidez com que insetos conseguem responder a odores? Adianto que a resposta está exatamente no balanço entre as populações neurais que o constituem.

Por se tratar principalmente de uma revisão, o leitor deve se sentir livre de pular este capítulo a menos da seção 5.4. Todas as referências subsequentes a informações contidas neste capítulo serão devidamente apontadas nos capítulos seguintes.

\subsection{Das antenas ao Corpo Cogumelar}

Os órgãos de insetos responsáveis por captar sinais de voláteis presentes no ar são as antenas. Nelas há receptores químicos aos quais os voláteis se ligam temporariamente por afinidade química. É possível visualizar por miscroscopia eletrônica esses receptores químicos, ${ }^{(77)}$ e na figura 5.1 incluo uma dessas imagens que foi disponibilizada em domínio público. Em abelhas, são contabilizadas aproximadamente 400 células receptoras por divisão da antena, geralmente 


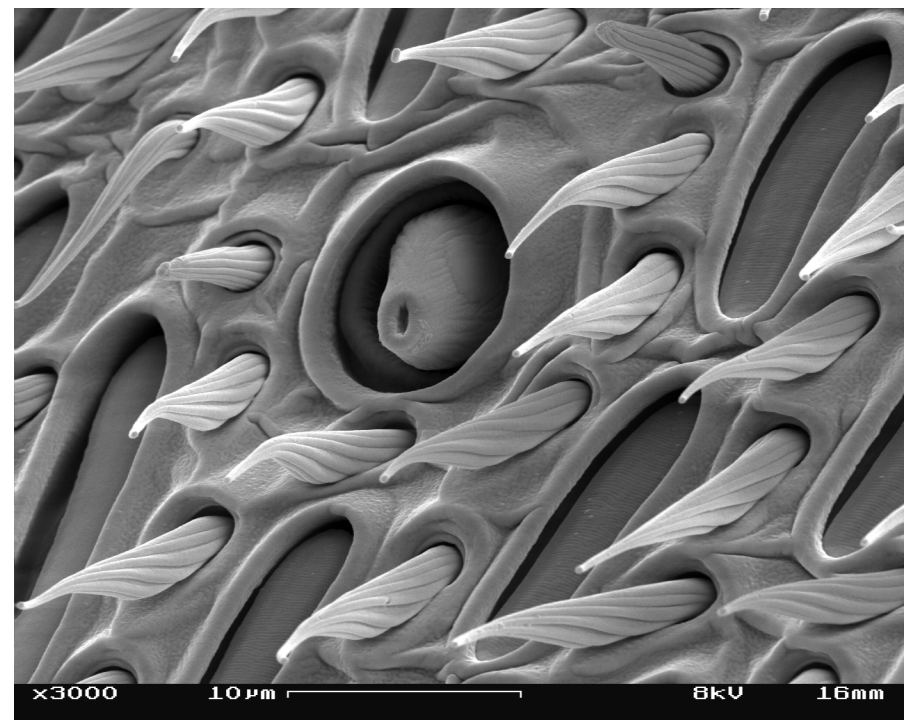

Figura 5.1- Microscopia eletrônica de uma antena de vespa (Vespula vulgaris), mostrando cílios comuns a diversos insetos e as células receptoras olfativas (estrutura rugosa e elíptica). Essas células têm proteínas específicas que se ligam a certos odorantes e desencadeiam um potencial de ação. Este potencial de ação sinaliza a detecção daquele odorante.

Fonte: SECRETDISC. ${ }^{(81)}$

começando da terceira seção em diante. Essas células possuem proteínas específicas que se ligam a certos odorantes, costumeiramente conhecidas do inglês como Odorant Binding Proteins. ${ }^{(78,79)}$ As primeiras proteínas descobertas com tal funcionalidade apareceram no início dos anos 80. ${ }^{(80)}$ Uma vez ligado, o receptor passa por uma mudança estrutural e ativa uma proteínas G, gerando entrada de cálcio e sódio na célula e a despolarizando, o que inicia um potencial de ação. Em termos de código neural, este spike será a sinalização desta célula de que um certo volátil foi detectado.

As células receptoras respondem para um espectro de voláteis. ${ }^{(79)}$ Este sinal então é transmitido ao Lóbulo Antenal $(A L)$, onde ocorre a primeira filtragem da informação olfativa. As conexões formadas entre as células receptoras e glomérulos no AL são fortemente determinados por genética, ${ }^{(82)}$ e os padrões produzidos por diferentes odores são muito parecidos em indíviduos de uma mesma espécie. ${ }^{(83,84)}$ Existe portanto um mapa genético de odores no $\mathrm{AL}$, onde já é possível discriminar razoavelmente odores. ${ }^{(85,86)}$ No entanto, neste estágio o sinal ainda é extremamente ruidoso e não-estacionário. ${ }^{(87)}$ Nos ALs, os principais neurônios responsáveis por receber e retransmitir o sinal neural são os Neurônios de Projeção (PNs).

Modelos computacionais do AL indicam que reconhecimento de odores é codificado rapi- 
damente, enquanto que concentração de voláteis pode estar codificada na latência da resopsta neural. ${ }^{(88)}$ No entanto, muitos experimentos mostram a presença de padrões espaço-temporais já no primeiro estágio do sistema olfativo (tanto em invertebrados como em vertebrados). ${ }^{(89-91)}$ Isto pode ser o resultado de um balanço entre excitação e inibição no AL. ${ }^{(92)}$ Este balanço é resultado da interação dos PNs com Neurônios Laterais (LNs), estes últimos em sua maioria inibitórios. PNs e LNs se comunicam indiretamente, usando glomérulos presentes no AL.

Todos estes fatores transformam e filtram o sinal olfativo que chega ao AL. Este sinal então é enviado ao CG, que então se encarrega do processo de tomada de decisão. Existe um consenso de que PNs e LNs são responsáveis por facilitar a computação dos CGs, embora ainda haja muito o que se entender sobre a função desempenhada pelo AL.

\subsection{Anatomia e fisiologia do Corpo Cogumelar}

Os Corpos Cogumelares (CGs) foram observados pela primeira vez em 1850 (note, antes dos desenhos de Ramon \& Cajal descritos no capítulo 1) pelo biólogo Francês Félix Dujardin. ${ }^{(93,94)}$ O nome "Cogumelar" vem de sua estrutura, mostrada na figura 5.2, que assemelha a dois cogumelos na parte superior, que na verdade são duas protuberâncias cálices. Retirado de um trabalho de Rybak e Menzel, ${ }^{(95)}$ reproduzo na figura 5.2 uma imagem de microscopia eletrônica em que o formato cogumelo fica evidente. É possível ver dois cálices (por hemisfério), um sendo o lateral (LC na figura) e o outro medial (MC). Note que essa seção do CG não tem mais do que $700 \mu \mathrm{m}$, embora concentre uma porção razoável do total de neurônios no cérebro de insetos. Já existe uma quantidade razoável de informações, classificando grupos característicos de neurônios e caminhos de suas fibras nervosas.

Os CGs são comuns a todos os insetos, e muitas de suas propriedades de forma geral se mantêm. No entanto, diferentes espécies podem apresentar ligeiras diferenças em termos de tamanho e formato. ${ }^{(96)}$ Por exemplo, moscas com cérebros com apenas 200 mil neurônios apresentam CGs com aproximadamente 2500 neurônios. Já em abelhas, do total de aproximadamente um milhão de neurônios, 350 mil estão nos CGs. Isso se deve provavelmente ao fato de, nestas mesmas moscas, os cálices serem bem menos proeminentes. ${ }^{(97,98)}$

O AL (200-300 $\mu \mathrm{m})$ direito também pode ser visto, na parte inferior da figura 5.2. Apesar 


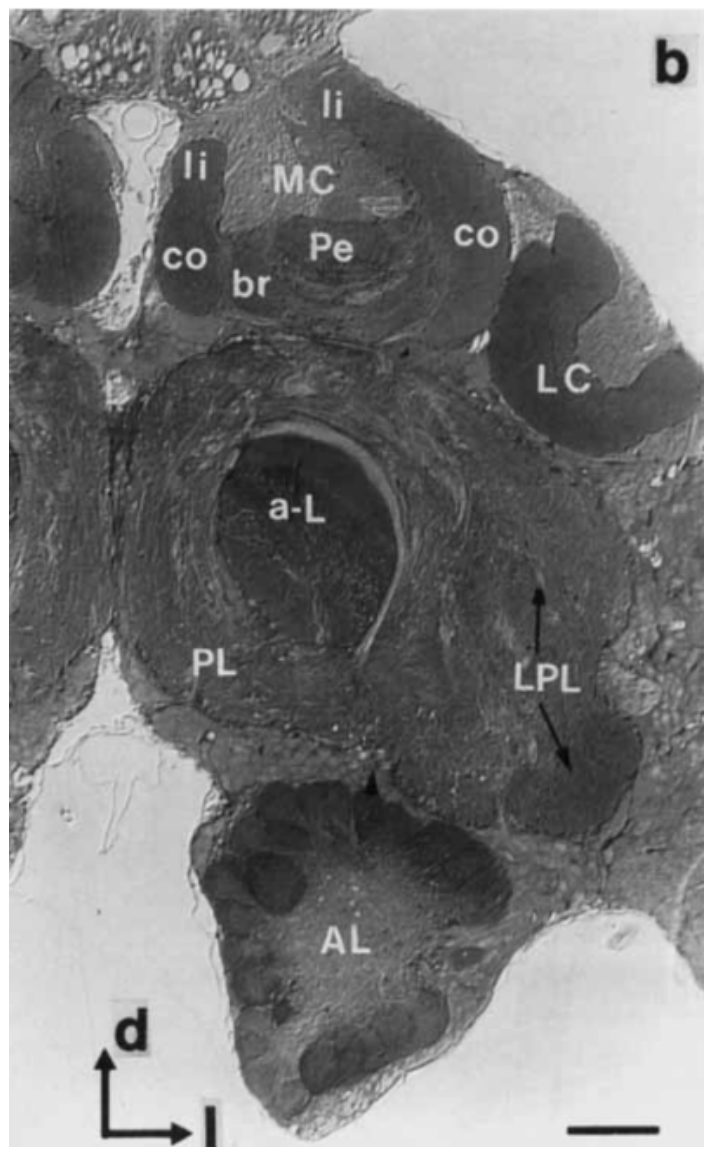

Figura 5.2- Microscopia do Corpo Cogumelar (CG) usando barra de escala de $100 \mu \mathrm{m}$. Os eixos d e I na figura indicam, respectivamente, o eixo dorsoventral e lateral mediano. Em outras palavras: o olhos composto direito da abelha estaria à direita da figura. As legendas mostram o mapeamento das áreas CG, das quais as mais importantes para o presente propósito são (de cima pra baixo): LC (Cálice Lateral), Pe (Pêdunculo), MC (Cálice Médio), a-L (lóbulo $\alpha$ ) e AL (Lóbulo Antenal).

Fonte: RYBAK; MENZEL '1993. ${ }^{(95)}$

de anatomicamente mais próximo dos lóbulos $\alpha, \beta$ e $\gamma, \mathrm{AL}$ projeta inervações nos cálices, constituídos por minúsculos neurônios conhecidos como Células Kenyon (KCs). Descritas pela primeira vez por Frederick C. Kenyon em 1896, ${ }^{(99)}$ estas células são centrais no aprendizado e formação de memória em todos os insetos. As KCs representam a maior populaccão dentro do CG, e elas são as responsáveis pela integração de informação de outras modalidades. ${ }^{(100)}$ Temos uma visão tridimensional desta estrutura na figura 5.3.

Um fator aparentemente comum entre insetos é a existência de código esparso na camada das KCs: fora sob estímulo, estas células mantêm-se praticamente silenciosas. ${ }^{(102,103)}$ Certos neurônios GABAérgicos podem estar ligados com a manutenção da esparsidade das KCs. Suspeita-se que a presença deste tipo de codificação seja uma solução biológica encontrada 


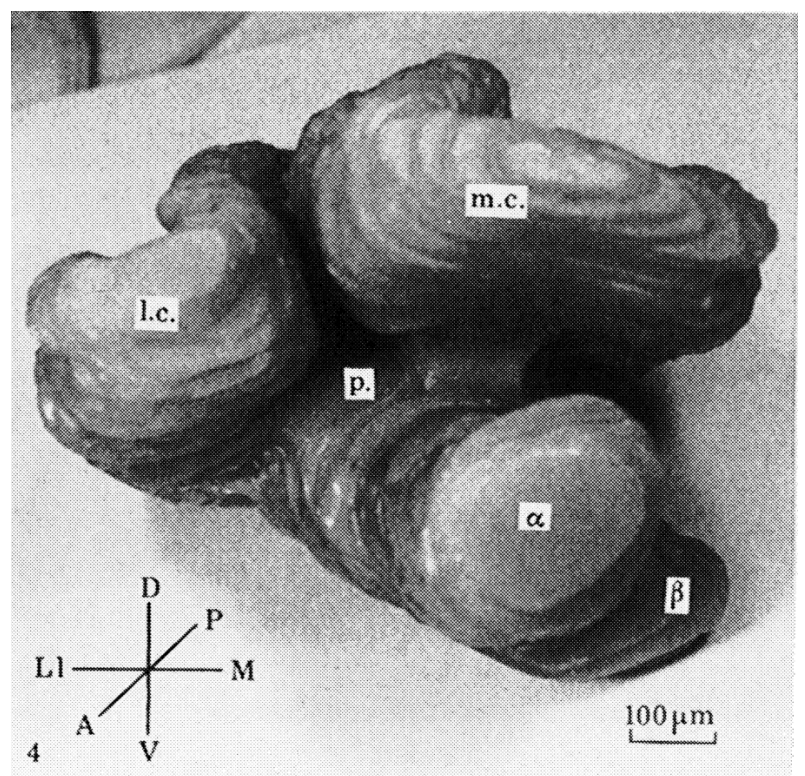

Figura 5.3- Microscopia eletrônica tridimensional do Corpo Cogumelar de uma abelha de mel (Apis mellifera). Esta imagem evidencia bem o formato dos cálices lateral e médio e dos lóbulos $\alpha$ e $\beta$. Compare com a representação pictórica na figura 5.4 .

Fonte: MOBBS '1982. (101)

para aprimorar o reconhecimento de padrões no olfato ${ }^{(22,104)}$ (discutirei mais a fundo este tópico no próximo capítulo).

Muitas vezes, as KCs também são chamadas de neurônios intrínsecos, por não inervarem áreas externas ao CG. Nos lóbulos $\alpha, \beta$ e $\gamma$ estão localizados os Neurônios Extrínsecos (ENs). Exceto por alguns ENs recorrentes (veja seção 5.2.2), os ENs inervam diversas áreas do cérebro, e por isso acredita-se que neles ocorre o processo de tomada de decisão. Uma das observações que comprovaram esta visão baseia-se em um experimento em que o inseto é recompensado com açúcar apenas quando a probóscide -aparelho alongado bucal de insetos, semelhante a uma pequena tromba capaz de sugar o alimento- é estendida quando certo odor é apresentado. ${ }^{(105)}$ Conforme o inseto aprende, é possível que os ENs rapidamente passam a responder ao odor correto, acionando o sistema motor que estende a probóscide. ${ }^{(105)}$ No que se segue, sempre que me referir a ENs deve-se entender pelos neurônios extrínsecos do lóbulo $\alpha$, a menos que especificado diferente.

Recentemente foi observado que na camada de saída do CG, especificamente no lóbulo $\beta$ (visível na figura 5.3), existe forte inibição lateral. ${ }^{(106)}$ Observou-se, tanto com simulações como com experimentos eletrofisiológicos, que essa inibição lateral se envolve no balanço 
de atividade dos ENs, especialmente evitando possíveis saturações causadas por plasticidade sináptica dependente de tempo (STDP). Este tipo de recorrência interna nos ENs já havia sido proposta anteriormente como uma necessidade básica para que o CG pudesse operar satisfatoriamente na discriminação de odores. ${ }^{(107,108)}$ É possível incluir esta inibição lateral em algoritmos de aprendizagem de máquina. ${ }^{(109)}$

\subsubsection{Balanço das populações}

Ao longo dos anos, acumularam-se dados sobre os tamanhos das populações mencionadas na seção anterior. Esta estrutura compreende grande parte do cérebro de insetos - aproximadamente $35 \%$ em abelhas - e pode ser o grande centro integrador das demais modalidades sensoriais de insetos. ${ }^{(96)}$ Este balanço é uma das características mais interessantes, do ponto de vista de reconhecimento de padrões, do CG, e será o ponto principal abordado nos capítulos seguintes.

Especificamente em abelhas Apis mellifera, estimam-se a existência de 350 mil neurônios só nos cálices (i.e., KCs) e dois mil PNs. Como os PNs projetam para as KCs, há uma grande divergência de sinal. Acredita-se que esta projeção divergente implemente uma estratégia de reconhecimento de padrões em que objetos são projetados em uma tela gigante (veja seção 5.3 para mais detalhes), onde suas diferenças e similaridades se tornam mais aparentes.

Das KCs, o sinal viaja para os ENs, que são muito menor em número: em torno de 400, com certa variabilidade entre indíviduos da mesma espécie. Essa convergência brutal - $350 \times 10^{3}$ KCs projetam para 400 ENs! - então parece também estar relacionada com características da computação que os ENs realizam. Uma das vantagens de tal estrutura é a amplificação de qualquer pequeno sinal que chegue aos PNs. No entanto, o ruído também pode ser amplificado e prejudicar alguns processos cognitivos. No capítulo 7 veremos que de fato é necessário tomar medidas para que o mínimo de ruído seja amplificado.

\subsubsection{Inibição recorrente}

Recentemente tem-se dado bastante atenção a um grupo de neurônios GABAérgicos que parecem inibir as KCs. ${ }^{(110,111)}$ De espécie em espécie, parece comum a existência de um grupo 
de neurônios com conexões recorrentes, embora detalhes (como quantidade, organização e fisiologia) possam diferir um pouco. Em grilos, por exemplo, há indícios da existência de alguns poucos neurônios GABA-érgicos, com o corpo celular gigante. ${ }^{(112)}$

Em abelhas, a observação e mapeamento destes neurônios foi realizada em 1993, categorizando como $A 3-d$ e $-v{ }^{(95)}$ Estes neurônios aparecem em dois grupos, somando cada um separadamente 60 neurônios aproximadamente. Dada sua localização, denominarei estes neurônios de neurônios do Trato Protocérebral Cálico (PCTs).

Existem ainda poucas medidas eletrofisiológicas, mas provavelmente estes neurônios estejam envolvidos na regulação e normalização da atividade do CG. ${ }^{(113)}$ Neste caso, esta regulação é vital para a manutenção do código esparso observado na camada das KCs. Os PCTs também podem ser responsávels por gerar resposta nas KCs após o fim da estimulação (conhecida como rebound) pela falta de inibição anterior. ${ }^{(102)}$ Também foi observado plasticidade sináptica e possível aprendizado pelos PCTs recentemente. ${ }^{(111)}$

Por estes motivos, incluirei no modelo um grupo de neurônios GABAérgicos, os PCTs. No capítulo 7 estes neurônios tomarão o centro das atenções como principal mecanismo de manutenção do código esparso das KCs.

\subsubsection{Resumo da morfologia}

De forma quase cartunesca, resumo a morfologia o Corpo Cogumelar (CG) como no esquema mostrado na figura 5.4. Há principalmente quatro populações: Neurônios de Projeção (PNs), Células Kenyon (KCs), Neurônios Extrínsecos (ENs) e células no Trato Protocérebal Cálico (PCTs). As sinapses entre KCs, PCTs e ENs são excitatórias, a menos de ENs com ENs -são GABAérgicas. Os PCTs têm sinapses inibitórias GABAérgicas. Ainda na figura 5.4, evidencio apenas o lóbulo $\alpha$, onde ficam os ENs, por ser meu principal objetivo no presente trabalho. Também evidencio a diferença de tamanhos (pictoricamente) entre cada uma das populações neurais consideradas.

O caminho da informação neural é: Antenas $\rightarrow$ ALs $\rightarrow \mathrm{KCs} \rightarrow$ ENs. Na última camada, ENs são então responsáveis pela tomada de decisão: identificar qual odor está estimulando as antenas. Em geral, após treinamento abelhas Apis mellifera conseguem detectar identidade 


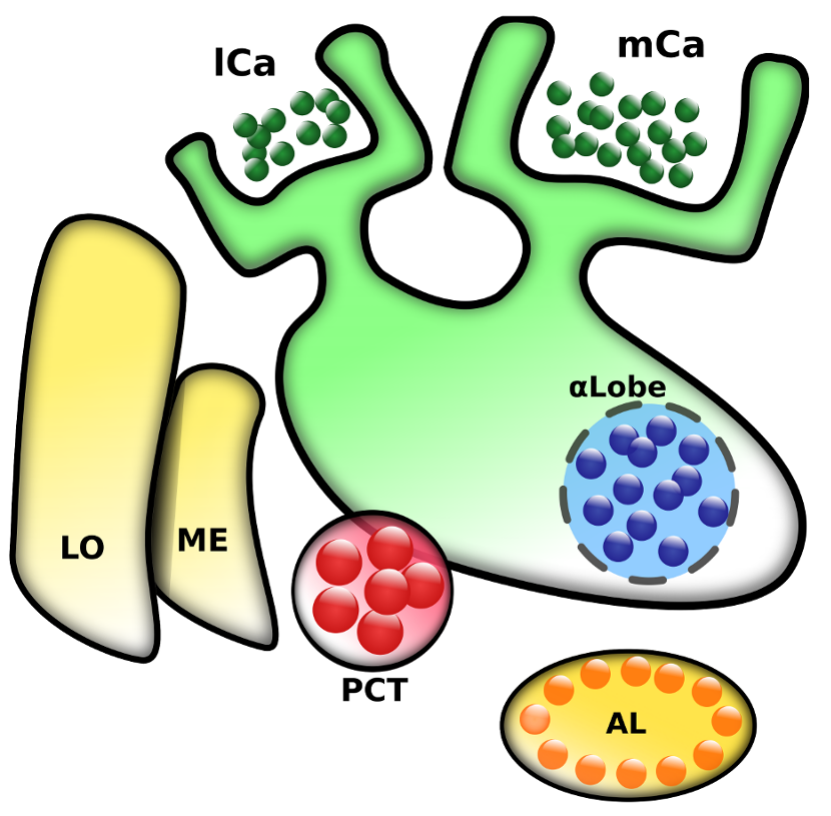

Figura 5.4- Visão cartunesca do Corpo Cogumelar, evidenciando as populações neurais centrais para o presente estudo: (i) Lóbulo Antenal ( $\mathrm{AL}$ ); (ii) Células Kenyon (KC) presentes nos Cálices lateral (ICa) e médio ( $\mathrm{mCa}$ ); (iii) o lóbulo $\alpha$, com neurônios extrínsecos (EN); e (iv) o Trato Protocalical (PCT). Para referência, estão também presentes os lóbulos ópticos. Compare a região verde com figura 5.3. LO e ME são regiões ligadas com a visão e servem para facilitar a logalização das outras áreas. Compare com a visão computacional dos CGs na figura 6.1, em que ficam evidentes os padrões de conexão são e o sentido do fluxo de informação olfativa.

Fonte: Elaborada pelo autor.

de um odor em apenas 50ms. A seguir discuto os CGs do ponto de vista cognitivo.

\subsection{Corpo cogumelar e aprendizagem}

As antenas captam voláteis que se ligam por afinidade química a um espectro de receptores. Com uma matriz de sensores químicos (usualmente chamado de nariz eletrônico) vemos exemplos de séries temporais devidos a voláteis. Na figura 5.5 mostro dois tipos de séries temporais: em (a) vemos a resposta do nariz eletrônico a monóxido de carbono (CO) em um túnel de vento, em um ambiente controlado (laboratório); em (b), o mesmo sensor em um ambiente realístico (fora do laboratório). Reconhecimento de padrões em séries temporais da figura 5.5 é um desafio interessante ainda hoje, e este é o tipo de problema que os CGs precisam resolver.

Evidências apontam que os CGs integram informação multimodal, sendo o ponto focal de todo o aprendizado ${ }^{(114)}$. Os CGs enfrentam fortes plasticidades sinápticas como resposta a 
(a)

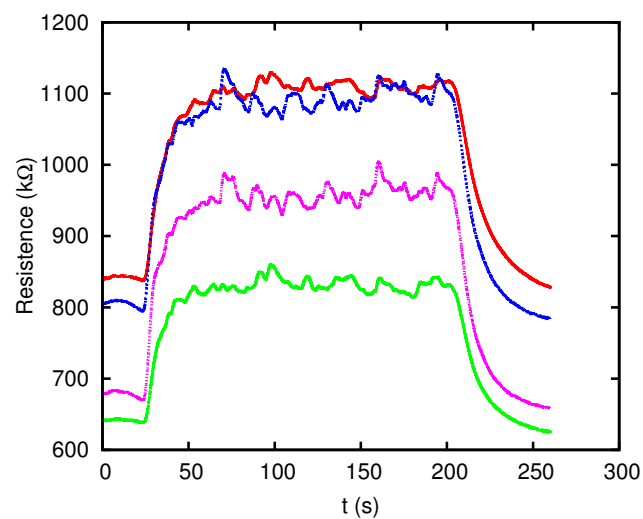

(b)

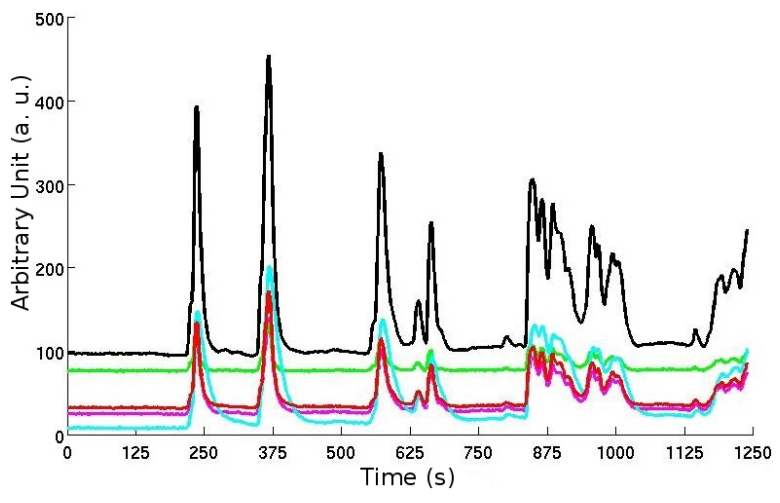

Figura 5.5- Propriedades do Corpo Cogumelar na aprendizagem de odores baseados em séries realísticas. (a): Resposta de um sensor químico a monóxido de carbono (CO). Dados disponíveis no UCI Machine Learning Repository. ${ }^{(1)}$ (b): Série captada por um sensor químico semelhante em um campo aberto, evidenciando a complexidade de um sinal olfativo. ${ }^{(2)}$

Fonte: (a) Elaborada pelo autor. (b) Cortesia de TRINCAVELLI. ${ }^{(2)}$

mudanças medidas por experimentos de condicionamento com odor. ${ }^{(115,116)}$ Martin Heisenberg, filho do físico Werner Heisenberg, estudou com grande profundidade como o CG impacta na aprendizagem em abelhas. ${ }^{(96)}$

Uma combinação entre aprendizado de Hebb e competição mútua via inibição parecem ser a principal estratégia para estudar como CGs conseguem extrair informação e aprender. $(107,117)$ A inibição lateral gera duas forças competindo para suprimir a outra, onde a classificação equilibra-se no lado vencedor (estratégia conhecida como winner-takes-all).

Outra hipótese interessante do ponto de vista de aprendizagem é a ideia de que as KCs formam uma tela gigante onde os PNs projetam a informação olfativa para que os ENs possam realizar reconhecimento de padrões. ${ }^{(22)}$ A ideia por detrás desta projeção é a mesma empregada em algoritmos de aprendizagem de máquina para realizar classificação, e iniciou com Cover. ${ }^{(118)}$ A base do funcionamento deste tipo de técnica se baseia na presença de código esparso, ${ }^{(102)}$ caso contrário ruído passa a contribuir mais do que a informação propriamente. A junção de projeção numa tela grande com código esparso é a base de funcionamento da técnica conhecida como máquina de vetor suporte, considerada estado de arte em termos de aprendizado de máquina. Vale, por fim, comentar que no hipocampo de mamíferos também é possível observar uma estrutura com uma projeção similar. ${ }^{(119)}$ 
Em termos de plasticidade e conectividade, modelos simplificados baseados em redes neurais artificiais são muitas vezes suficientes para estudar aprendizagem nos CGs. Muitas vezes, estes modelos simplificados são até tratáveis analiticamente. Entretanto, estas abordagens não capturam a rica dinâmica presente nos ALs ou CGs. Por exemplo, não é possível obter facilmente estimativas de concentrações de odorantes por meio destas abordagens. Resumindo, integração temporal nos CGs ainda é um mistério com poucas contribuições.

\subsection{Antecipação na detecção de odores}

Em 2012, Strube-Bloss e colabroadores ${ }^{(3)}$ descobriram que, apesar de duas sinapses depois, os ENs antecipavam o reconhecimento do odor em comparação aos PNs. Note que dada a distância entre estas populações, duas sinapses podem significar ao menos $5 \mathrm{~ms}$. Este resultado foi observado em abelhas Apis mellifera (abelha de mel), embora acredita-se que isso possa valer para, ao menos, uma grande gama de insetos, uma vez que a estrutura principal do Corpo Cogumelar se mantem muito parecida em toda a classe insecta. Apesar de parecer contraditório, diversas medidas indicavam que a saída (output) do CG parece computar mais rápido que a própria entrada (input).

Estes experimentos foram realizados com eletrodos de tungstênio, medindo separadamente PNs e ENs. Às abelhas, que nunca haviam participado de experimentos de condicionamento, foram apresentados dois odores (1-hexanol and 2-octanone). Na figura 5.6 é possível ver a atividade de cada uma dessas populações, bem como o nosso modelo já ajustado (mais detalhes no capítulo seguinte). Com as atividades neurais de cada uma destas populações, foi possível avaliar o tempo de resposta de cada uma delas separadamente.

Essa antecipação ocorre numa escala de tempo muito maior que os atrasos sinápticos: os ENs antecipam o código dos PNs em $40 \mathrm{~ms}$ em média, pelo menos cinco vezes mais rápido que qualquer estimativa conservadora dos atrasos sinápticos. Este resultado aparentemente paradoxal ocorre porque por tempo de reação me refiro ao tempo com que a população neural toda respondeu ao estímulo. Portanto, esse paradoxo na verdade é explicado com a existência de PNs específicos que respondem mais rápido que seus pares. A existência de tais neurônios vem sendo alvo de estudos que tentam classificar PNs como especialistas e generalistas. ${ }^{(120)}$ 


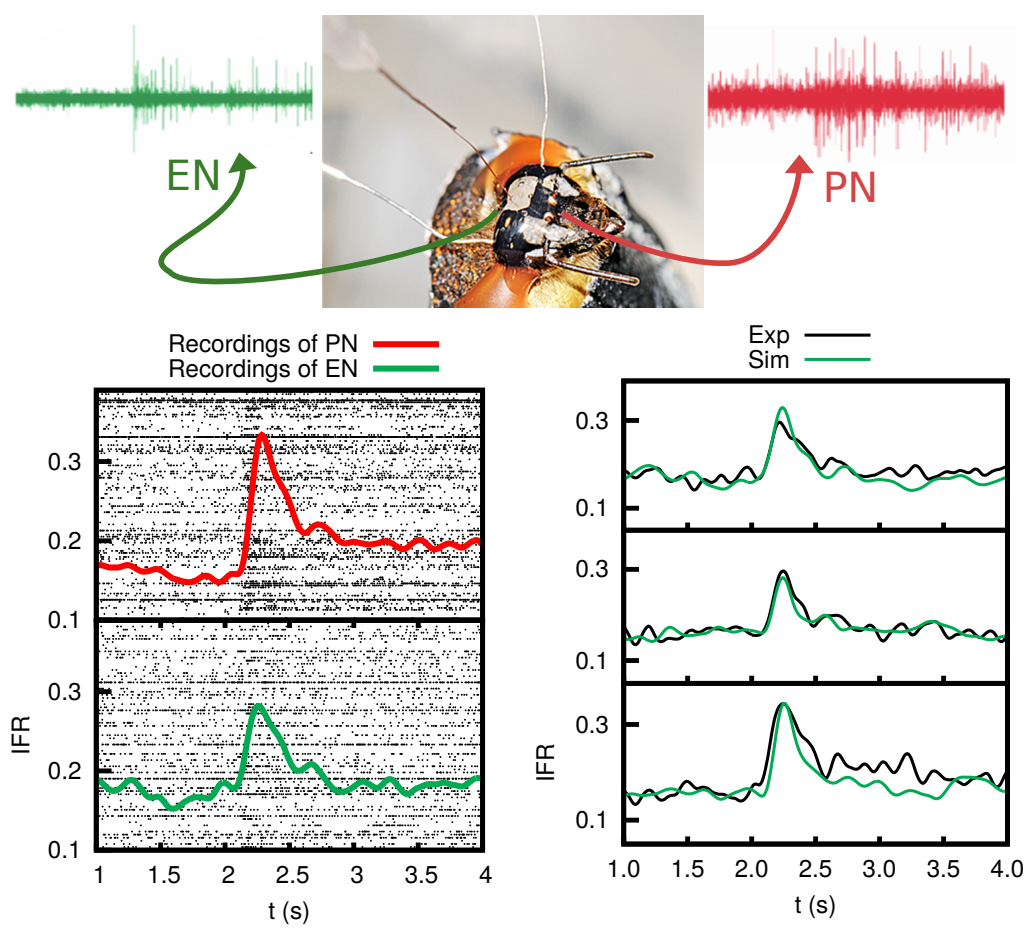

Figura 5.6- Medidas eletrofisiológicas em abelhas (Apis mellifera) de ambos Neurônios de Projeção (PNs) e Neurônios Extrínsecos (ENs). Embora os PNs estejam na primeira camada neural que recebe informação olfativa, estas medidas foram utilizadas por Strube-Bloss e colaboradores ${ }^{(3)}$ para demonstrar a antecipação dos ENs em reconhecimento de odores. À esquerda, medidas reais e respectivos raster plots. À direita, resultados usando o modelo introduzido no capítulo 6 para diferentes experimentos.

Fonte: Elaborada pelo autor.

Como abelhas usam olfato para encontrar fontes de alimento (pólen), e isso ocorre em pleno voo, $40 \mathrm{~ms}$ a mais pode representar um erro de alguns metros de erro na trajetória do voo. Como as abelhas tendem a serem guiadas por plumas de voláteis, e durante o vôo atingem diversos metros por segundo, seria natural esperar que evolutivamente as melhores estratégias temporais para detecção de odores foram preservadas.

Usarei os dados destes experimentos para não apenas ajustar meu modelo, como também responder à seguinte questão:

\section{qual a propriedade fundamental do Corpo Cogumelar \\ por de trás desta aceleração não usual?}

Esta pergunta será respondida no capítulo 7, usando a metodologia descrita no capítulo 6 . A importância associada a esta pergunta vai além da curiosidade científica: compreender quais os principais mecanismos que aceleram a codificação do olfato pode gerar novas concepções de 
dispositivos eletrônicos mais eficientes. Como tais dispositivos tendem a ser ordens de grandeza mais lentos, ${ }^{(22)}$ algoritmos bioinspirados podem ser a chave para diminuir esta diferença e otimizar processos derivados. 


\section{Capítulo 6}

\section{Metodologia: Modelo do Corpo}

\section{Cogumelar}

Neste capítulo, exponho detalhes sobre o modelo que desenvolvi para olfato em insetos, baseado em uma extensa lista de observações de comportamento e eletrofisiologia. Na maior parte, me atenho a medidas realizadas em abelhas da espécie Apis mellifera (também conhecidas como abelhas de mel). Começo com uma exposição na seção 6.1 sobre os fundamentos computacionais por detrás dos Corpos Cogumelares (CGs). A partir da seção 6.2 passo a descrever detalhes do modelo e implementação.

Vale comentar que o código para reproduzir estas simulações será em breve tornado público, e qualquer pesquisador poderá ter acesso e realizar simulações com base em seus interesses próprios.

\subsection{Fundamentos computacionais}

No capítulo 5, introduzi uma série de dados anatômicos e fisiológicos sobre olfato em insetos, sempre enfatizando em abelhas da espécie Apis mellifera (abelha de mel comum). Nesta primeira seção, extraio os princípios computacionais mais importantes que utilizarei para construir um modelo dinâmico do CG.

- No $A L$, a informação passa por uma primeira filtragem, analogamente ao processo de 
Seleção de Atributos (Feature Selection). Deste ponto de vista, a ideia é tornar o sinal o mais simples possível sem perder parte importante da informação olfativa.

- Então esse sinal já filtrado é projetado na camada das KCs, que pode ser vista como uma grande tela onde é mais fácil discernir diferentes objetos. Esta projeção é uma estratégia comum em algoritmos de Aprendizagem de Máquina. ${ }^{(118)}$

- A camada KC sempre mantém código esparso, em que apenas uma pequena parte se mantem ativa $(\sim 10 \%)$. Não apenas em Aprendizagem de Máquina esta é uma estratégia fundamental, como já foi verificado que o código esparso ajuda na classificação de odores. ${ }^{(121)}$

- Convergência forte da camada $\mathrm{KC}$ no lóbulo $\alpha$, onde estão os ENs. Dado que o código é esparso, esta convergência amplifica pequenas diferenças entre objetos dissimilares, e pode tornar a classificação mais precisa.

- Os ENs tendem a se associar em grupos que codificam cada odor ou alguma informação sobre determinado odor. Acredita-se que esta é a camada onde ocorre de fato a tomada de decisão "qual odor?". Na seção 6.1.1 exponho um exemplo de modelo que usa este mecanismo.

- Na camada dos ENs existe forte inibição lateral, ${ }^{(106)}$ mecanismo base para modelos de tomada de decisão. Essa inibição gera competição entre os diversos padrões já aprendidos pela rede neural, fundamento conhecido como winner-takes-all.

- Para garantir estabilidade do código das populações, os PCTs inibem as KCs dependendo da atividade induzida pelos PNs. Odores com alta concentração podem gerar sobrecargas de atividade que então seriam suprimidas pelos PCTs. A inibição baseia-se em sinapses GABAérgicas. ${ }^{(122)}$

A figura 6.1 resume todas as características levantadas acima, e pode ser entendida como um arcabouço esquemático para compreender computacionalmente o CG. Este conjunto de característica torna o CG de abelhas de mel capaz de classificar odores mais rapidamente que 


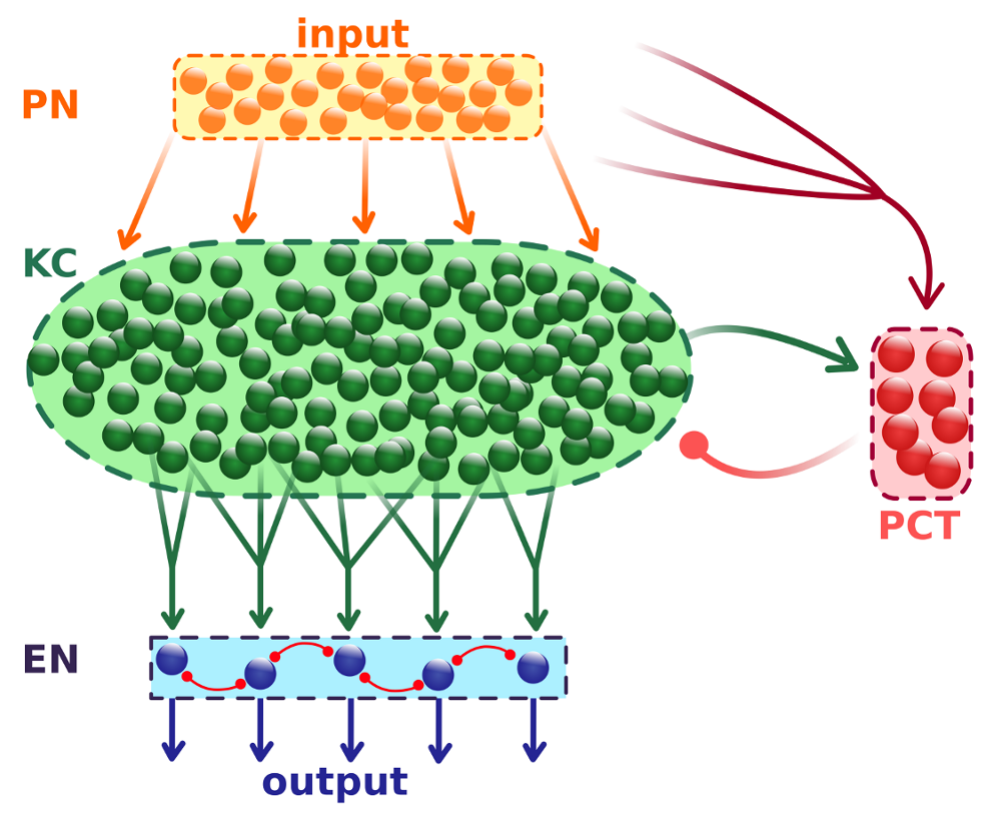

Figura 6.1- Visão computacional do funcionamento do Corpo Cogumelar (CG) para reconhecimento de padrões olfativos. São retratadas qualitativamente a maioria das características que tornam o CG um excelente dispositivo de reconhecimento de padrões em olfato. As características estão resumidas na seção 6.1. Setas indicam sinapses excitatórias, enquanto bolas indicam inibitórias. Os tamanhos relativos de cada populção neural também está qualitativamente indicado: as KCs representam a maior parcela do CG; os ENs são mais numerosos que os ENs (em abelhas de mel, aproximadamente de quatro a cinco vezes maiores); os PCTs formam o menor grupo.

Fonte: Elaborada pelo autor.

qualquer dispositivo eletrônico atual. Sua performance também é invejável, especialmente dado o tamanho (menos de um milimetro de comprimento).

A seguir, exponho uma primeira modelagem da qual variações foram amplamente empregadas nos primeiros estudos envolvendo o CG.

\subsubsection{Classificando odores realísticos}

Este será um parênteses na linha da discussão para introduzir um conceito que será bastante útil ao final das discussões. Um modelo super simples pode ser construído para identificar odores realísticos, ${ }^{(22)}$ usando séries temporais obtidas de experimentos em túneis de vento. ${ }^{(123,124)}$ Como detalhes deste modelo ${ }^{(105,107,125)}$ não contribuem significativamente para o tópico que estamos discutindo nesta tese, o apresentarei brevemente.

Usarei o modelo de McCulloch-Pitts para cada neurônio. Seja o vetor $N_{P N^{-}}$-dimensional 
$X=\left(x_{1}, x_{2}, \ldots\right)$ a atividade de cada PN. A projeção para as $\mathrm{KCs}$, representadas pelo vetor $Y$ de $N_{K C}$ dimensões, pode ser descrita como

$$
y_{j}=F\left(C X-\theta_{K C}\right)=F\left(\sum_{k=1}^{N_{P N}} C_{k j} x_{k}-\theta_{K C}\right),
$$

em que $C$ é a matriz $N_{P N} \times N_{K C}$ de pesos sinápticos entre PNs e KCs e $\theta_{K C}$ é o threshold de ativação das KCs. A função $F$ é a função de Heaviside:

$$
F(x)= \begin{cases}0 & , \text { se } x<0 \\ 1 & , \text { se } x>0\end{cases}
$$

De forma similar, podemos escrever a projeção das KCs para os ENs como

$$
\begin{aligned}
& z_{j}=F\left[(1+\mu) W Y-\mu Z-\theta_{E N}\right]= \\
& F\left[(1+\mu) \sum_{k=1}^{N_{K C}} W_{k j} y_{k}-\mu \sum_{p=1}^{N_{E N}} \sum_{k=1}^{N_{K C}} W_{k p} y_{k}-\theta_{E N}\right],
\end{aligned}
$$

em que desta vez $W$ é a matriz $N_{K C} \times N_{E N}$ de pesos sinápticos entre PNs e KCs e $\theta_{E N}$ é o threshold de ativação dos ENs. Note que inclui neste modelo a inibição lateral observada em experimentos. ${ }^{(126)}$

A aprendizagem será realizada em $W$, i.e., entre KCs e ENs. Para descrever a evolução de $W$, usemos $t$ discreto para denotar a iteração do sistema aprendendo. Para atualizar os pesos sinápticos,

$$
W_{j k}(t+1)= \begin{cases}W_{j k}(t)+1, & \text { se } z=1, y=1 \\ \max \left[W_{j k}(t)-1,0\right], & \text { se } z=1, y=0 \\ W_{j k}(t), & \text { caso contrário }\end{cases}
$$

Esta regra apresentada é uma versão da aprendizagem de $\mathrm{Hebb}^{(105,125)}$ e pode também ser usada em uma versão probabilística ${ }^{(107)}$ : definindo a taxa $p_{+}$de reforço positivo, i.e., probabilidade de realizar mudança no peso sináptico caso $z=1$ e $y=1$; e a taxa $p_{-}$de reforço negativo, i.e., probabilidade de naquele passo realizar mudança no peso sináptico caso $z=1$ e $y=0$. Ambas $p_{+}$e $p_{-}$devem ser encaradas como parâmetros livres (ou metaparâmetros, 
(a)

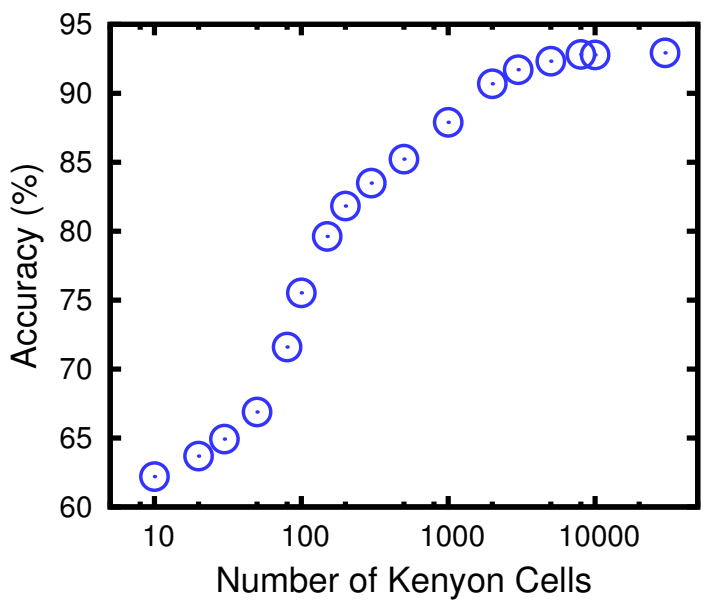

(b)

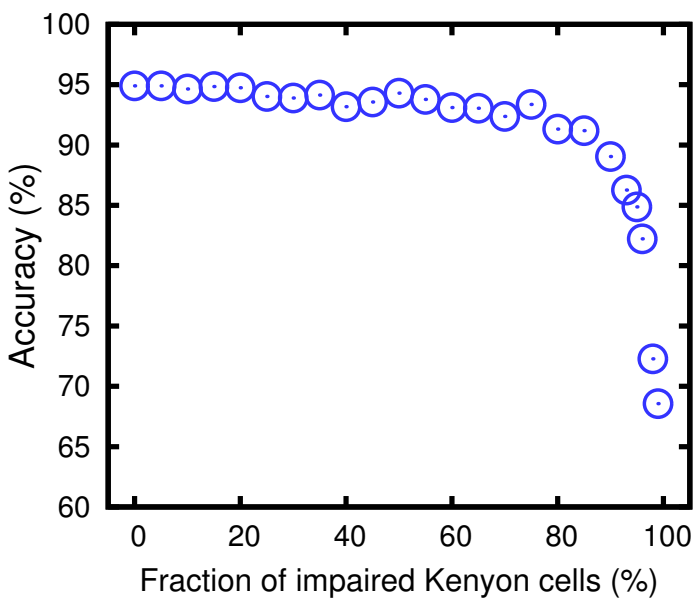

Figura 6.2- Propriedades do Corpo Cogumelar na aprendizagem de odores baseados em séries realísticas.

Fonte: Elaborada pelo autor.

em termos de Aprendizado de Máquina), e portanto devem ser otimizados (usando validação cruzada $\left.^{(127,128)}\right)$ para cada problema.

Com este modelo e usando como entrada séries temporais capturadas em um túnel de vento, ${ }^{(123,124)}$ esta rede é capaz de discernir entre dois odores (veja a figura 6.2). Mais especificamente, na figura 6.2a está um resultado clássico em Aprendizagem de Máquina, especialmente relacionado com Redes Neurais Artificiais: quanto maior a rede, melhor a performance desta rede. ${ }^{(129)}$ Comumente, existe uma performance máxima, geralmente indicada por uma saturação (como na figura 6.2a a partir de $10000 \mathrm{KCs}$ ). Este comportamento esterotipado revela que em geral redes grandes têm uma maior capacidade de classificação e guardar memória. Vale comentar que este modelo super simples já demonstra uma resiliência altíssima contra danificações nas KCs: apenas a partir de $90 \%$ das KCs danificadas observamos na figura 6.2a uma queda significativa na performance.

\subsubsection{Ligação com Máquinas de Vetor Suporte}

O modelo anterior é uma rede neural bastante simples, não muito mais complexa que o famoso Perceptron. E muitos das características inseridas neste modelo, assim como das citadas na seção 6.1, refletem a aplicação de certas estratégias que parecem inerentes à biologia dos CGs. Estas estratégias também são empregadas em Máquinas de Vetor Suporte (SVMs), ${ }^{(130)}$ 
modelo considerado estado da arte em termos de Aprendizagem de Máquina. ${ }^{(131)}$

O fato interessante a ser marcado é a semelhança entre SVMs e os CGs. ${ }^{104,132)}$ Note que todas estas estratégias aplicadas em Aprendizagem de Máquina, que vêm sendo desenvolvidas nos últimos 50 anos, estiveram sempre presentes nos CGs e têm sido a base da sobrevivência de diversas espécies, tal como em abelhas.

\subsection{Modelo com dinâmica temporal}

Começo nesta seção a discutir como serão modelados os CGs usando modelos dinâmicos (em contraste com modelos estáticos como usado na seção 6.1.1). Como não utilizei nenhum modelo exótico de dinâmica neural, farei uma breve exposição do que não constituir grande novidade com respeito à literatura atual, para discutir em detalhes minhas contribuições.

\subsubsection{Modelo Integra-e-Dispara}

Começo com um modelo neural básico capaz de reproduzir diversas características da dinâmica neural sem exigir grande esforço computacional. Seja $V(t)$ o potencial de membrana, i.e., o potencial intracelular com respeito ao potencial no infinito (meio extracelular). Os disparos são rápidos aumentos em $V(t)$, que duram em torno de $1 \mathrm{~ms}$.

A evolução temporal do potencial de membrana será

$$
\tau_{m} \frac{d V}{d t}(t)=-V(t)+V_{0}+R I(t)
$$

em que $\tau_{m}$ é um período característico do potencial, $R$ a resistência da membrana e $I(t)$ uma corrente externa ao neurônio. A equação 6.2.1 simplesmente descreve o relaxamento do potencial de membrana, a partir de qualquer valor $V$, até $V_{0}$, definido como potencial de repouso. Em geral, $V_{0} \sim-60 \mathrm{mV}$. Costuma-se escolher $\tau$ de acordo com a escala de tempo do neurônio sendo descrito.

Supondo por exemplo $I(t)=I_{0}$, a solução da equação 6.2 .1 fica

$$
V(t)=\left(V(0)+R I_{0}\right)\left[1-e^{t / t_{m}}\right]+V(0) e^{t / t_{m}}
$$




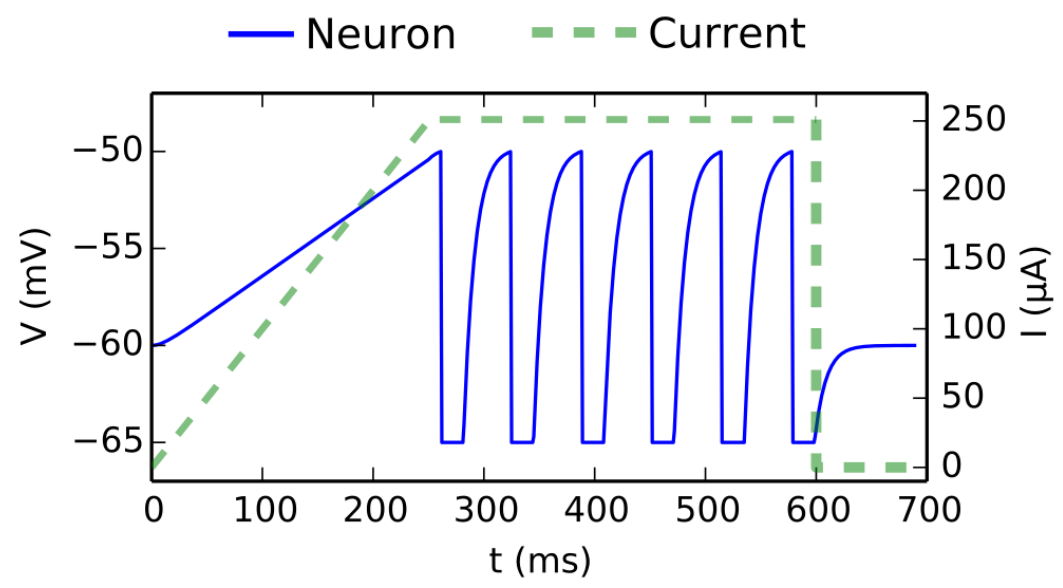

Figura 6.3- Exemplo de uma simulação usando um neurônio Integra-e-Dispara com Vazamento (LIF, de Leaky Integrate-and-Figre). A curva em verde mostra a corrente em função do tempo e a curva azul, o potencial de membrana. Sempre que o neurônio atinge $-50 \mathrm{mV}$, o programa assume que houve um disparo e retorna para $V_{r}=-65 \mathrm{mV}$. Após um período refratário $t_{r e f}=20 \mathrm{~ms}$, o neurônio volta a evoluir no tempo. Nesta simulação, uso $t_{r e f}$ propositalmente longo para torná-lo mais visível na figura, em geral este parâmetro varia de 1 a $10 \mathrm{~ms}$. Note que apenas a partir de um certo valor de corrente, o neurônio passa a disparar. Também mostro o relaxamento que ocorre quando na ausência de corrente (últimos $100 \mathrm{~ms}$ de simulação). Compare com o resultado de um modelo mais realístico na figura $1.1 \mathrm{~b}$.

Fonte: Elaborada pelo autor.

Com $t \rightarrow \infty, V(t)$ tende a $V_{0}+R I_{0}$. Note que o termo $-V(t)+V_{0}$ denota então um "vazamento" de corrente da célula.

Para gerar spikes, define-se um limiar $V_{t h}$ a partir do qual consideraremos que o neurônio disparou. Assim, junto com a equação 6.2.1 unimos a condição

$$
\text { se } V(t)>V_{t h} \text {, então } V(t+d t)=V_{r} \text {. }
$$

Neste caso, $V_{r}$ é o potencial que o neurônio terá logo após disparar o spike. Em geral, $V_{r}<V_{0}$. Neste caso, podemos ver que não é qualquer corrente $I_{0}$ que será capaz de gerar spikes num neurônio, e disso decorre a condição $I_{0}>I_{\text {th }}$ para que ocorra spikes, em que

$$
I_{t h}=\frac{V_{t h}-V_{0}}{R}
$$

Veja que não há geração do potencial de ação, especialmente porque o modelo consiste 
simplesmente de uma equação diferencial linear com uma condição de limiar. Comparado a outros modelos, como na simulação da figura 1.1 b, essas características representam uma substancial diminuição na complexidade do modelo. Em geral, implementações mais avançadas envolvem a utilização de soluções semianalíticas baseadas em equações como 6.2.2. Portanto, em situações em que a forma do potencial não é o fator mais importante, este modelo pode ser uma excelente opção. Tendo isto em mente, para as análises a seguir usarei os tempos em que o neurônio dispara, i.e., os momentos em que a equação 6.2 .3 ocorre.

Como neste modelo o neurônio integra a corrente e relaxa na ausência de corrente, este modelo é costumeiramente conhecido como Integra-e-Dispara com vazamento (LIF). A figura 6.3 exemplifica as características principais dos LIFs. O próximo passo é conectar diversos LIFs e criar uma população neural. Trato deste assunto na seção 6.3.

\subsubsection{Modelos baseados em condutâncias variáveis}

No capítulo 2 adiantei que todo o balanço eletroquímico intracelular é controlado por canais iônicos. ${ }^{(13)}$ Estas estruturas são essenciais para a compreensão completa do funcionamento da dinâmica neural. A forma mais comum de modelar estas estruturas é por meio de correntes iônicas. Cada uma destas correntes, associadas a íons diferentes (e.g., Na, K, Ca, etc), é caracterizada por um termo do tipo $g[V-E]$, em que $g$ define a condutância do canal iônico e $E$, o potencial de reversão do íon. ${ }^{(4,133)}$ Nos casos de maior interesse, $g$ é função de $V$, o que gera efeitos não lineares ao sistema.

No modelo LIF, no entanto, só existe uma única corrente: a de vazamento, termo proporcional a $-V(t)+V_{0}$. No entanto, note que a condutância não depende do próprio potencial neste caso. Em geral, ao menos dois outros canais devem ser adicionados e a condutância precisa depender do potencial para que a geração do potencial de ação não precise ser imposta a mão (como feito pela condição 6.2.3). Na figura 1.1b, por exemplo, foram usados correntes de K, Na e de vazamento. Por este motivo, costuma-se chamar estes modelos mais complexos de Modelos Baseados em Condutância (ou Conductance Based Models).

A implementação desenvolvida para este trabalho contempla modelos baseados em condutância, e todos os resultados mostrados não se alteram. Como, no entanto, estes modelos 
inserem muitos outros parâmetros, discuti-los em detalhe nesta tese impactaria na coesão do texto que segue, e por isso omitirei detalhes sobre estes modelos mais realísticos. No entanto, posso adiantar que não é preciso um ajuste fino de parâmetros para reproduzir os resultados descritos no capítulo 7.

\subsection{Modelo de conectividade}

Uma vez que o modelo de neurônio está definido, usa-se a corrente $I(t)$ para conectar os neurônios. Para simular uma população de $N$ neurônios, será necessário acompanhar a evolução tempora do potencial de membrana $V_{j}(t)$ de cada neurônio $j$, seguindo equações análogas à 6.2.1:

$$
\tau_{m} \frac{d V_{j}}{d t}(t)=-V_{j}(t)+V_{j 0}+R I_{j}(t)
$$

Apesar de não estarem explícitos, $\tau_{m}$ e $R$ podem também depender de $j$ (veja mais a seguir). A cada par $j, k$ de neurônios conectados associamos ao peso sináptico $\mathcal{W}_{j, k}$, e a contribuição do potencial de $k$ para $j$ entra como

$$
I_{j}(t)=I_{\text {ext }}+\sum_{k=0}^{N} \mathcal{W}_{j, k} f_{k}(t)
$$

em que $f_{k}$ é uma função não linear resposta. ${ }^{(4)}$ Chama-se a matriz $\mathcal{W}$ de Matriz de Adjacências (veja a seção 3.2).

Como o principal foco deste presente trabalho é estudar quão rápido ENs conseguem responder a um estímulo dos PNs, é necessário considerar o tempo $\Delta$ em que o spike viaja entre os neurônios pre- e posssináptico. Este tempo gera um atraso nas equações. Para qualquer hipótese que for levantada para explicar a aceleração dos ENs, será necessário garantir que ela se mantém mesmo válida para $\Delta \neq 0$, assumindo valores que façam juz às distâncias das populações consideradas. Apresento estimativas baseadas em morfologia na seção 6.3.2.

Supondo que dado que o neurônio $k$ disparou no tempo $\tau$, utilizei dois tipos de funções resposta: (i) delta, em que

$$
f_{j}(t)=\delta_{j}[t-(\tau+\Delta))
$$


e (ii) função $\alpha$, em que

$$
f_{j}(t)=\frac{t-(\tau+\Delta)}{\tau_{s}} e^{\frac{t-(\tau+\Delta)}{\tau_{s}}}
$$

$\operatorname{com} \tau_{s}$ sendo um parâmetro a ser ajustado. Usar a função $\alpha$ torna a simulação mais realista. ${ }^{(4,13)}$

\subsubsection{Conectividade no Corpo Cogumelar}

Em populações grandes, como nos casos tratados nos capítulos 2-4, conectam-se os neurônios usando grafos aleatórios. Neste capítulo, farei uso de grafos ainda mais simples que os tratados anteriormente, para definir conectividade entre as populações do CG. Veja a seção 3.2 para mais detalhes.

Considere as seguintes quatro populações: $P N s, K C s, E N s$ e $P C T s$. Entre dois grupos de neurônios $X$ e $Y$, definimos a probabilidade $p(\mathrm{X} \mapsto \mathrm{Y})$ de que um neurônio escolhido uniformemente de $X$ conecte-se com outro escolhido uniformemente de $Y$. Naturalmente, da figura 6.1 temos

$$
\begin{aligned}
p(\mathrm{EN} \mapsto \mathrm{PCT})=p(\mathrm{PCT} & \mapsto \mathrm{EN})=p(\mathrm{PN} \mapsto \mathrm{EN})=p(\mathrm{EN} \mapsto \mathrm{PN}) \\
& =p(\mathrm{PCT} \mapsto \mathrm{PN})=p(\mathrm{KC} \mapsto \mathrm{PN})=p(\mathrm{EN} \mapsto \mathrm{KC})=0 .
\end{aligned}
$$

Também seguindo indicações experimentais, $p(\mathrm{X} \mapsto \mathrm{X})=0$ a menos que $X=E N$. Neste caso, $p(\mathrm{EN} \mapsto \mathrm{EN})$ representa a inibição lateral que ocorre na camada dos ENs (veja ao final da seção 5.2). Todas as outras probabilidades são não nulas e serão determinadas ajustando de acordo com os dados experimentais que tenho em mãos (veja seção 6.4). Note, por fim, que não há conectividade recorrente dentro da camada dos KCs.

Por simplicidade, para cada par de populações $X$ e $Y$ associo também um único peso sináptico $\mathcal{W}(\mathrm{X} \mapsto \mathrm{Y})$. Assim, dados neurônios $j$ da população $X$ e $k$ da $Y$ conectados, então $\mathcal{W}_{j, k}=\mathcal{W}(\mathrm{X} \mapsto \mathrm{Y})$. Apesar de esta simplificação não seguir qualquer fundamento biológico, é muito comum para diminuir a complexidade do modelo a ser estudado. Em passos futuros, os pesos sinápticos podem ser extraídos aleatoriamente de uma distribuição com média $\mathcal{W}(\mathrm{X} \mapsto \mathrm{Y})$ e certa variância. Em alguns casos, é conhecido que considerações 
do tipo podem gerar resultados levemente diferentes. O valor absoluto depende fortemente das constantes do modelo, e serão também determinados usando um algoritmo para ajustar o resultado das simulações com os dados experimentais.

\subsubsection{Estimando o atraso sináptico}

É possível estimar um intervalo razoável para os atrasos sinápticos baseando-se nas distâncias entre as diferentes populações. Imagens de microscopia eletrônica (veja figura 5.2) podem ser usadas para esta finalidade. O atraso sináptico também depende da população específica. Por isso, denoto por $\Delta(\mathrm{X} \mapsto \mathrm{Y})$ o atraso para um spike viajando da população $\mathrm{X}$ à $\mathrm{Y}$. Como base para nossos cálculos, considero que spikes viajam de 10 a $30 \mathrm{~m} / \mathrm{s}$ (um intervalo bastante conservador), especialmente lembrando que insetos não apresentam mielina. ${ }^{(134)}$

Na tabela 6.1, listo os intervalos de valores que utilizei para cada um dos atrasos sinápticos. Por exemplo, das imagens PNs e KCs estão afastados diversas centenas de micrômetros, então $\Delta(\mathrm{PN} \mapsto \mathrm{KC}) \sim 2-6 \mathrm{~ms}$. Além disso, como estou usando apenas a distância entre as populações para estimar os atrasos sináptios, o intervalo de valores para $\Delta(\mathrm{X} \mapsto \mathrm{Y})$ deve ser o mesmo para $\Delta(\mathrm{Y} \mapsto \mathrm{X})$. Isso não significa, por exemplo, que eu tenha fixado $\Delta(\mathrm{KC} \mapsto \mathrm{PCT})=\Delta(\mathrm{PCT} \mapsto \mathrm{KC})$, apenas que o intervalo é o mesmo.

É importante notar que o objetivo não é ter uma estimativa de $\Delta(\mathrm{X} \mapsto \mathrm{Y})$, mas um intervalo de valores que façam sentido de acordo com as figuras de microscopia eletrônica. Caso as predições do modelo se apresentem robustas dentro deste intervalo, temos um bom indicativo de que nossas hipóteses estão corretas.

Durante o processo de otimização, descrito na seção $6.4, \Delta(\mathrm{X} \mapsto \mathrm{Y})$ podem variar dentro

Tabela 6.1- Tabela com os intervalos de valores utilizados para os atrasos sinápticos de cada populção. Veja o texto para detalhes sobre considerções feitas para estas estimativas.

\begin{tabular}{lc}
\hline Parâmetro & Valores (ms) \\
\hline$\Delta(\mathrm{PN} \mapsto \mathrm{KC})$ & $2-6$ \\
$\Delta(\mathrm{KC} \mapsto \mathrm{EN})$ & $0.5-3$ \\
$\Delta(\mathrm{PCT} \mapsto \mathrm{KC})$ & $0.5-3$ \\
$\Delta(\mathrm{KC} \mapsto \mathrm{PCT})$ & $0.5-3$ \\
$\Delta(\mathrm{PN} \mapsto \mathrm{PCT})$ & $1-4$
\end{tabular}

Fonte: Elaborada pelo autor. 
dos intervalos definidos acima para melhor ajustar o modelo com os registros experimentais. No entanto, como testes de robustês, verifiquei se a maioria dos resultados continuam válidos mesmo se atrasos diferentes são utilizados, respeitando sempre os intervalos estimados.

\subsection{Ajuste de parâmetros}

O modelo até o momento apresenta um número grande de parâmetros que podem ser ajustados livremente. Na seção 5.4 explico os experimentos de Martin Strube-Bloss e colaboradores, e a explicação do fenômeno observado nestes dados é o objetivo final deste estudo: qual o mecanismo por detrás da aceleração no código neural dos ENs em respeito aos PNs.

Estes dados compreendem gravações de PNs e ENs sob estimulação olfativa. Para averiguar como os ENs vão responder a um dado sinal dos PNs, forçarei os PNs em minhas simulações a seguirem exatamente a mesma atividade registrada nos experimentos. Com isso, a resposta dos ENs é então simulada e pode ser comparada ao registro experimental. Portanto, para ajustar os parâmetros da simulação usarei uma comparação entre a atividade simulada dos ENs contra a atividade registrada nos experimentos.

O objetivo do algoritmo de ajuste dos parâmetros é buscar pela melhor solução que descreva os registros experimentais. Para tal, são necessários dois elementos: uma função perda e um método de busca. A seguir considero este problema de duas formas diferentes: a primeira usando um algoritmo guloso, para demonstrar que estarei trabalhando em um certo regime de sobreajuste (overfitting), e a segunda usando um algoritmo completamente novo e extremamente eficiente computacionalmente.

\subsubsection{Ajuste guloso}

Algoritmos de busca de mínimos baseados em exaustivas avaliações num certo domínio são costumeiramente chamados de algoritmos gulosos. A vantagem destes algoritmos é que deles podemos ter uma ideia de como a função perda se comporta no domínio de interesse. No entanto, esses algoritmos são computacionalmente caros e não usam qualquer heurística para se dirigirem ao ponto mínimo. 


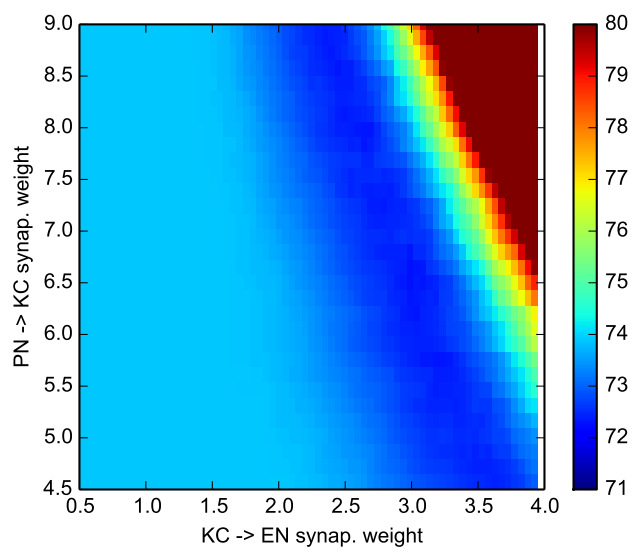

Figura 6.4- Sobreajuste gerado pela ignorância na camada das $\mathrm{KCs}$, evidenciado pela região circular em azul escuro. Todos os conjuntos de parâmetros nesta região são candidatos em pé de igualdade, no que se refere à função perda definida para este algoritmo. Este resultado demorou em torno de um dia para ser calculado por completo.

Fonte: Elaborada pelo autor.

Com este algoritmo usarei uma função perda clássica: diferença de quadrados. Suponha que $F_{o}(t)$ seja a atividade dos ENs registrada nos experimentos, enquanto $F_{s}(t)$ é a atividade resultante da simulação para um certo conjunto de parâmetros. Então, considere a função

$$
E=\int_{t_{0}}^{t_{f}} \frac{d t}{2}\left[F_{o}(t)-F_{s}(t)\right]^{2},
$$

com $t_{0}=-1 \mathrm{~s}$ e $t_{f}=4 \mathrm{~s}$. Esta função perda é tão menor quanto "menos" diferente $F_{s}(t)$ for de $F_{o}(t)$. Esta função costuma ser a primeira a ser testada nas mais variadas aplicações. ${ }^{(135)}$

Realizando uma busca exaustiva por meus parâmetros e avaliando a função perda em cada ponto, obtive a figura 6.4. Nela é possível observar um forte sobreajuste (ou overfitting). Isso é natural, dado que não tenho qualquer informação da atividade das KCs e dos PCTs, o que significa que diversas soluções, muitas vezes que não representam apropriadamente a atividade dos KCs e PCTs, podem apresentarem-se como soluções candidatas.

Infelizmente, não há como resolver por completo este problema. Mas existem técnicas que podem ajudar a amenizar o efeito desta falta de informação.

Por exemplo: discutimos no capítulo 5 evidências que apontam a importância do código esparso nas KCs. Isso significa que soluções com altíssimos pesos sinápticos devem ser descar- 
tadas. Além disso, também sabemos que na camada dos ENs existe uma forte inibição lateral, representada em nosso modelo pelo peso sináptico $\mathcal{W}(E N \mapsto E N)$, que deve ser bastante negativo (i.e., forte inibição).

\subsubsection{Metodologia Fuzzy}

Como existêm fontes de ruído internos ao modelo, ajustar os parâmetros de forma ingênua pode levar a outros tipos de sobreajuste: ajustar ruído. Por isso usarei uma abordagem fuzzy, que em vez de, para cada conjunto de parâmetros, a atividade da rede ser uma curva no tempo, a atividade será representada como um intervalo. Este tipo de abordagem modifica um pouco a forma como médias e variâncias são encaradas, e por isso nesta seção tomarei o cuidado de definir com um pouco mais de cuidado esses conceitos. Na figura 6.6b mostro um resultado de simulação em que essa abordagem fuzzy é utilizada.

Sempre que for necessário avaliar como o modelo está se comportando, $N_{r}$ cópias do modelo são criadas, com as mesmas condições iniciais, e a evolução da atividade neural $F_{j}(t)$ de cada cópia $j$ é considerada conjuntamente. Para cada intervalo $[t, t+\Delta t)$, a probabilidade de que a atividade resultante do modelo esteja numa região centrada em $F_{j}(t)$ (de tamanho $\Delta F)$, será $1 / N_{r} \times n$, com $n$ sendo o número de casos $k$ em que $F_{k}(t)=F_{j}(t)$. Em outras palavras, com esta abordagem estamos levantando não apenas a atividade média, mas toda a distribuição que esta atividade pode ter.

Para exemplificar esta abordagem, na figura 6.5 mostro uma simulação com $N_{r}=100$. As curvas pretas indicam, para cada instante de tempo $t$, quais os máximo e mínimo valores atingidos por quaisquer das $N_{r}$ cópias. Elas indicam, portanto, um intervalo em que a atividade dos ENs, dado um conjunto de parâmetros, deve se encontrar. Chamarei de envelope as curvas máxima e mínima de um dado modelo. Além disso, a curva azul mais escura, central, indica a média dentre todas as atividades observadas. No que segue, usarei os envelopes e a média para estudar a atividade neural na camada EN. Para meus experimentos numéricos, fixei $N_{r}$ entre 20 e 50 .

Para detalhes em modelagem fuzzy e manuseio de variáveis fuzzy, existe uma enorme literatura disponível. ${ }^{(136,137)}$ No entanto, o texto será autocontido neste âmbito, e por isso 


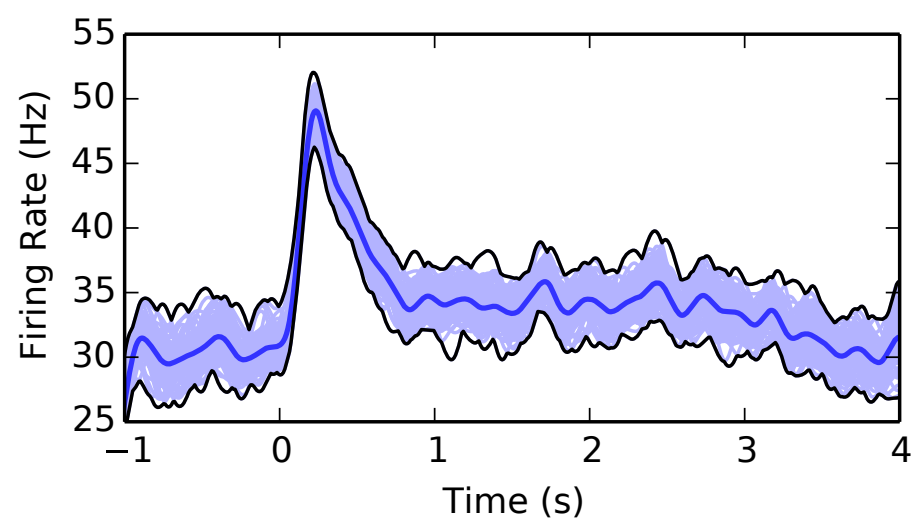

Figura 6.5- Simulação com exemplo da abordagem fuzzy. Neste caso, foram realizadas $N_{r}=$ 100 cópias do modelo, que foram simuladas de forma independente. Curvas azuis são as atividades individuais de cada cópia, enquanto as curvas pretas indicam, para cada tempo $t$, os maior e menor valores da atividade dos ENs dentre todas as cópias. Por fim, a curva azul escura (central) é a média da atividade dentre todas as $N_{r}$ observações. Note que as curvas azuis ocupam praticamente todo o espaço entre as curvas pretas.

Fonte: Elaborada pelo autor.

não é esperado do leitor nenhuma leitura complementar.

\subsubsection{Função perda}

A seguir proponho uma função perda (ou função objetivo na literatura de otimização) para usar em um algoritmo de busca mais eficiente (veja seção 6.4.4). Primeiramente, a função perda utilizada anteriormente (equação 6.4.1) apresenta alguns problemas, e o principal está em considerar, com mesmo peso, a comparação de todos os pontos das curvas sendo comparadas. Como existe ruído intrínseco do sinal registrado experimentalmente, não é bem verdade que gostaríamos de tornar a atividade que é descrita pelo modelo igual ao que foi registrado experimentalmente. Caso contrário, estaremos reproduzindo ruído, não o código neural de fato. Esta é a definição clara de sobreajuste. A função que proponho a seguir remove este tipo de sobreajuste completamente, pagando um preço: é consideravelmente mais complexa que o erro quadrático usado anteriormente. Adianto, no entanto, que isso não impactará tanto em termos de tempo computacional no final das contas.

Fundamentalmente, a nova função será uma média ponderada entre alguns fatores específicos. Apesar de estes fatores aplicarem-se apenas no presente caso, este método pode ser facilmente generalizado para outros contextos. No entanto, esta generalização foge ao escopo 
do presente trabalho. As características que considerei são:

- a atividade basal antes da estimulação olfativa iniciar;

- o tempo em que o máximo de atividade ocorre;

- o valor do máximo;

- e o formato da atividade ao longo dos dois primeiros segundos após o início da estimulação.

Estas quatro características representam o que há de fundamental nos registros experimentais e provavelmente as características que carregam maior quantidade de informação.

Note que, especialmente no contexto atual, em que o interesse é no mecanismo com que os ENs conseguem responder rapidamente a estímulos olfativos, os segundo e terceiro itens são especialmente desejáveis. Portanto, esta função perda fará com que estas propriedades sejam absorvidas pelo modelo da melhor forma possível.

Portanto, a função perda que proponho baseia-se na comparação destas características. Na figura 6.6a, cada um dos termos acima descritos estão representados graficamente. Usando os mesmos símbolos que na figura,

$$
\mathcal{E}=\alpha \Delta_{\bar{F}}+\beta \Delta_{t^{*}}+\gamma \Delta_{F^{*}}+\eta \Delta_{<F>}+\zeta E,
$$

em que $E$ vem da equação 6.4.1. Os pesos $\alpha, \beta, \gamma, \eta$ e $\zeta$ são escolhidos de forma a balancear cada um dos termos, que podem ter ordens de grandeza muito diferentes. Bons valores estão listados na tabela 6.2. Em ordem, os termos representam: diferença entre os níveis basais,

$$
\Delta_{\bar{F}}=\left(\int_{-1}^{0} d t\left\{F_{o}(t)-F_{s}(t)\right\}\right)^{2}
$$

a diferença entre os tempos em que ocorrem o máximo,

$$
\Delta_{t^{*}}=\left[\underset{t}{\operatorname{argmax}}\left\{F_{o}(t)\right\}-\underset{t}{\operatorname{argmax}}\left\{F_{s}(t)\right\}\right]^{2} ;
$$


a diferença entre os máximos de atividade,

$$
\Delta_{F^{*}}=\left[\max _{t}\left\{F_{o}(t)\right\}-\max _{t}\left\{F_{s}(t)\right\}\right]^{2} ;
$$

e a diferença entre a forma da atividade durante os primeiros $2 \mathrm{~s}$ de estimulação,

$$
\Delta_{<F>}=\int_{0}^{2} \frac{d t}{2}\left[F_{o}(t)-F_{s}(t)\right]^{2}
$$

Analisando a equação 6.4.2 fica claro que $\mathcal{E}$ baseia-se em três integrais e duas minimizações. Vale comentar, no entanto, que algumas estratégias podem ser implementadas para otimizar ao máximo o custo computacional desta função perda. Lembre que em geral algoritmos de busca necessitam avaliar a função perda diversas vezes, e por isso qualquer ganho em termos de tempo de computação pode ser vital ao final.

Uma das estratégias baseia-se em reduzir $\Delta_{t^{*}}$ e $\Delta_{F^{*}}$ a um único processo de otimização, uma vez que encontrar o valor da maior atividade inerentemente significa encontrar o ponto em que este valor ocorre. Uma segunda estratégia é calcular $\Delta_{<F>}$ e depois calcular $E$ como

$$
E=\Delta_{<F>}+\int_{-1}^{0} \frac{d t}{2}\left[F_{o}(t)-F_{s}(t)\right]^{2}+\int_{2}^{4} \frac{d t}{2}\left[F_{o}(t)-F_{s}(t)\right]^{2}
$$

É fácil verificar a igualdade (basta somar as integrais).

Tabela 6.2- Tabela com os valores utilizados para os pesos de cada uma das contribuições na função perda. Pequenas variações não causam qualquer efeito perceptível no algoritmo. O fator mais crítico é manter $\zeta$ ao menos uma ordem de grandeza menor que os outros parâmetros.

Fonte: Elaborada pelo autor.

\begin{tabular}{cc}
\hline Parâmetro & Valores \\
\hline$\alpha$ & 2.0 \\
$\beta$ & 1.0 \\
$\gamma$ & 1.0 \\
$\eta$ & $10^{-2}$ \\
$\zeta$ & $10^{-3}$ \\
\hline
\end{tabular}


(a)

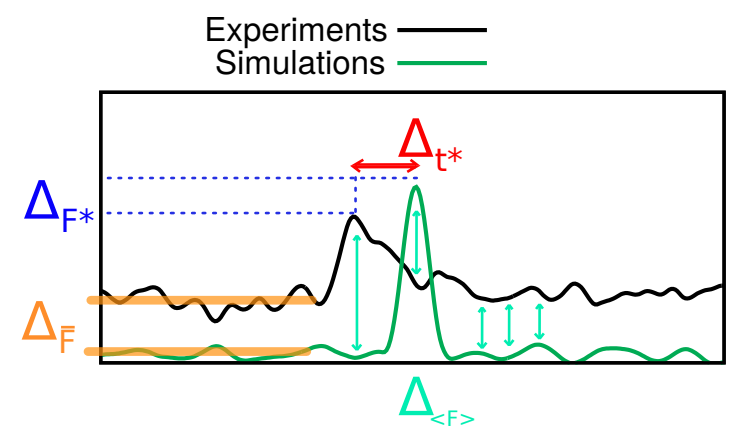

(b)

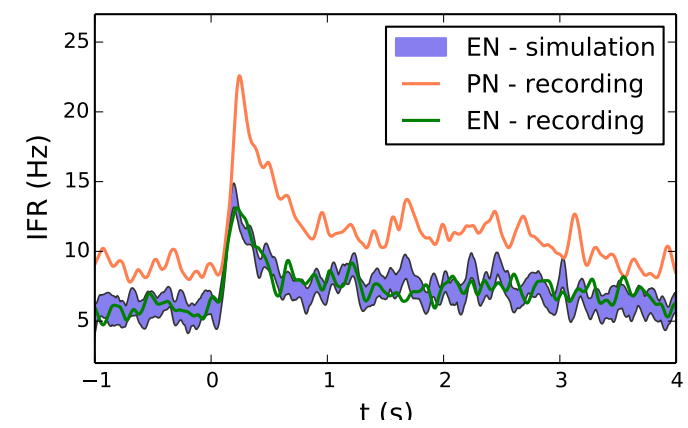

Figura 6.6- Ajuste dos parâmetros livres usando o algoritmo baseado em uma Cadeia de Markov Monte Carlo. Em comparação ao sum dia inteiro de computação do algoritmo guloso, este método leva cerca de uma hora para obter resultados similares ou melhores. (a): definição gráfica de cada contribuição da função perda $\mathcal{E}$ (veja equação 6.4.2 e o texto para detalhes). (b): Exemplo de resultado do ajuste de parâmetros contra um dos possíveis experimentos. Vale comentar que a presença dos PCTs pode gerar uma diminuição próxima de $30 \%$ no valor final de $\mathcal{E}$.

Fonte: Elaborada pelo autor.

\subsubsection{Cadeias de Markov Monte Carlo}

Para buscar por mínimos da função perda $\mathcal{E}$ usarei uma abordagem baseada em Cadeias de Markov Monte Carlo, ${ }^{(138)}$ muito similar a algoritmos como o de Metrópolis ou Simulated Annealing.

Como uma revisão relâmpago, cadeias de Markov são processos estocásticos em tempo discreto, cujo estado $X(t)$ num dado tempo $t$ depende apenas do estado no tempo anterior $t-1^{(70)}$ Isto é,

$$
\mathbb{P}[X(t) \mid X(t-1), X(t-\tau)]=\mathbb{P}[X(t) \mid X(t-1)]
$$

qualquer que seja $\tau>0$. Cadeias de Markov são comumente utilizadas para modelar diversos tipos de sistemas. Embora não tenha comentado explicitamente, no capítulo 3 são utilizadas cadeias de Markov (o próprio modelo neural formal com que trabalhamos naquele capítulo é uma cadeia de Markov).

Cadeias de Markov Monte Carlo são uma classe especial de cadeias: elas são construídas de forma que sua distribuição de equilíbrio obedeça uma certa distribuição dada. ${ }^{(139)}$ Por exemplo, certas distribuições são consideravelmente complexas para podermos calcular médias e/ou quaisquer outras características. A distribuição de Gibbs frequentemente cai nesta categoria 


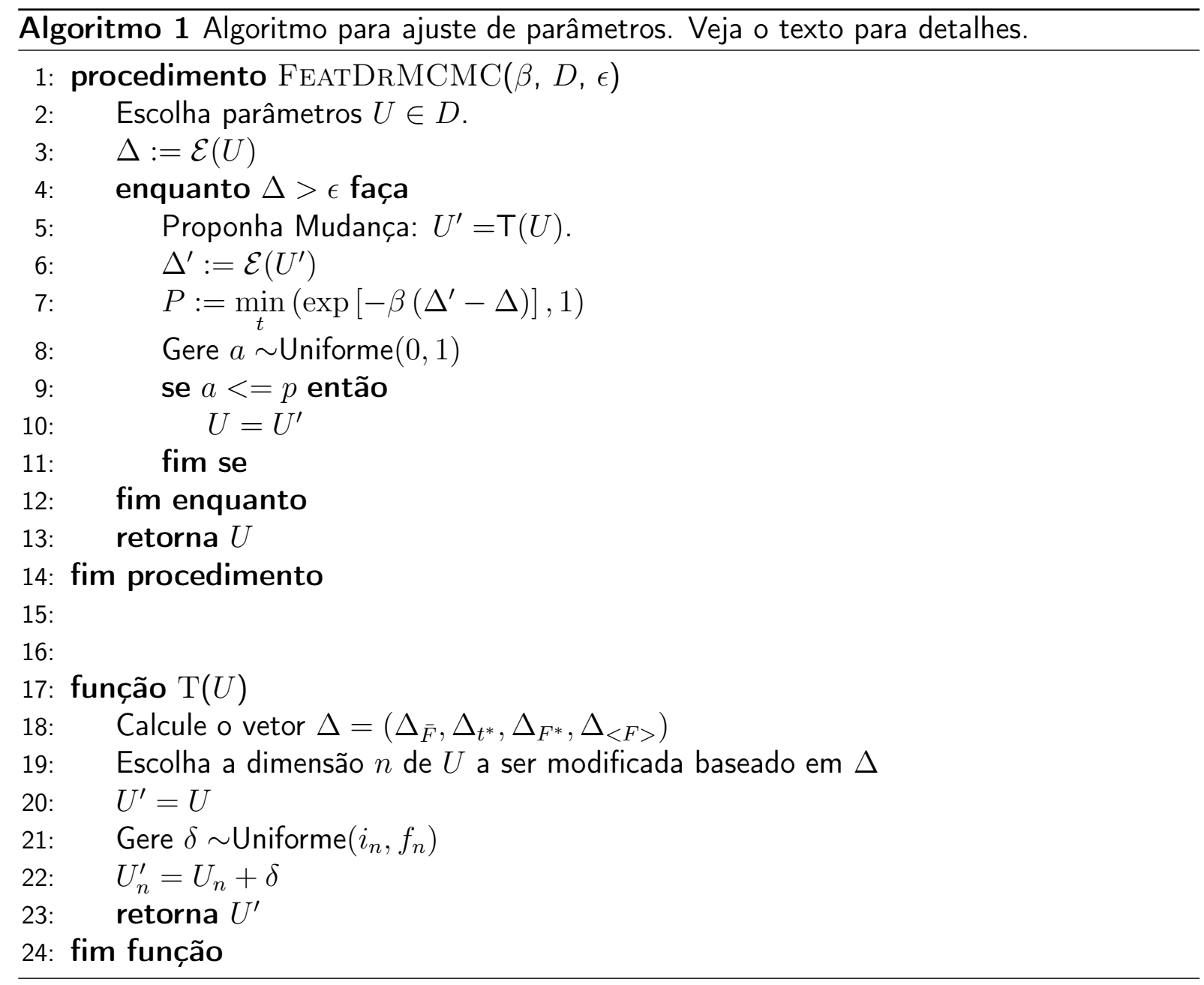

em física estatśtica. ${ }^{(36)}$ Neste cenário, é mais fácil criar uma cadeia de Markov que no equilíbrio comporta-se exatamente como tal distribuição e calcular o que se deseja calcular usando estatísticas sobre realizações da cadeia. Atualmente, cadeias de Markov são a base para diversos processos estatísticos e de otimização.

Uma destas aplicações é exatamente obter mínimos de funções. A seguir, defino um exemplo de cadeia de Markov que utilizei para minimizar $\mathcal{E}$. Este algoritmo segue a ideia do Simulated Annealing, no entanto seguindo os termos de $\mathcal{E}$ como mostrado no algoritmo 1 .

O algoritmo principal, FeatDrMCMC, recebe três argumentos: $\beta$ representa o nível de ruído da cadeia (ruído térmico ${ }^{(139)}$ ), $D$ define o domínio sobre o qual os parâmetros serão considerados e $\epsilon$ o valor que se espera obter para $\mathcal{E}$. $D$ tem tantas dimensões quanto o número de parâmetros a variar. Na maioria das minhas simulações, são todos os pesos sinápticos, atrasos e probabilidades de conexão. Uma configuração possível do modelo é então representada pelo vetor $U \in D$. 
A ideia por detrás de FeatDrMCMC é passear pelo espaço de estados $D$ guiado pela função perda $\mathcal{E}$. No entanto, para que os passos não sejam simplesmente cegos, defini a função $\mathrm{T}(U)$, que basicamente usa $\Delta_{\bar{F}}, \Delta_{t^{*}}, \Delta_{F^{*}}$ e $\Delta_{<F>}$ para decidir qual parâmetro exatamente utilizar. Uma vez então decidido qual parâmetro será alterado, digamos, associado à dimensão $n$, simplesmente uso $\delta$ distribuiído como uma uniforme entre $\left(i_{n}, f_{n}\right)$ como uma pequena alteração. Note que o intervalo da distribuição uniforme deve ser escolhido de acordo com cada dimensão. Na tabela 6.3 listo todos os $i_{n}$ e $f_{n}$ utilizados.

Por fim, veja na figura 6.6b um exemplo de atividade depois de ajustar o modelo com o algoritmo baseado em Cadeias de Markov Monte Carlo. O algoritmo converge com $\mathcal{E} \approx 10$ em aproximadamente uma hora (redução drástica comparada ao algoritmo guloso). Também é interessante notar que com os PCTs são retirados, um aumento de $30 \%$ é notado no $\mathcal{E}$ mínimo.

Tabela 6.3- Tabela com os intervalos utilizados para atualizar cada uma das categorias de parâmetros usados no modelo.

\begin{tabular}{lll}
\hline Parâmetro & $i_{n}$ & $f_{n}$ \\
\hline Probabilidade de conexão & -0.05 & 0.05 \\
Peso sináptico & -0.5 & 0.5 \\
Atraso sináptico & -0.3 & 0.3 \\
\hline
\end{tabular}

Fonte: Elaborada pelo autor. 


\section{Capítulo 7}

\section{Resultados: Balanço entre}

\section{performance e agilidade}

Neste capítulo exponho os resultados que o modelo descrito no capítulo anterior traz com respeito à antecipação neural descrita na seção 5.4. Em principal, investigo a influência causada pela estrutura morfológica do Corpo Cogumelar (CG) e o tamanho da camada de células Kenyon (KCs). Ao final, vemos que a atividade dos Neurônios Extrínsecos (ENs) consegue antecipar o código vindo dos Neurônios de Projeção (PNs) por causa do grande número de KCs. No entanto, mostro que há uma briga entre duas tendências: quanto mais KCs, melhor a detecção do tipo de odor, mas menor a agilidade nesta deteção.

\subsection{Reprodução da antecipação dos ENs}

Nesta seção, exponho uma análise estatística sobre este fenômeno de antecipação que os ENs têm sobre os PNs. Para tal, (i) investigarei os dados experimentais de forma mais aprofundada, (ii) verificarei se simulações já ajustadas reproduzem tal efeito e qual a ordem de grandeza da antecipação, e (iii) apresentarei um novo protocolo de estimulação artificial do Corpo Cogumelar (CG).

Usando o modelo descrito no capítulo anterior e o registro dos PNs para dois odores diferentes, é possível medir como os ENs modelo se saem em termos de tempo de reação. Nas figuras 7.1 a e $7.1 \mathrm{~b}$ temos as atividades registrada e simulada de ambas as populações. Para 
(a)

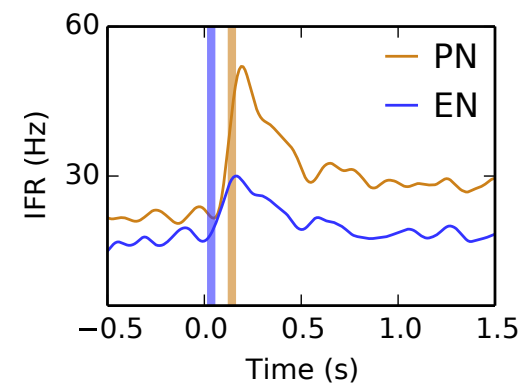

(b)

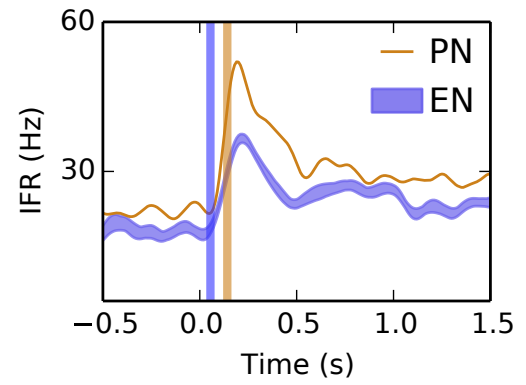

(c)

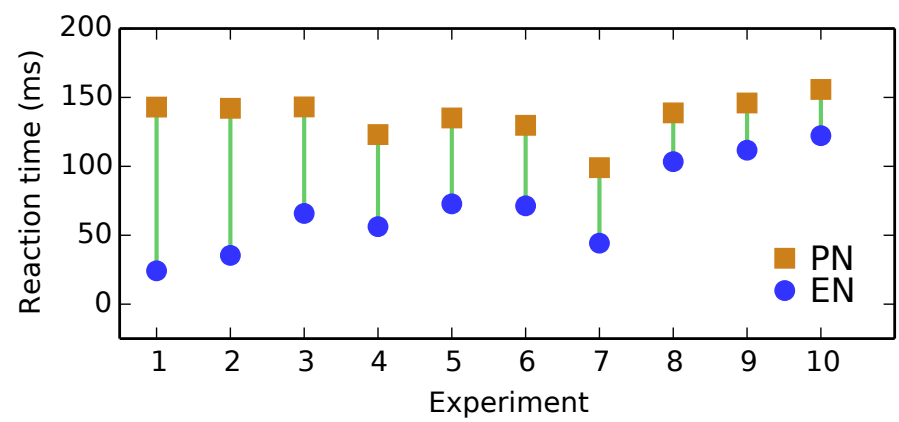

Figura 7.1- Estudo do tempo de respota dos ENs usando o modelo. (a): Registro experimental da atividade dos PNs e ENs. (b): Atividade do modelo com os parâmetros ajustados, em resposta à atividade registrada dos PNs. (c): Tempo de reação dos PNs e ENs: em todos os experimentos ocorre a antecipação. Os resultados mostrados acima são para 1-hexanol. A ordem dos experimentos foi escolhida de forma a ordenar decrescentemente a diferença entre os tempos de reação. A diferença é estatisticamente significativa (segundo teste de Mann-Whitney) com $p$-valor menor que $10^{-2}$.

Fonte: Elaborada pelo autor.

cada experimento com cada um dos odores, medi o tempo de reação dos ENs simulados e comparei com o dos PNs. A figura 7.1a mostra os resultados para um dos odores (1-hexanol): em todos os casos os ENs antecipam os PNs.

Usando o teste estatístico de Mann-Whitney, é garantido com $p$-valor menor que $10^{-2}$ que o tempo de reação dos ENs tende a ser menor que o dos PNs. Em média, há uma diferença de aproximadamente $40 \mathrm{~ms}$, bem próximo do observado experimentalmente por Strube-Bloss e colaboradores.

Apesar de superficialmente os valores baterem, nem sempre o tempo de reação da atividade simulada é exatamente igual ao da registrada experimentalmente. Isso não é um problema, dado que existe um de nível incerteza inerente ao ruído neural nos registros experimentais. Em geral, a ordem de grandeza corresponde bem, e sempre que a diferença nos tempos de reação entre PNs e ENs diminui na simulação, também diminui nos experimentos. Isso significa que 
aquele experimento pode ter características intrínsecas que dificultaram a codificação. Isso é esperado em experimentos baseados em estímulos que não são exatamente controlados: repetições do mesmo odor não representam a mesma estimulação neural nas antenas.

Vale comentar que mudando os parâmetros, é possível obter modelos que respondem ainda mais rápido aos estímulos neurais. No entanto, esses parâmetros falham em reproduzir a atividade registrada experimentalmente. Portanto, estes casos são puramente artificiais e foram simplesmente descartados.

\subsubsection{Estimulação artificial}

Para criar um ambiente mais controlado, a seguir defino um protocolo de estimulação do CG que imita as principais características dos estímulos reais. Por isso o nome de "estimulação artificial". Partindo de um ruído basal (convencionado como $5 \mathrm{~Hz}$ ), os PNs recebem uma estimulação extra em $t=2 \mathrm{~s}$. Este estímulo consiste de um processo de Poisson que se aplica apenas a uma subpopulação dos PNs, simulando que aqueles PNs foram evocados por voláteis específicos que se ligaram aos correspondentes receptores químicos na antena. Esta subpopulação foi fixada como da ordem de $10 \%$ do total de PNs. A partir de $2 \mathrm{~s}$, a taxa do proceso de Poisson varia com o tempo de forma linear, com coeficiente angular $\Delta$. Quando este estímulo atingir $r_{\max }$, a taxa deste processo cessa seu crescimento e se estabiliza neste nível. Esta estimulação induz uma atividade similar nos ENs.

Para evitar viciar os resultados com possíveis ruídos e oscilações espúrias nos sinais de PNs e ENs, para cada par $\Delta$ e $r_{\max }$ foram realizadas 100 repetições (suficiente para que a variância no sinal caisse consideravelmente). Usando as atividades médias, os tempos de resposta (tal como usado nas seções anteriores) são avaliados. Para facilitar a comparação, calculei os tempos de resposta dos ENs com respeito ao dos PNs. Portanto, tempos negativos significam antecipação; positivos, significam atrasos.

A figura 7.2a exemplifica a atividade induzida em PN por este protocolo, variando $\Delta \mathrm{e}$ fixando $r_{\max }=150 \mathrm{~Hz}$. Note que a atividade máxima induzida nos $\mathrm{PNs}$ é de $\sim 23 \mathrm{~Hz}$, algo compatível com valores observados nos experimentos das seções anteriores. A figura $7.2 \mathrm{~b}$ mostra que, para $\Delta=2.0 \mathrm{~Hz} / \mathrm{ms}$, fica clara a antecipação dos ENs, ultrapassando os PNs logo 
(a)

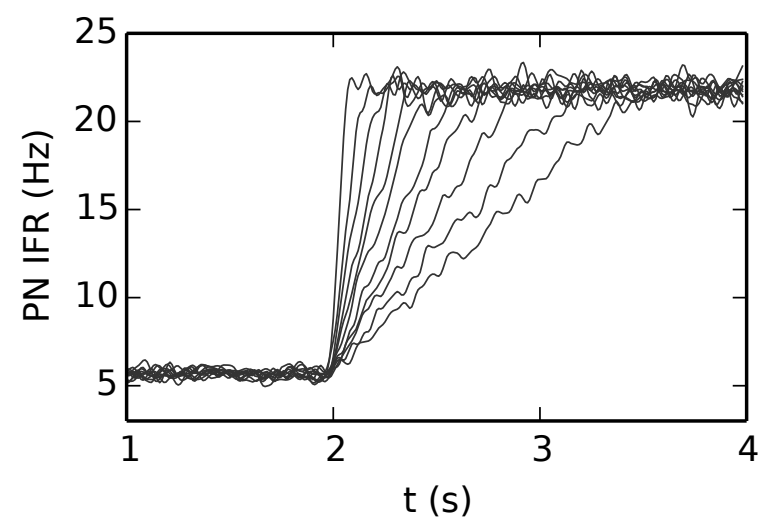

(b)

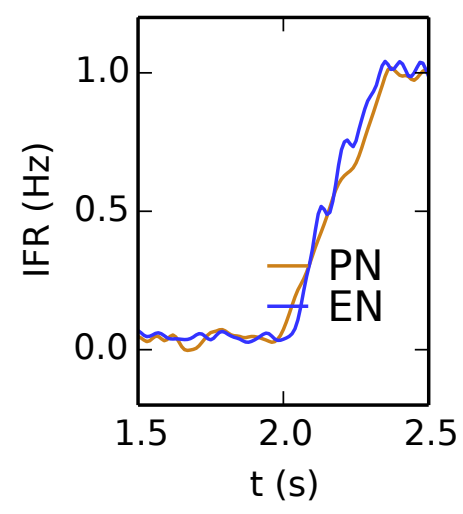

Figura 7.2- Protocolo de estimulação artificial para testar de forma mais controlada a resposta do Corpo Cogumelar (CG). Este protocolo consiste em estímular os Neurônios de Projeção (PNs), iniciando em $t=2 \mathrm{~s}$ e evoluindo linearmente de 0 a $r$ max com derivada (i.e., inclinação) $\Delta$. (a): Atvidade dos PNs em resposta para diversos valores de $\Delta$, mantendo fixo $r_{\max }=150 \mathrm{~Hz}$. (b): Lado a lado, atividade dos PNs e dos Neurônios Extrínsecos (ENs). De forma qualitativa, vemos que os ENs tendem a ultrapassar os PNs.

Fonte: Elaborada pelo autor.

(a)

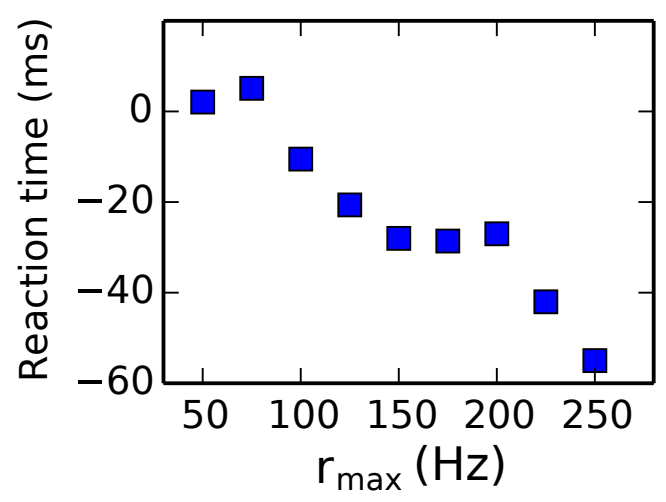

(b)

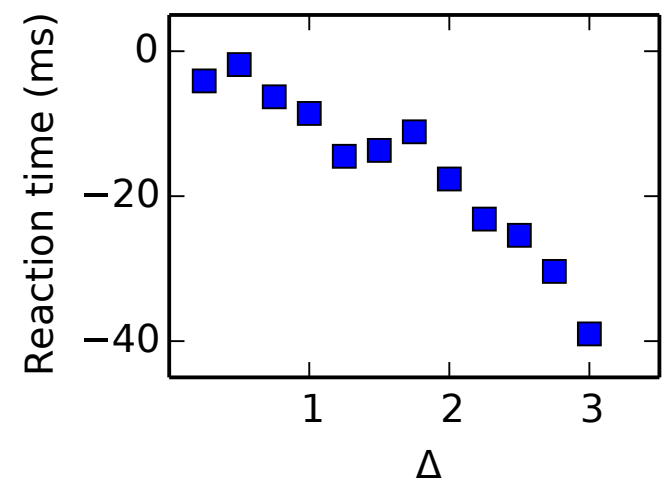

Figura 7.3- Tempos de resposta dos Neurônios Extrínsecos (ENs) ao protocolo de estimulação artificial. Todos os tempos foram medidos com respeito ao tempo de resposta dos neurônios de projeção, e por isso tempos negativos indicam que ENs responderam mais rapidamente que PNs. (a): Mantendo fixo $\Delta$, vario $r_{\text {max }}$. Fica claro que para baixos $r_{\max }(<90 \mathrm{~Hz})$, os PNs respondem mais rapidamente. Este efeito era esperado: Nesse intervalo, a frequência de disparo induzida nos PNs é muito baixa e completamente incompatível com experimentos ou estímulos reais. (b): Fixando $r_{\max }=150 \mathrm{~Hz}$, o que induz nos PNs uma taxa de disparo de aproximadamente $23 \mathrm{~Hz}$ (veja figura 7.2), vario $\Delta$. Para todos os valores testados, os ENs sempre ultrapassam os PNs. Note que com altas inclinações $\Delta$, ENs chegam a avançar em $40 \mathrm{~ms}$, compatível com os dados experimentais que temos usado.

Fonte: Elaborada pelo autor. 
no início (primeiros 100ms).

É possível argumentar que, se $r_{\max }$ não for muito grande, a taxa de disparo máxima induzida nos PNs também não será suficiente para gerar uma resposta razoável nos ENs. Portanto, seria razoável esperar que os ENs não antecipararão os PNs neste caso. Com efeito, isso foi observado e retrato este efeito na figura 7.3a. Note que quando $r_{\max }>80 \mathrm{~Hz}$, o efeito de antecipação volta a ocorrer; e quanto maior $r_{\max }$, mais pronunciada é a antecipação. A ordem de grandeza da antecipação concorda com os experimentos anteriormente descritos (em média $\sim 40 \mathrm{~Hz}$ ). Variando $\Delta$ não apenas não destroi a antecipação, como pode itensificá-la, de acordo com a figura 7.3b.

\subsection{Fidelidade da atividade neural e tamanho da rede}

Como adiantado algumas vezes, o número de KCs deve ter grande influência no código neural, e para testar exatamente estes efeitos fiz algumas simulações observando como a atividade dos ENs se acomoda para diferentes tamanhos da camada de KCs. Note que, para cada tamanho, o algoritmo de ajuste é executado novamente para garantir que todos resultados sejam compatíveis e comparáveis.

Na figura 7.4a mostro que existe um impacto grande em termos da variância da atividade. Conforme o número cresce, oscilações espúrias podem aparecer. A amplificação de ruído pelo grande número de KCs é a explicação mais plausível. Também mostro que a variância cresce superlinearmente com o número de KCs. A linha é um ajuste não-paramétrico que serve como guia. Isso significa que este crescimento das KCs pode desregular a atividade dos ENs e atrapalhar a codificação da identidade de odores.

Este efeito parece especialmente acentuado antes do início da estimulação. Após aproximadamente $100 \mathrm{~ms}$, a rede tende a relaxar para um estado dinâmico estacionário. A figura 7.4a mostra que neste estado esta influência negativa das $\mathrm{KCs}$ é mais forte. Especialmente como este estado estacionário codifica a identidade do odor, estas oscilações espúrias podem ser compreendidas como incertezas adicionais na tomada de decisão do inseto, induzindo possivelmente erros neste processo de classificação.

No entanto, logo quando o estímulo é iniciado, a atividade se torna bastante fiel: veja 
(a)
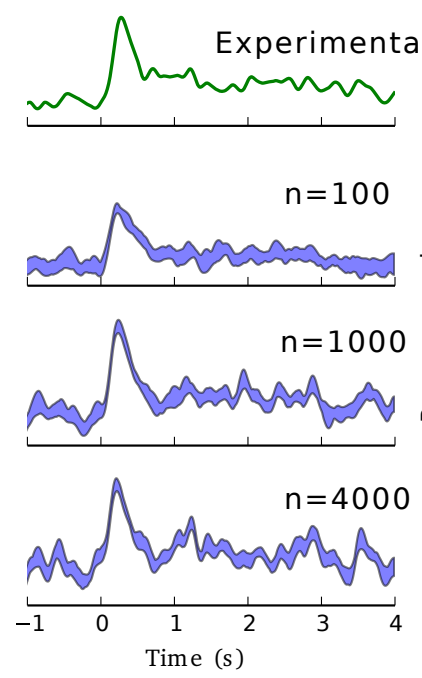

(b)
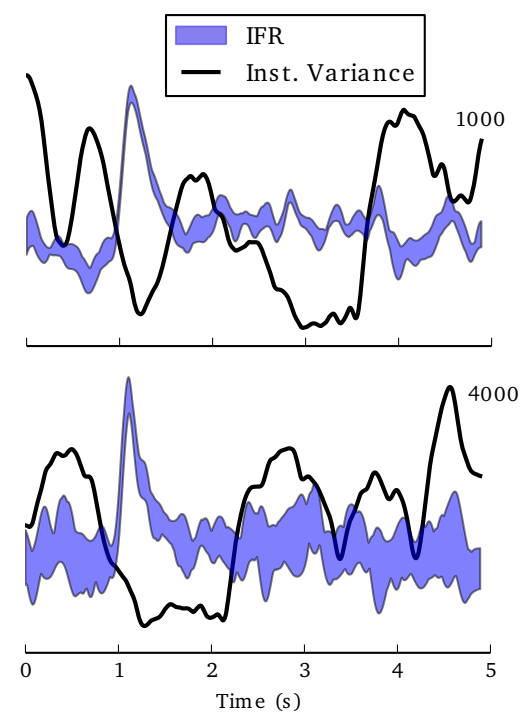

Figura 7.4- Durante a estimulação da rede (entre 1 e 3 segundos), a variância cai significativamente, indicando alta fidelidade com o código neural. (a): Quanto maior o número $n$ de Células Kenyon (KCs), maior o ruído induzido. Isto indica amplificação (indesejada) de ruído vindo dos PNs. Observe à direita que esta variância espúria cresce superlinearmente (linha é apenas um guia para os olhos). (b): Queda abrupta da variância no início da estimulação olfativa.

Fonte: Elaborada pelo autor.

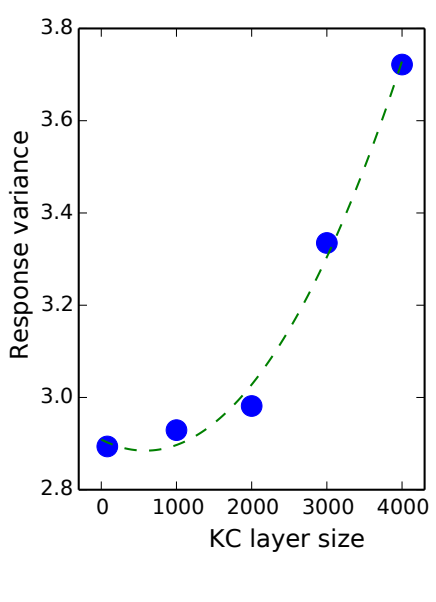

na figura $7.4 \mathrm{~b}$ que a variância instantânea (fuzzy) decresce substancialmente neste ponto. Para medir a variância instantânea, calcula-se a variância em cada trecho de tamanho $\Delta t$ considerando todas as repetições. Adicionalmente, esse decréscimo é mais acentuado e dura quanto maior a camada de KCs. Assim, um maior número de KCs tende a filtrar melhor a informação olfativa e transmitir menos ruído nos primeiros momentos de estimulação.

Esta característica é bastante desejável, embora isso também signifique oscilações mais fortes quando os ENs tiverem já relaxado para um estado estacionário. A única forma de balancear estas duas tendências conflitantes é por meio de um mecanismo que abafe eficientemente ruído sem necessariamente silenciar as $\mathrm{KCs}$ durante a estimulação. A seção seguinte trata deste mecanismo.

\subsection{Controle robusto de ganho}

O principal resultado da seção 7.2 mostra que o tamanho da camada $\mathrm{KC}$ tem uma influência muito forte sobre a atividade dos ENs, e isso pode ser prejudicial. Assim como argumentado na 


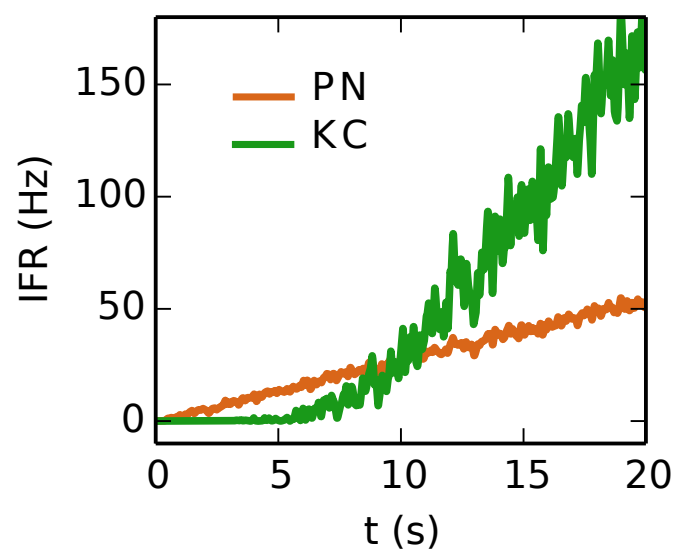

Figura 7.5- Resposta das Células Kenyon (KCs) para uma atividade dos Neurônios de Projeção (PNs) que cresce linearmente. A explosão de atividade não apenas indica falta de controle de ganho, como certamente atrapalharia no processo de aprendizagem e reconhecimento de padrões (como argumentado nas seções 5.3 e 6.1).

Fonte: Elaborada pelo autor.

seção 6.1, um dos fatores que contribuem para o CG funcionar tão bem no reconhecimento de odores é a esparsidade do código das KCs. Em outras palavras, eles precisam estar em silêncio e serem evocados com cuidado, caso contrário o argumento que os relaciona com a projeção multidimensional presente em variados métodos de Aprendizagem de Máquina não é mais válida. Um possível mecanismo seria ajustar o CG de forma que os PCTs pudessem blindar as KCs de qualquer excesso de atividade advinda dos PNs. No entanto, a figura 7.5 mostra que, se os PNs estimularem as KCs crescendo linearmente com o tempo, as KCs explodem superlinearmente - ou seja, um desastre em termos de manter a esparsidade do código das KCs. Seguindo nessa linha, a seguir investigarei a existência de condições conhecidas como Controle de Ganho Robusto.

Recentemente, condições parecidas foram demonstradas para o lóbulo antenal, ${ }^{(140)}$ embora as soluções encontradas não sejam realmente aplicáveis.

A seguir, proponho um modelo simplificado para o CG, analiticamente tratável, que nos guiará na busca por condições de controle de ganho. Usarei a teoria em volta de Sistemas Dinâmicos ${ }^{(133,141,142)}$ e Controle Ótimo para buscar por essas condições. No entanto, o texto seguinte será autocontido: todos os conceitos realmente necessários para a compreensão . Sejam, respectivamente, $X(t), Y(t), U(t)$ e $Z(t)$ as atividades instantâneas (em $\mathrm{Hz}$ ) das populações de PNs, KCs, PCTs e ENs. No entanto, $X(t)$ será encarado como uma função 
conhecida, a entrada para o CG. Então podemos modelar o CG como o seguinte sistema de equações diferenciais ordinárias:

$$
\begin{aligned}
\frac{d Y}{d t}(t) & =-\beta_{y} Y(t)+F_{y}\left[-g_{u y} U(t)+g_{x y} X(t)\right], \\
\frac{d Z}{d t}(t) & =-\beta_{z} Z(t)+F_{z}\left[g_{y z} Y(t)\right], \\
\frac{d U}{d t}(t) & =-\beta_{u} U(t)+F_{u}\left[g_{z u} Z(t)+g_{y u} Y(t)+g_{x u} X(t)\right] .
\end{aligned}
$$

Para definir os parâmetros deste sistema dinâmico, usaremos os índices $j, k=Y, U, Z$. Desta forma, $\beta_{j}$ é a dispersão da atividade da população $j$, e $F_{j}$ representa a função resposta daquela população. Como hipótese, costuma-se pedir que $F_{j}(x)$ é monótonamente crescente com $x$, não necessariamente precisando ser linear ou com uma forma funcional conhecida. Para facilitar nossas contas, também supomos que seja diferenciável ao menos uma vez em toda a reta real.

Por fim, $g_{j k}$ representam as conexões entre as populações. Para ligar com o modelo completo, defina

$$
g_{j k}=N_{j} p_{j k} w_{j k},
$$

com $N_{j}$ o número de neurônios em $j, p_{j k}$ a probabilidade de um neurônio de $j$ conectar-se com um de $k$ e $w_{j k}$ o peso sináptico destas conexões.

Os pontos fixos deste sistema dinâmico são as soluções $X^{*}, Y^{*}, U^{*}$ e $Z^{*}$ de

$$
\frac{d X}{d t}(t)=0, \quad \frac{d Y}{d t}(t)=0, \quad \frac{d U}{d t}(t)=0, \quad \frac{d Z}{d t}(t)=0 .
$$

Isso significa que, uma vez que o sistema atinge este estado - i.e., se acontecer de $X(t)=X^{*}$, $Y(t)=Y^{*}, U(t)=U^{*}$ e $Z(t)=Z^{*}-$, então o sistema não sairá mais deste estado. Para mais informações e um estudo mais aprofundado sobre os pontos fixos deste sistema, veja a 
seção 7.3.1. Resolvendo, obtemos

$$
\begin{aligned}
Y^{*} & =\frac{1}{\beta_{y}} F_{y}\left[-g_{u y} U^{*}+g_{x y} X^{*}\right], \\
Z^{*} & =-\frac{1}{\beta_{z}} F_{z}\left[g_{y z} Y^{*}\right], \\
U^{*} & =\frac{1}{\beta_{u}} F_{u}\left[g_{z u} Z^{*}+g_{y u} Y^{*}+g_{x u} X^{*}\right] .
\end{aligned}
$$

Se $F_{j}$ fossem todas lineares, então seria possível encontrar facilmente uma solução para esse sistema de equação. De não linearidades nessas funções, no entanto, podem surgir novos pontos fixos e nem sempre é possível encontrar as formas funcionais ou soluções analíticas destes pontos fixos. Apesar de isso ser verdade, em geral ocorre apenas um ponto fixo . Então no que se segue, suponho trabalhar em um desses pontos fixos (soluções do problema algébrico acima).

A ideia fundamental por trás do conteúdo a seguir é encontrar condições e amarras para os parâmetros de forma que estes pontos fixos sejam atratores e tal que uma varição $d X$ na atividade dos PNs não gere uma sobreatividade $d Y$ grande nas KCs. De forma ótima, gostaríamos de descobrir uma condição suficiente para

$$
\frac{d Y}{d X}=0
$$

Desta forma, a atividade $Y(t)$ fica controlada e blindada contra sobrecargas dos PNs. A seguir, vamos primeiro verificar a estabilidade destes pontos fixos e, em seguida, procurar por uma solução para a equação 7.3.9.

\subsubsection{Análise de estabilidade dos pontos fixos}

Conhecer apenas os pontos fixos descritos pelas equações 7.3.6-7.3.8 não significa muito. Há diversas dinâmicas que apresentam pontos fixos que modificam os sistemas das formas mais variadas.

Segue um exemplo rápido para ajudar a visualização deste conceito. Um sistema massamola apresenta um ponto fixo: quando o comprimento da mola $x(t)$ bate com o seu compri- 
mento natural $x_{0}$. Suponha uma força de atrito $-\gamma\left(x(t)-x_{0}\right)$. Então, não importa qual o deslocamento $x(0)$ inicial dado ao sistema, ele sempre evoluirá para $x(\infty)=x_{0}$. Suponha no que segue $\gamma=0$. Neste caso, o ponto fixo ainda existe, umas vez que se o sistema é posto no ponto de equilíbrio (ou seja, $x(0)=x_{0}$ e $\dot{x}(0)=0$ ) significa que $x(t)=x_{0}$ fixamente. A menos que o sistema seja colocado neste ponto de equilíbrio, o sistema nunca ficará parado em seu ponto de equilíbrio, e ficará oscilando com sua frequência natural. Este é um exemplo de pontos fixos com diferentes estabilidades. Diversos textos mostram como estudar a estabilidade de um ponto fixo, ${ }^{(141,143-145)}$ e isto é o que faremos em seguida.

Em sistemas dinâmicos, pontos fixos podem ser atratores ou repulsores. Este conceito em Física é conhecido como estabilidade de um ponto mínimo de algum potencial. Para que o ponto fixo definido nas equações 7.3.6-7.3.8 seja atrator, é necessário que os autovalores do Jacobiano $\mathcal{J}$ do sistema, calculado nesse ponto, sejam estritamente menores que zero. ${ }^{(141)}$ Da definição de Jacobiano,

$$
\mathcal{J}(X, Y, U, Z)=\left[\begin{array}{ccc}
-\beta_{y} & -c_{f} g_{u y} & 0 \\
c_{h} g_{y u} & -\beta_{u} & 0 \\
\left.g_{y z} \frac{d}{d \xi_{1}} F_{z}\left(\xi_{1}\right)\right|_{\xi_{1}=Y g_{y z}} & 0 & -\beta_{z}
\end{array}\right] .
$$

Para calcular os autovalores de $\mathcal{J}(X, Y, U, Z)$ basta resolver para $\lambda$ a seguinte equação:

$$
\operatorname{det}(\mathcal{J}(X, Y, U, Z)-\lambda \mathbb{I})=0,
$$

em que II é a identidade (tridimensional) e det é o determinante. Resolver este polinômio de terceiro grau exige simples esforço algébrico e será omitido. $\mathrm{O}$ auto valores são:

$$
\begin{aligned}
& \lambda_{0}=-\beta_{z}, \\
& \lambda_{-}=-\frac{\beta_{u}-\beta_{y}}{2}-\frac{1}{2} \sqrt{\beta_{u}^{2}-2 \beta_{u} \beta_{y}+\beta_{y}^{2}-4 c_{f} c_{h} g_{u y} g_{y u}}, \\
& \lambda_{+}=-\frac{\beta_{u}-\beta_{y}}{2}+\frac{1}{2} \sqrt{\beta_{u}^{2}-2 \beta_{u} \beta_{y}+\beta_{y}^{2}-4 c_{f} c_{h} g_{u y} g_{y u}}
\end{aligned}
$$

Não é difícil demonstrar que a parte real de todos os autovalores são negativos sempre, a 
menos de uma transição interessante entre um nó e um foco estável, dependendo do sinal de $\left(\beta_{y}+\beta_{u}\right)^{2}-c_{f} c_{u} g_{u y} / g_{y u}$.

\subsubsection{Condição suficiente para controle de ganho}

Usando os pontos fixos 7.3.6-7.3.8, é possível calcular também os diferenciais

$$
\begin{aligned}
d y & =\left.\left(d u \frac{g_{u y}}{\beta_{y}}+d x \frac{g_{x y}}{\beta_{y}}\right) \frac{d F_{y}}{d \xi}(\xi)\right|_{\xi=-g_{u y} U^{*}+g_{x y} X^{*}}, \\
d z & =-\left.d y \frac{g_{y z}}{\beta_{z}} \frac{d F_{z}}{d \xi}(\xi)\right|_{\xi=g_{y z} Y^{*}}, \\
d u & =\left.\left(d x \frac{g_{x u}}{\beta_{u}}+d y \frac{g_{y u}}{\beta_{u}}\right) \frac{d F_{u}}{d \xi}(\xi)\right|_{\xi=g_{z u} Z^{*}+g_{y u} Y^{*}+g_{x u} X^{*}}
\end{aligned}
$$

As derivadas das funções $F_{j}(j=y, u, z)$ acima existem por hipótese (as defini como diferenciáveis) e podem ser consideradas como constantes, uma vez que estão calculadas no ponto fixo do sistema. Assim, podemos definir

$$
c_{j}=\frac{d F_{j}}{d \xi}\left(\xi^{*}\right)
$$

em que $\xi^{*}$ representa o ponto fixo para cada $j$ diferente.

Simplesmente manipulando algebricamente as equações 7.3.15-7.3.17 e forçando que haja controle de ganho robusto, i.e.,

$$
\frac{d y}{d x}=0
$$

obtive

$$
\frac{g_{x u} g_{u y}}{g_{x y}}=\frac{\beta_{u}}{c_{u}}
$$

Vale lembrar que esta predição vem de um modelo simplificado, e que constitui apenas uma indicação que usarei como guia. Na seção 7.3.3, verifico numericamente a validade desta predição.

Note que todos os fatores envolvidos com a conectividade do CG estão à esquerda da equação 7.3.20. Nele há duas tendências diferentes competindo: $g_{x u} g_{u y}$ referem-se ao quão forte os PCTs são ativados pelos KCs e PNs; $g_{x y}$ representa a intensidade da excitação das 
KCs pelos PNs. Note que $g_{u y}$ simplesmente não aparece, o que significa que o que realmente deve importar para que haja controle de ganho é como a atividade dos PCTs relaxa com o tempo (representado por $\beta_{u}$ ).

Ainda mais, vale comentar que não há contribuição de $g_{z u}$ mesmo se a inserirmos no começo das contas. De fato esta conexão entre ENs e PCTs nunca foi observada empiricamente, e com isso demonstro que a contribuição para o mecanismo de controle de ganho deve ser mínima.

\subsubsection{Verificando numericamente controle de ganho}

Para testar as predições de nosso sistema simplificado, resumido na equação 7.3 .20 , fiz ensaios numéricos para calcular $d Y / d X$ usando o modelo completo. Da seção 7.3.2, descobrimos que essas soluções devem apresentar-se como uma linha reta num gráfico de $w_{x y}$ contra $w_{u y}$. Além disso, a inclinação desta reta deve variar linearmente com $g_{u y}$.

De fato, realizar esta medida não é exatamente trivial, e para tal criei o seguinte protocolo. Uma subpopulação dos PNs, aleatoriamente escolhida, é estimulada com um processo de Poisson. Na maioria dos casos, esta subpopulação representa apenas $10 \%$ do total de PNs, analogamente ao que ocorre em situações realísticas. A taxa deste processo de Poisson, no entanto, varia no tempo lentamente, gerando uma atividade similar ao mostrado na figura 7.5. Desta forma, ambas as atividades dos PNs e KCs são próximas a retas. Após a simulação, é possível ajustar uma reta com respeito à atividade dos PNs e das KCs. Sejam $\alpha_{P N}$ e $\alpha_{K C}$ os coeficientes angulares destas retas ajustadas. Então,

$$
\frac{d Y}{d X}=\frac{d Y / d t}{d X / d t}=\frac{\alpha_{K C}}{\alpha_{P N}}
$$

Portanto, a equação 7.3.21 estabelece uma forma de medir numericamente $d Y / d X$. Como em alguns casos há fortes flutuações (especialmente para pesos sinápticos altos), $d Y / d X$ foi calculado como a média de dez repetições deste protocolo.

Note a semelhança entre este protocolo e o protocolo introduzido na seção 7.1.1. De forma equivalente, o atual protocolo usaria $\Delta$ muito grande e $r_{\max } \rightarrow \infty$.

A figura 7.6a mostra os resultados para $d Y / d X=0$ calculado extensivamente para uma 
(a)
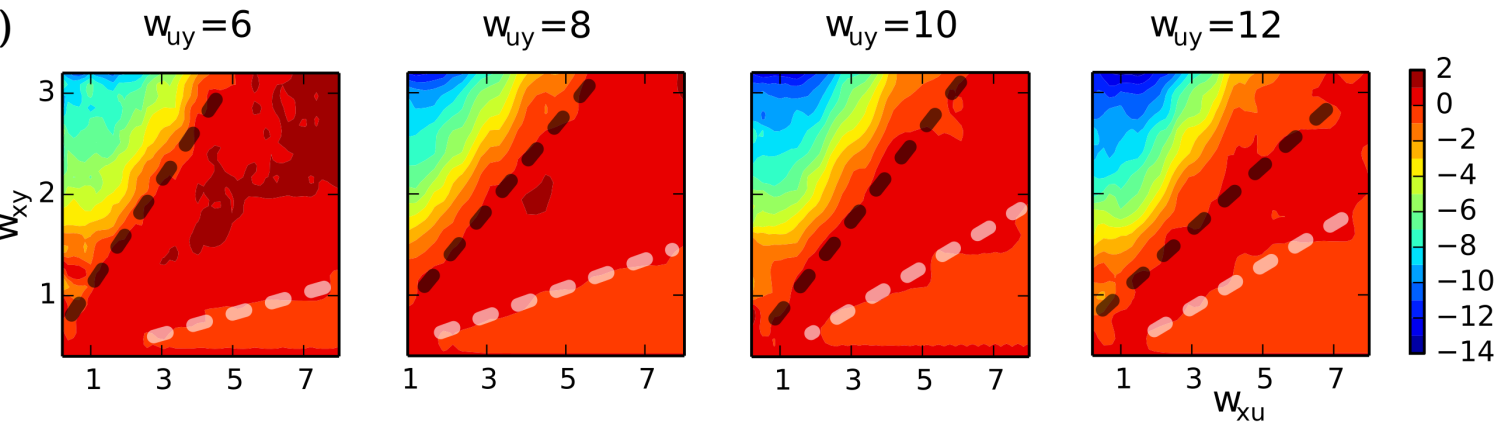

(b)

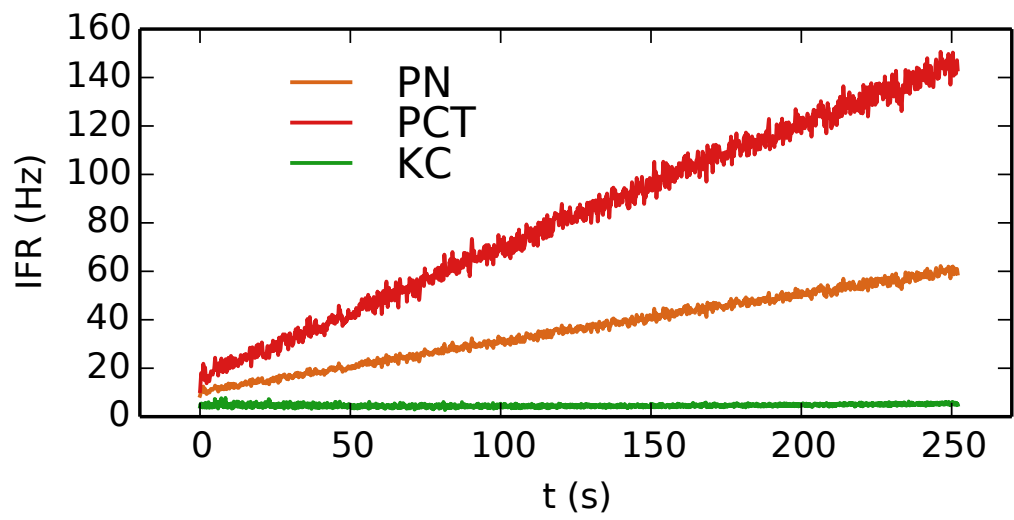

Figura 7.6- Controle de ganho na camada das células Kenyon (KCs). (a): Com os neurônios do Trato Protocerébro Calical (PCT), é possível ajustar o ganho da camada de KCs de forma que com o aumento da intensidade do sinal dos Neurônios de Projeção (PNs) não atrapalhe a esparsividade do código, consequentemente não danificando o processo de reconhecimento de padrões no sinal olfativo.

Fonte: Elaborada pelo autor.

região do espaço de parâmetros. Para realizar estes cálculos num tempo razoável, paralelizei meu código de forma a rodar 15 processos por vez e dividir os pontos a serem calculados. As retas claras demarcam soluções em que $d Y / d X$, e o coeficiente linear desta reta varia linearmente com $g_{u y}$. Na figura $7.6 \mathrm{~b}$, mostro o mesmo experimento realizado na figura 7.5 , exceto que neste caso utilizo os parâmetros que garantem controle de ganho. Veja que a atividade das KCs se mantém estável, embora a atividade dos PNs cresce. Além disso, note que a atividade dos PCTs cresce junto com a dos PNs. Portanto, os PCTs estão reprimindo a sobrecarga gerada pelos PNs para controlar o código das KCs.

Especialmente para altos valores de $g_{u y}$, é possível ver que a forma da linha $d Y / d X=0$ na figura 7.6a se distorce razoavelmente. Esta divergência provavelmente se deve a efeitos que o sistema simplificado não captura.

A linha preta na figura 7.6a demarca outra solução que apresenta $d Y / d X=0$. No entanto, há motivos para acreditar que esta segunda solução não se trata de outro ponto fixo: a 
inclinação desta reta não varia linearmente com $g_{u y}$. Uma outra alternativa é que se trata de um fenômeno não capturado pelo sistema simplificado, o que é esperado dada a redução significativa da complexidade com respeito ao sistema completo. De qualquer forma, trata-se de uma outra solução com a mesma propriedade de controle de ganho ótimo. Investigações preliminares não demonstraram qualquer diferença significativa entre usar parâmetros relacionadas a qualquer uma das duas curvas.

Para avaliar quantitativamente a subida das $\mathrm{KCs}$, ajustei uma reta na atividade das $\mathrm{KCs}$ da figura 7.6b. Isso é equivalente a tomar uma média nos pontos, enquanto que o coeficiente angular ajustado revela quanto essa média tende a subir (por causa da atividade dos PNs). Surpreendentemente, o coeficiente angular sempre se manteve da ordem de $10^{-3} \mathrm{~Hz} / \mathrm{s}$, com um erro da mesma ordem. Esse resultado indica que qualquer crescimento observado pode ser simplesmente devido a um erro no ajuste da reta. Isso respalda minha afirmação de que as PCTs estão de fato blindando bem as KCs de sobrecargas de atividade.

\section{4 Ótimo tamanho de rede para antecipação da to- mada de decisão}

Tendo soluções com controle de ganho robusto, é possível fazer o seguinte experimento: fixado o número de PNs e ENs, como o número de KCs impacta o tempo de resposta dos ENs? Apesar de quanto maior os CGs, melhor a performance em reconhecimento de padrões (veja seção 6.1.1), a figura 7.7 mostra que existe um tamanho ótimo de KCs para que o tempo de resposta seja o mais baixo possível.

Para realizar este experimento computacional, foi preciso definir um protocolo específico: (i) o modelo é criado e configurado para um dado número $N_{K C}$ de $\mathrm{KCs}$; (ii) o algoritmo de ajuste de parâmetros foi executado para que todos os parâmetros do modelo possam comportar $N_{K C}$ sem que a rede deixe de se comportar como nos experimentos de StrubeBloss e colaboradores; (iii) são realizadas 50 simulações para gerar as atividades fuzzy para todas os registros experimentais disponíveis dos PNs; (iv) o tempo médio de reação dos ENs é então medido e comparado ao dos PNs. O erro avaliado às estimativas de tempo de reação 


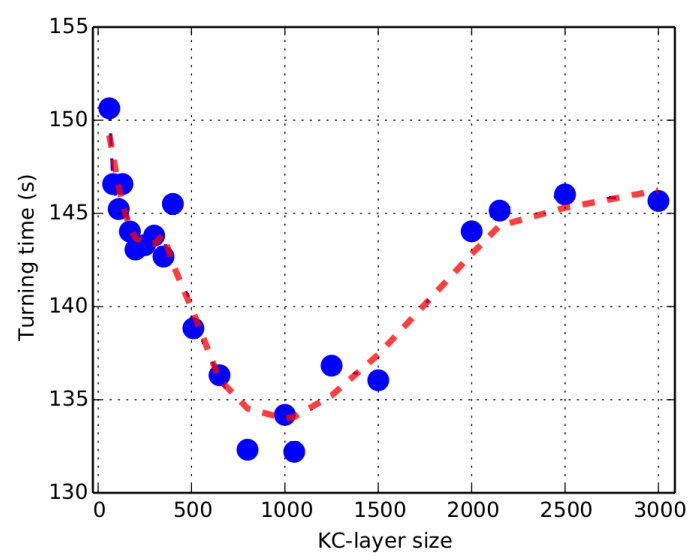

Figura 7.7- Efeito do tamanho da camada de Células Kenyon (KCs) no tempo de reação dos Neurônios Extínsecos (ENs). Existe um tamanho ótimo de KCs que torna o tempo de reação o menor possível. A diferença entre o caso ótimo e casos subótimos é de quase $30 \mathrm{~ms}$, uma diferneça de tempo muito maior que a soma dos delays sinápticos e da ordem do tempo de reação total em moscas já treinadas. Adicionalmente, este tempo é próximo do tempo de reação de outras modalidades sensoriais (visão, por exemplo).

Fonte: Elaborada pelo autor.

foram mantidas sempre num limiar baixo (menos de $5 \mathrm{~ms}$ ).

Fica evidente que este experimento tem um custo computacional bastante elevado, e pode levar de um a dois dias para completar já considerando processamento paralelo e em um computador de última geração (12 CPUs, $3.2 \mathrm{GHz}$, intel i7, 16GB de RAM).

Note que a diferença entre um caso ótimo e um subótimo chega próximo de $30 \mathrm{~ms}$, uma diferença considerável para os tempos de reações de insetos. Por exemplo, o sistema visual em geral consegue gerar respostas motoras em menos de 50ms. Assim como comentado na seção 5.4, 30ms pode representar, durante a busca por alimento, um erro da ordem de metros no voo de moscas.

Certamente um grande número de KCs pode impactar negativamente o ritmo do código neural, e isto já foi observado anteriormente na seção 7.2: um número excessivo de KCs torna a atividade dos ENs mais oscilante e ruidosa. Isso significa que além da própria informação olfativa, ruído pode estar sendo amplificado e atrapalhando os ENs.

Por fim, note que o tamanho ótimo da camada das KCs ocorre logo após mil neurônios, o que é próximo de dez vezes maior do que o número de PNs. Dos experimentos revisados na seção 5.2.1, sabemos que esta razão para abelhas Apis mellifera deve ser próxima de 15. Dado 
o nível de detalhamento que temos no momento, este é um resultado bastante impressionante.

\subsection{Balanço entre Performance e Agilidade no Reco- nhecimento de Odores}

O resultado anterior não reflete apenas uma otimização puramente, mas vai de encontro ao que se acredita em termos de performance de redes neurais. Em geral, quanto maior a rede neural melhor a performance para reconhecimneto de padrões, e assim se acredita que os CGs funcionariam. Na seção 6.1.1, mostro que isso é verdade baseado em um modelo simplificado de CGs, usando séries temporais de odores reais.

Isso significa que existe uma briga entre duas tendências: agilidade contra performance no reconhecimento de odores. Em muitas situações, é razoável imaginar que uma queda pequena em performance possa ser desejável frente a um ganho de quase $30 \mathrm{~ms}$ no tempo em que a decisão ocorre. Talvez esta predição do modelo possa ser testada experimentalmente danificando cuidadosamente os CGs e/ou modificando geneticamente algumas abelhas para desenvolverem mais ou menos os cálices e, portanto, mudar o número de KCs. Estas questões são certamente bastante interessantes e devem ser testadas no futuro próximo. 


\section{Capítulo 8}

\section{Conclusões}

\subsection{Processamento de informação, criticalidade e leis de potência}

Primeiramente, os resultados referentes à seção 4.3 despertam interesse por configuraremse como um exemplo de modelo crítico sem leis de potência, observadas nos últimos anos (a partir de 2012). (41) Estes mesmos resultados também podem trazer alguma luz a outros experimentos ${ }^{(42)}$ que não observam leis de potência e que, baseados unicamente neste fato, sugerem dúvidas sobre a existência de criticalidade na dinâmica neural. Note que não apenas mostrei que pode existir um fenômeno crítico por detrás de uma distribuição diferente de uma lei de potência, como pode existir uma dinâmica subcrítica escondida às sombras de tal distribuição. Portanto, a mensagem final é de que as distribuições de avalanches não são suficientes para inferir sobre a existência ou não de um fenômeno crítico.

Ainda mais recentemente, outros grupos de pesquisadores reportaram, ${ }^{(146-148)}$ após uma primeira publicação minha com meu orientador Leonardo P. Maia, ${ }^{(20)}$ observações de dinâmicas críticas sem necessariamente apresentar leis de potência. Por fim, em algumas comunicações privadas e que estão sob investigação, soubemos da possibilidade de haver ainda outros modelos que apresentavam uma fenomenologia não usual que merecem nossa atenção.

Primeiramente, nossos resultados concordam - em alguns aspectos até quantitativamente - com os de Friedman e colaboradores (dentre os quais está Beggs) ${ }^{(41)}$ e complementa o ponto 
central do texto: apesar da quebra da lei de potência (embora com resquícios de invariância de escala), diversos outros indícios de criticalidade estão presentes. Mais especificamente, usando - UCM, fui capaz de reproduzir inclusive os expoentes dos regimes iniciais de leis de potência do trabalho de Friedman et al usando como expoente da distribuição de graus -3.5 , muito embora eu não tenha acesso aos dados da conectividade inferida pelos autores. Também fixei o expoente da distribuição de graus em $\sim-2.2$, em correspondência a medidas de conectividade funcional no córtex cerebral, $(45,47)$ e toda a fenomenologia proposta continua válida.

Além disso, as distribuições cumulativas que apresento na seção 4.3 são qualitativamente muito similares às mostradas por Dehgahni e colaboradores, ${ }^{(42)}$ em que o ponto central era o de mostrar quebra de invariância de escala na atividade neural. Nossa modelagem mostra que mesmo assim essas dinâmicas podem ser críticas, ou seja, não é o suficiente para negar a hipótese de criticalidade neural. Este ponto é bastante apelativo, principalmente devido à grande visibilidade da área, mas eu gostaria de deixar claro que estes resultados não devem ser compreendidos como uma prova de que há criticalidade na dinâmica neural. Mais ainda, uma prova cabal de tal fenômeno só viria de experimentos como os de Shew e colaboradores, $(27,38,40)$ em que uma transição de fase extremamente palpável é induzida e observada.

Ainda nessa linha, como estes novos experimentos têm advogado no sentido de que medidas mais robustas mostram falta de invariância de escala, apresentei na seção 4.3.1 que argumentos parecidos com os apresentados por Ribeiro e colaboradores ${ }^{(31)}$ podem clarear mais a situação: as avalanches críticas geradas pelo modelo $\mathrm{GH}$ podem se tornar leis de potência se subamostrarmos a rede neural. Dessa forma, é natural que primeiros experimentos tenham apresentado leis de potência, embora isso não signifique necessariamente que todos aqueles (primeiros) experimentos devem ser subamostragens de distribuições com bumps um acréscimo de massa probabilística inesperada nos eventos mais extremos de avalanches. Reveja o segundo parágrafo da seção 4.3.1 para maiores detalhes. Portanto deixo claro que isso não implica necessariamente no fato de que as observações de dinâmicas neurais críticas em forma de leis de potências sejam artefatos da metodologia de medida. Isso se confirma dado que existem topologias (como a ERM) em que as avalanches críticas de fato seguem leis de potências com expoentes clássicos e medidos na maior parte dos experimentos. 


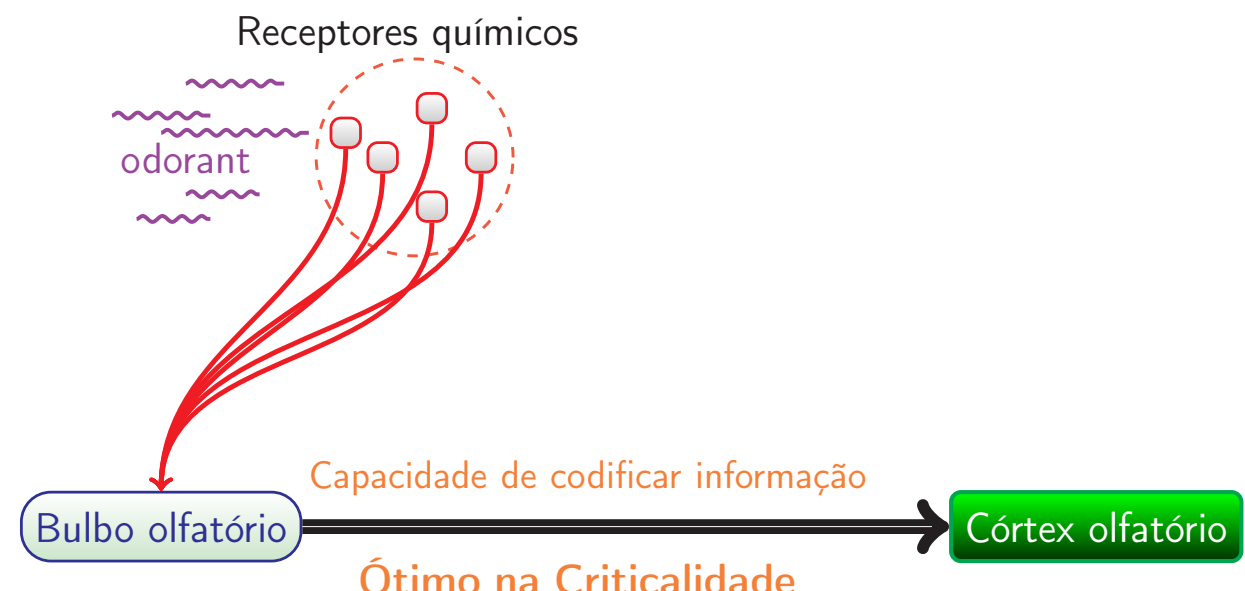

Figura 8.1- Analogia com o processamento de informação no bulbo olfatório, em que existe um canal de comunicação entre o bulbo e o córtex olfatório. Espécies químicas associadas ao estímulo olfativo chegam a receptores químicos usualmente posicionados nas narinas de animais ou em partes específicas de insetos (antenas, por exemplo). Estes receptores químicos, ao se ligarem com as partículas dos odorantes, enviam disparos de potencial de ação ao bulbo olfatório, que é composto por camadas de células especializadas e que comunicam-se com o cortex olfatório. A entropia de duração de avalanches está ligada com a capacidade de codificação deste canal.

Fonte: Elaborada pelo autor.

Por fim, mostro que a ocorrência dos chamados bumps influencia a faixa dinâmica através da entropia de durações de avalanche, derrubando a hipótese de que avalanches distribuídas de acordo com uma lei de potência são responsáveis por esta otimização. Em um sentido mais relaxado, esta entropia de durações de avalanche pode ser conectada com a capacidade máxima de transferência de informação do canal que liga o bulbo olfatório - primeiro sistema responsável por computar informação sensorial com respeito ao olfato - e o cortex olfatório. $\mathrm{Na}$ figura 8.1, ilustro esta ideia.

\subsection{Antecipação no reconhecimento de odores}

Acredito que existam poucos textos que reunam informações como no capítulo 5, especialmente sob o ponto de vista computacional. Apesar de tornar o texto um pouco mais longo, considero uma possível fonte de informação para pesquisadores que almeijem contribuir para esta área ou compreender questões ligadas ao como os Corpos Cogumelares (CGs) computam informação 
olfativa. Resumidamente, Neurônios de Projeção (PNs) recebem e retransmitem a informação para os CGs. Os primeiros neurônios dos CGs a receber esta informação são as Células Kenyon (KCs). Então, as KCs projetam para os ENs, que são responsáveis por identificar a identidade dos odorantes em questão -i.e., processo de tomada de decisão. Além disso, existem os neurônios do Trato Protocérebral Cálico (PCTs) que acredita-se estarem ligados com a manutenção da atividade das KCs (um dos meus resultados, veja a seguir). Durante todo o texto também frisei o fato de as $\mathrm{KCs}$, camada do meio dos CGs, ser gigantesca em comparação com as outras populações. Por este motivo, esta estrutura é costumeiramente chamada de fan-in, fan-out (convergência, divergência).

Ao final deste mesmo capítulo 5, introduzi a questão central que resolvi: como é possível que ENs antecipem os PNs na reação à estimulação olfativa, mesmo estando duas sinapses distantes da entrada da informação? No capítulo 7 introduzi um modelo e todo o ferramental capaz de responder esta questão.

De acordo com o modelo, a estrutura fan-in, fan-out induz um balanço entre a performance na detecção da identidade dos odores contra a agilidade com que esta detecção ocorre. Este fato é extremamente inesperado: é muito comum que quanto maior a rede neural, melhor sua performance (reveja resultados e discussão da seção 6.1.1). O fenômeno por detrás deste fato é exatamente a estrutura fan-in, fan-out, que induz a transferência ágil de informação, mas que também intensifica ruído.

É importante notar que os modelos até hoje considerados dos CGs baseiam-se em modelos estáticos, sem dinâmica temporal. Isso significa que não havia como averiguar ao certo como o ruído das séries temporais olfativas seria passado para os ENs. Esta integração temporal, no entanto, gera dificuldades técnicas que ainda precisam ser avaliadas com cuidado e tempo. Por exemplo, apesar de existirem propostas de regras de aprendizagem no tempo, este campo de estudo ainda está bastante volátil e é bastante difícil de desenhar experimentos que consigam diretamente medir plasticidade sináptica.

Para garantir que este efeito não estava sendo reproduzido pelo modelo simplesmente por causa do ajuste de dados, a antecipação do código foi observada em um protocolo artificial de estimulação (reveja a seção 7.1.1). Com este protocolo, o modelo apresenta tempos de 
reação similares aos observados em experimentos.

Estudando de forma mais aprofundada este assunto, vimos no capítulo 7.2 como essa transmissão de ruído ocorre. Em especial, conforme o número de KCs cresce com a variância na atividade dos ENs cresce de forma superlinear (figura 7.4a), enquanto que a fidelidade da atividade dos ENs logo no começo da estimulação se torna extremamente alta. Concluímos, ao final da seção 7.2 , que isto se reflete em uma maior indecisão na tomada de decisão dos ENs.

Especialmente porque este efeito poderia ser extremamente prejudicial, na seção 7.3 apresento um possível mecanismo de controle de ganho que os PCTs podem implementar para garantir que as KCs mantenham o código esparso e para segurar ruído e outros fatores prejudiciais para os ENs. Como um guia para este mecanismo, vimos um modelo simplificado (estilo mean-field) que fornece uma equação que amarra os parâmetros para garantir que haja controle de ganho. Esta solução analítica foi verificada numericamente com sucesso. Este mecanismo de controle de ganho é extremamente robusto e perturbações sinápticas não quebram este balanço.

Portanto, encontramos diversos indícios de que a existência de uma estrutura fan-in, fanout está longe de ser acidental e pode estar não apenas ligada com a performance em reconhecimento de odores, como também ser a característica principal por detrás da codificação veloz realizada pelos CGs. Vale comentar que insetos em geral conseguem reconhecer odores com performance excelente, e ao menos uma ordem de grandeza mais rápido que os melhores dispositivos eletrônicos disponíveis atualmente. 


\section{Referências}

1 VERGARA, A.; FONOLLOSA, J.; MAHIQUES, J.; TRINCAVELLI, M.; RULKOV, N.; HUERTA, R. On the performance of gas sensor arrays in open sampling systems using Inhibitory Support Vector Machines. Sensors and Actuators B, v. 185, p. 462-477, 2013. doi: 10.1016/j.snb.2013.05.027.

2 TRINCAVELLI, M.; CORADESCHI, S.; LOUTFI, A. Odour classification system for continuous monitoring applications. Sensors and Actuators B, v. 139, n. 2, p. 265-273, 2009. doi: 10.1016/j.snb.2009.03.018.

3 STRUBE-BLOSS, M. F.; HERRERA-VALDEZ, M. A.; SMITH, B. H. Ensemble response in mushroom body output neurons of the honey bee outpaces spatiotemporal odor processing two synapses earlier in the antennal lobe. PloS one, v. 7, n. 11, p. e50322, 2012. doi: 10.1371 /journal. pone.0050322.

4 ABBOTT, L.; DAYAN, P. Theoretical Neuroscience: computational and mathematical modeling of neural systems. Massachusetts: The MIT Press, 2001.

5 GERSTNER, W.; KISTLER, W. M. Spiking neuron models: single neurons, populations, plasticity. Cambridge: Cambridge University Press, 2005.

6 KANDEL, E. R.; SCHWARTZ, J. H.; JESSELL, T. M. Principles of neural science. New York: McGraw-Hill, 2000.

7 HODGKIN, A. L.; HUXLEY, A. F. A quantitative description of membrane current and its application to conduction and excitation in nerve. The Journal of Physiology, v. 117, n. 4, p. 500-544, 1952.

8 BEAN, B. P. The action potential in mammalian central neurons. Nature Reviews Neuroscience, v. 8, n. 6, p. 451-465, 2007. doi: 10.1038/nrn2148.

9 ENGEL, A.; DEN BROECK, C. V. Statistical Mechanics of Learning. Cambridge: Cambridge University Press, 2004.

10 ROMAN, S. Coding and Information Theory. Fullerton: Springer-Verlag, 1992. 
11 WILLIAMS, R. W.; HERRUP, K. The Control of Neuron Number. Annual Review of Neuroscience, v. 11, p. 423-453, 1988. doi: 10.1146/annurev.ne.11.030188.002231.

12 AZEVEDO, F. A. C.; CARVALHO, L. R. B.; GRINBERG, L. T.; FARFEL, J. M.; FERRETTI, R. E. L.; LEITE, R. E. P.; FILHO, W. J.; LENT, R.; HERCULANO-HOUZEL, S. Equal numbers of neuronal and nonneuronal cells make the human brain an isometrically scaled-up primate brain. The Journal of Comparative Neurology, v. 513, n. 5, p. 532-541, 2009. doi: 10.1002/cne.21974.

13 PURVES, D.; AUGUSTINE, G. J.; FITZPATRICK, D.; HALL, W. C.; LAMANTIA, A.-S.; WHITE, L. E. Neuroscience. Sunderland: Sinauer Associates, 2012.

14 GOLLO, L. L.; KINOUCHI, O.; COPELLI, M. Active dendrites enhance neuronal dynamic range. PLoS computational biology, v. 5, n. 6, p. e1000402, 2009. doi: 10.1371/journal.pcbi. 1000402.

15 MATIAS, P.; GUARIENTO, R. T.; DE ALMEIDA, L. O. B.; SLAETS, J. F. W. Modular Acquisition and Stimulation System for Timestamp-Driven Neuroscience Experiments. Applied Reconfigurable Computing, v. 9040, p. 339-348, 2015. doi: 10.1007/978-3-319-16214-0_29.

16 Quian Quiroga, R.; PANZERI, S. Extracting information from neuronal populations: information theory and decoding approaches. Nature reviews. Neuroscience, v. 10, n. 3, p. 173-85, 2009. doi: 10.1038/nrn2578.

17 MOSQUEIRO, T. S.; AKIMUSHKIN, C.; MAIA, L. P. Dynamical aspects of KinouchiCopelli model: emergence of avalanches at criticality. In: . Águas de Lindoia: , c2011 (. p. 251-254.

18 AMIGO, J. M.; MOSQUEIRO, T. S.; HUERTA, R. Predicting synchronization of three mutually inhibiting groups of oscillators with strong resetting. Applied Mathematics \& Information Sciences, v. 9, n. 5, p. 2245-2256, 2015. doi: 10.12785/amis/090505.

19 GUARIENTO, R. T.; MOSQUEIRO, T. S.; CAPUTI, A. A.; PINTO, R. D. A simple model for eletrocommunication: "refractoriness avoidance response"? BMC Neuroscience, v. 15, n. Suppl 1, p. P68, 2014. doi: 10.1186/1471-2202-15-S1-P68.

20 MOSQUEIRO, T. S.; MAIA, L. P. Optimal channel efficiency in a sensory network. Physical Review E, v. 88, n. 1, p. 12712, 2013. doi: 10.1103/PhysRevE.88.012712.

21 MAIA, L. P.; MOSQUEIRO, T. S. Structural features beneath neuronal avalanches. BMC Neuroscience, v. 14, n. Suppl 1, p. O18, 2013. doi: 10.1186/1471-2202-14-S1-O18.

22 MOSQUEIRO, T. S.; HUERTA, R. Computational models to understand decision making and patternrecognition in the insect brain. Current Opinion in Insect Science, v. 6, n. i, p. 80-85, 2014. doi: 10.1016/j.cois.2014.10.005. 
23 MOSQUEIRO, T.; DE LECEA, L.; HUERTA, R. Control of sleep-to-wake transitions via fast amino acid and slow neuropeptide transmission. New Journal of Physics, v. 16, n. 11, p. 115010, 2014. doi: 10.1088/1367-2630/16/11/115010.

24 MOSQUEIRO, T. S. Probabilistic greenberg-hastings. 2015. doi: 10.5281/zenodo.19154. Software.

25 BEGGS, J. M.; PLENZ, D. Neuronal Avalanches in Neocortical Circuits. The Journal of Neuroscience, v. 23, n. 35, p. 11167-11177, 2003.

26 BAK, P.; TANG, C.; WIESENFELD, K. Self-organized criticality: An explanation of the 1/f noise. Phys. Rev. Lett., v. 59, n. 4, p. 381-384, 1987. doi: 10.1103/PhysRevLett.59.381.

27 SHEW, W. L.; YANG, H.; YU, S.; ROY, R.; PLENZ, D. Information Capacity and Transmission Are Maximized in Balanced Cortical Networks with Neuronal Avalanches. The Journal of Neuroscience, v. 31, n. 1, p. 55-63, 2011. doi: 10.1523/JNEUROSCI.4637-10.2011.

28 BARLOW, H. B. Single units and sensation: A neuron doctrine for perceptual psychology? Perception, v. 38, n. 6, p. 371-394, 2009. doi: 10.1068/p010371.

29 BEGGS, J. M.; PLENZ, D. Neuronal avalanches are diverse and precise activity patterns that are stable for many hours in cortical slice cultures. The Journal of neuroscience, v. 24, n. 22, p. 5216-5229, 2004. doi: 10.1523/JNEUROSCI.0540-04.2004.

30 MAZZONI, A.; BROCCARD, F. D.; GARCIA-PEREZ, E.; BONIFAZI, P.; RUARO, M. E.; TORRE, V. On the Dynamics of the Spontaneous Activity in Neuronal Networks. PLoS ONE, v. 2, n. 5, p. e439, 2007. doi: 10.1371/journal.pone.0000439.

31 RIBEIRO, T. L.; COPELLI, M.; CAIXETA, F.; BELCHIOR, H.; CHIALVO, D. R.; NICOLELIS, M. A. L.; RIBEIRO, S. Spike avalanches exhibit universal dynamics across the sleep-wake cycle. PloS one, v. 5, n. 11, p. e14129, 2010. doi: 10.1371/journal.pone.0014129.

32 POIL, S.-S.; VAN OOYEN, A.; LINKENKAER-HANSEN, K. Avalanche dynamics of human brain oscillations: relation to critical branching processes and temporal correlations. Human brain mapping, v. 29, n. 7, p. 770-777, 2008. doi: 10.1002/hbm.20590.

33 PETERMANN, T.; THIAGARAJAN, T. C.; LEBEDEV, M. A.; NICOLELIS, M. A. L.; CHIALVO, D. R.; PLENZ, D. Spontaneous cortical activity in awake monkeys composed of neuronal avalanches. Proceedings of the National Academy of Sciences of the United States of America, v. 106, n. 37, p. 15921-6, 2009. doi: 10.1073/pnas.0904089106.

34 BAK, P.; TANG, C.; WIESENFELD, K. Self-organized criticality. Phys. Rev. A, v. 38, n. 1, p. 364-374, 1988. doi: 10.1103/PhysRevA.38.364.

35 REICHL, L. A Modern Course in Statistical Physics. Weinheim: Wiley-VCH, 2009. 
36 CHRISTENSEN, K.; MOLONEY, N. R. Complexity and criticality. London: Imperial College Press, 2005.

$37 \mathrm{KINOUCHI}$, O.; COPELLI, M. Optimal dynamical range of excitable networks at criticality. Nature Physics, v. 2, p. 348-352, 2006. doi: 10.1038/nphys289.

38 SHEW, W. L.; YANG, H.; PETERMANN, T.; ROY, R.; PLENZ, D. Neuronal avalanches imply maximum dynamic range in cortical networks at criticality. The Journal of neuroscience, v. 29 , n. 49, p. 15595-600, 2009. doi: 10.1523/JNEUROSCI.3864-09.2009.

39 HALDEMAN, C.; BEGGS, J. M. Critical Branching Captures Activity in Living Neural Networks and Maximizes the Number of Metastable States. Phys. Rev. Lett., v. 94, n. 5, p. 58101, 2005. doi: 10.1103/PhysRevLett.94.058101.

40 YANG, H.; SHEW, W. L.; ROY, R.; PLENZ, D. Maximal Variability of Phase Synchrony in Cortical Networks with Neuronal Avalanches. The Journal of Neuroscience, v. 32, n. 3, p. 1061-1072, 2012. doi: 10.1523/JNEUROSCI.2771-11.2012.

41 FRIEDMAN, N.; ITO, S.; BRINKMAN, B. A. W.; SHIMONO, M.; DEVILLE, R. E. L.; DAHMEN, K. A.; BEGGS, J. M.; BUTLER, T. C. Universal Critical Dynamics in High Resolution Neuronal Avalanche Data. Physical Review Letters, v. 108, n. 20, p. 208102, 2012. doi: 10.1103/PhysRevLett.108.208102.

42 DEHGHANI, N.; HATSOPOULOS, N. G.; HAGA, Z. D.; PARKER, R. A.; GREGER, B.; HALGREN, E.; CASH, S. S.; DESTEXHE, A. Avalanche Analysis from Multielectrode Ensemble Recordings in Cat, Monkey, and Human Cerebral Cortex during Wakefulness and Sleep. Frontiers in physiology, v. 3, n. 302, p. 302, 2012. doi: 10.3389/fphys.2012.00302.

43 SPORNS, O. Brain Connectivity. Scholarpedia, v. 2, n. 10, p. 4695, 2007. doi: 10.4249/scholarpedia.4695.

44 SPORNS, O. Networks of the Brain. Massachusetts: The MIT Press, 2011.

45 EGUILUZ, V. M.; CHIALVO, D. R.; CECCHI, G. A.; BALIKI, M.; APKARIAN, A. V. Scale-Free Brain Functional Networks. Physical Review Letters, v. 94, n. 1, p. 18102, 2005. doi: 10.1103/PhysRevLett.94.018102.

46 ZAMORA-LóPEZ, G.; ZHOU, C.; KüRTHS, J. Exploring brain function from anatomical connectivity. Frontiers in Neuroscience, v. 5, p. 11-83, 2011. doi: 10.3389/fnins.2011.00083.

47 ACHARD, S.; SALVADOR, R.; WHITCHER, B.; SUCKLING, J.; BULLMORE, E. A Resilient, Low-Frequency, Small-World Human Brain Functional Network with Highly Connected Association Cortical Hubs. Journal Neuroscience, v. 26, n. 1, p. 63-72, 2006. doi: 10.1523/JNEUROSCI.3874-05.2006. 
48 SPORNS, O.; ZWI, J. The small world of the cerebral cortex. Neuroinformatics, v. 2, n. 2, p. 145-162, 2004.

49 DE HAAN, W.; PIJNENBURG, Y. A. L.; STRIJERS, R. L. M.; VAN DER MADE, Y.; VAN DER FLIER, W. M.; SCHELTENS, P.; STAM, C. J. Functional neural network analysis in frontotemporal dementia and Alzheimer's disease using EEG and graph theory. BMC Neuroscience, v. 10, p. 101-112, 2009. doi: doi:10.1186/1471-2202-10-101.

50 SCHWARZ, A. J.; MCGONIGLE, J. Negative edges and soft thresholding in complex network analysis of resting state functional connectivity data. Neurolmage, v. 55, n. 3, p. 1132-1146, 2011. doi: 10.1016/j.neuroimage.2010.12.047.

51 BRAUN, U.; PLICHTA, M. M.; ESSLINGER, C.; SAUER, C.; HADDAD, L.; GRIMM, O.; MIER, D.; MOHNKE, S.; HEINZ, A.; ERK, S.; WALTER, H.; SEIFERTH, N.; KIRSCH, P.; MEYER-LINDENBERG, A. Test-retest reliability of resting-state connectivity network characteristics using $\mathrm{fMRI}$ and graph theoretical measures. Neurolmage, v. 59, n. 2, p. 14041412, 2012. doi: 10.1016/j.neuroimage.2011.08.044.

52 ERDöS, P.; RéNYI, A. On random graphs I. Publicationes Mathematicae, v. 6, p. 290-297, 1959.

53 MOLLOY, M.; REED, B. A critical point for random graphs with a given degree sequence. Random Structures \& Algorithms, v. 6, n. 2-3, p. 161-180, 1995. doi: $10.1002 /$ rsa.3240060204.

54 CATANZARO, M.; BOGUñá, M.; PASTOR-SATORRAS, R. Generation of uncorrelated random scale-free networks. Physical Review E, v. 71, n. 2, p. 27103, 2005. doi: 10.1103/PhysRevE.71.027103.

55 BARABáSI, A.-L.; ALBERT, R. Emergence of Scaling in Random Networks. Science, v. 286, n. 5439, p. 509-512, 1999. doi: 10.1126/science.286.5439.509.

56 MOLLOY, M.; REED, B. The Size of the Giant Component of a Random Graph with a Given Degree Sequence. Combinatorics, Probability and Computing, v. 7, n. 03, p. 295-305, 1998. doi: null.

57 BOGUñá, M.; PASTOR-SATORRAS, R.; VESPIGNANI, A. Cut-offs and finite size effects in scale-free networks. The European Physical Journal B, v. 38, n. 2, p. 205-209, 2004. doi: 10.1140/epjb/e2004-00038-8.

58 DOROGOVTSEV, S. N.; MENDES, J. F. F. Evolution of Networks: From biological nets to the internet and WWW. Oxford: Oxford University Press, 2003.

59 DOROGOVTSEV, S.; MENDES, J.; SAMUKHIN, A. Structure of Growing Networks with Preferential Linking. Physical Review Letters, v. 85, n. 21, p. 4633-4636, 2000. doi: 10.1103/PhysRevLett.85.4633. 
60 LARREMORE, D. B.; SHEW, W. L.; RESTREPO, J. G. Predicting Criticality and Dynamic Range in Complex Networks: Effects of Topology. Physical Review Letters, v. 106, n. 5, p. 058101, 2011. doi: 10.1103/PhysRevLett.106.058101.

61 LARREMORE, D. B.; SHEW, W. L.; OTT, E.; RESTREPO, J. G. Effects of network topology, transmission delays, and refractoriness on the response of coupled excitable systems to a stochastic stimulus. Chaos, v. 21, n. 2, p. 25117, 2011. doi: 10.1063/1.3600760.

62 COPELLI, M.; ROQUE, A. C.; OLIVEIRA, R. F.; KINOUCHI, O. Physics of psychophysics: Stevens and Weber-Fechner laws are transfer functions of excitable media. Physical Review E, v. 65, n. 6, p. 60901, 2002. doi: 10.1103/PhysRevE.65.060901.

63 COPELLI, M.; KINOUCHI, O. Intensity coding in two-dimensional excitable neural networks. Physica A, v. 349, n. 3-4, p. 431-442, 2005. doi: 10.1016/j.physa.2004.10.043.

64 COPELLI, M.; CAMPOS, P. R. A. Excitable scale free networks. The European Physical Journal B, v. 56, n. 3, p. 273-278, 2007.

65 NEWMAN, M. E. J. Power laws, Pareto distributions and Zipf's law. Contemporary Physics, v. 49, n. 5, p. 323-351, 2005. doi: 10.1080/00107510500052444.

66 CLAUSET, A.; SHALIZI, C. R.; NEWMAN, M. E. J. Power-Law Distributions in Empirical Data. SIAM Review, v. 51, n. 4, p. 661-703, 2009. doi: 10.1137/070710111.

67 COVER, T. M.; THOMAS, J. A. Elements of Information Theory. Hoboken: John Wiley \& Sons, 2006.

68 HARRIS, T. E. The Theory of Branching Processes. Mineola: Courier Dover Publications, 2002.

69 FELLER, W. Introduction to Probability Theory and its Applications. New York: John Wiley \& Sons, 1957.

70 KARLIN, S.; TAYLOR, H. M. A first course in stochastic processes. New York: Academic Press, 1975.

71 ZAPPERI, S.; LAURITSEN, K. B.; STANLEY, H. E. Self-Organized Branching Processes: Mean-Field Theory for Avalanches. Physical Review Letters, v. 75, n. 22, p. 4071-4074, 1995. doi: 10.1103/PhysRevLett.75.4071.

72 LARREMORE, D. B.; CARPENTER, M. Y.; OTT, E.; RESTREPO, J. G. Statistical properties of avalanches in networks. Physical Review E, v. 85, n. 6, p. 66131, 2012. doi: 10.1103/PhysRevE.85.066131. 
73 SETHNA, J. P.; DAHMEN, K. A.; MYERS, C. R. Crackling noise. Nature, v. 410, n. 6825 , p. 242-50, 2001. doi: $10.1038 / 35065675$.

74 PAPANIKOLAOU, S.; BOHN, F.; SOMMER, R. L.; DURIN, G.; ZAPPERI, S.; SETHNA, J. P. Universality beyond power laws and the average avalanche shape. Nature Physics, v. 7, p. 316-320, 2011. doi: 10.1038/nphys1884.

75 KUNTZ, M. C.; SETHNA, J. P. Noise in disordered systems: The power spectrum and dynamic exponents in avalanche models. Physical Review B, v. 62, n. 17, p. 11699-11708, 2000. doi: 10.1103/PhysRevB.62.11699.

76 MEHTA, A. P.; MILLS, A. C.; DAHMEN, K. A.; SETHNA, J. P. Universal pulse shape scaling function and exponents: Critical test for avalanche models applied to Barkhausen noise. Physical Review E, v. 65, n. 4, p. 46139, 2002. doi: 10.1103/PhysRevE.65.046139.

77 LI, X.; LU, D.; LIU, X.; ZHANG, Q.; ZHOU, X. Ultrastructural characterization of olfactory sensilla and immunolocali-zation of odorant binding and chemosensory proteins from an ectopara-sitoid Scleroderma guani (Hymenoptera: Bethylidae). International Journal of Biological Sciences, v. 7, n. 6, p. 848-868, 2011. doi: 10.7150/ijbs.7.848.

78 PELOSI, P. Odorant-binding proteins: structural aspects. Annals of the New York Academy of Sciences, v. 855, n. 3, p. 281-293, 1998. doi: 10.3109/10409239409086801.

79 KRIEGER, J.; BREER, H. Olfactory reception in invertebrates. Science, v. 286, n. 5440, p. $720-723,1999$. doi: $10.1126 /$ science.286.5440.720.

80 PELOSI, P.; BALDACCINI, N. E.; PISANELLI, A. M. Identification of a specific olfactory receptor for 2-isobutyl-3-methoxypyrazine. The Biochemical journal, v. 201, n. 1, p. 245-8, 1982.

81 SECRETDISC. Vespula vulgaris sem antenna 03. https://commons.wikimedia.org/wiki/File:VespulavulgarisSEMAntenna03.jpg. Acessado em: 20 de Julho de 2015.

82 SCOTT, K.; BRADY, R.; CRAVCHIK, A.; MOROZOV, P.; RZHETSKY, A.; ZUKER, C.; $A X E L, R$. A chemosensory gene family encoding candidate gustatory and olfactory receptors in Drosophila. Cell, v. 104, n. 5, p. 661-73, 2001.

83 GALIZIA, C. G.; SACHSE, S.; RAPPERT, A.; MENZEL, R. The glomerular code for odor representation is species specific in the honeybee Apis mellifera. Nature neuroscience, v. 2, n. 5, p. 473-8, 1999. doi: 10.1038/8144.

84 JOERGES, J.; KüTTNER, A.; GALIZIA, C. G.; MENZEL, R. Representations of odours and odour mixtures visualized in the honeybee brain. Nature, v. 387, n. 6630, p. 285-288, 1997. doi: $10.1038 / 387285 a 0$. 
85 GALáN, R. F.; SACHSE, S.; GALIZIA, C. G.; HERZ, A. V. M. Odor-Driven Attractor Dynamics in the Antennal Lobe Allow for Simple and Rapid Olfactory Pattern Classification. Neural Computation, v. 16, n. 5, p. 999-1012, 2004. doi: 10.1162/089976604773135078.

86 KROFCZIK, S.; MENZEL, R.; NAWROT, M. P. Rapid odor processing in the honeybee antennal lobe network. Frontiers in Computational Neuroscience, v. 2, n. 9, 2009. doi: 10.3389/neuro.10.009.2008.

87 VICKERS, N. J.; CHRISTENSEN, T. A.; BAKER, T. C.; HILDEBRAND, J. G. Odourplume dynamics influence the brain's olfactory code. Nature, v. 410, n. 6827, p. 466-70, 2001. doi: $10.1038 / 35068559$.

88 BELMABROUK, H.; NOWOTNY, T.; ROSPARS, J.-P.; MARTINEZ, D. Interaction of cellular and network mechanisms for efficient pheromone coding in moths. Proceedings of the National Academy of Sciences, v. 108, n. 49, p. 19790-19795, 2011. doi: 10.1073/pnas.1112367108.

89 LAURENT, G.; STOPFER, M.; BHAGAVAN, S.; SMITH, B. H. No Title. Nature, v. 390, n. 6655 , p. $70-74,1997$. doi: 10.1038/36335.

90 SACHSE, S.; GALIZIA, C. G. Role of Inhibition for Temporal and Spatial Odor Representation in Olfactory Output Neurons: A Calcium Imaging Study. J Neurophysiol, v. 87, n. 2, p. 1106-1117, 2002.

91 WILSON, R. I. Role of GABAergic Inhibition in Shaping Odor-Evoked Spatiotemporal Patterns in the Drosophila Antennal Lobe. Journal of Neuroscience, v. 25, n. 40, p. 9069 9079, 2005. doi: 10.1523/JNEUROSCI.2070-05.2005.

92 OLSEN, S. R.; WILSON, R. I. Lateral presynaptic inhibition mediates gain control in an olfactory circuit. Nature, v. 452, n. 7190, p. 956-960, 2008. doi: 10.1038/nature06864.

93 DUJARDIN, F. Memoire sur le systeme nerveux des insectes. Annales des Sciences Naturelles, v. 14, p. 195-206, 1850.

94 STRAUSFELD, N. J.; HANSEN, L.; LI, Y.; GOMEZ, R. S.; ITO, K. Evolution, Discovery, and Interpretations of Arthropod Mushroom Bodies. Learning \\& Memory, v. 5, n. 1, p. 11-37, 1998. doi: 10.1101/lm.5.1.11.

95 RYBAK, J.; MENZEL, R. Anatomy of the mushroom bodies in the honey bee brain: the neuronal connections of the alpha-lobe. The Journal of comparative neurology, v. 334, n. 3 , p. 444-65, 1993. doi: 10.1002/cne.903340309.

96 HEISENBERG, M. What Do the Mushroom Bodies Do for the Insect Brain? An Introduction. Learning \\& Memory, v. 5, n. 1, p. 1-10, 1998. doi: 10.1101/lm.5.1.1. 
97 POWER, M. E. The brain of Drosophila melanogaster. Journal of Morphology, v. 72, n. 3, p. 517-559, 1943. doi: 10.1002/jmor.1050720306.

98 STRAUSFELD, N. Atlas of an Insect Brain. Berlin: Springer, 2012.

99 KENYON, F. C. The brain of the bee. A preliminary contribution to the morphology of the nervous system of the arthropoda. Journal of Comparative Neurology, v. 6, n. 3, p. 133-210, 1896. doi: $10.1002 /$ cne.910060302.

100 EHMER, B.; GRONENBERG, W. Segregation of visual input to the mushroom bodies in the honeybee (Apis mellifera). Journal of Comparative Neurology, v. 451, n. 4, p. 362-373, 2002. doi: $10.1002 /$ cne.10355.

101 MOBBS, P. G. The Brain of the Honeybee Apis Mellifera. I. The Connections and Spatial Organization of the Mushroom Bodies. Philosophical Transactions of the Royal Society B: Biological Sciences, v. 298, n. 1091, p. 309-354, 1982. doi: 10.1098/rstb.1982.0086.

102 SZYSZKA, P.; DITZEN, M.; GALKIN, A.; GALIZIA, C. G.; MENZEL, R. Sparsening and temporal sharpening of olfactory representations in the honeybee mushroom bodies. Journal of neurophysiology, v. 94, n. 5, p. 3303-13, 2005. doi: 10.1152/jn.00397.2005.

103 PEREZ-ORIVE, J.; MAZOR, O.; TURNER, G. C.; CASSENAER, S.; WILSON, R. I.; LAURENT, G. Oscillations and sparsening of odor representations in the mushroom body. Science, v. 297, n. 5580, p. 359-65, 2002. doi: 10.1126/science.1070502.

104 NOWOTNY, T.; HUERTA, R. On the equivalence of Hebbian learning and the SVM formalism. In: . IEEE, c2012. p. 1-4.

105 BAZHENOV, M.; HUERTA, R.; SMITH, B. H. A computational framework for understanding decision making through integration of basic learning rules. The Journal of neuroscience, v. 33, n. 13, p. 5686-97, 2013. doi: 10.1523/JNEUROSCI.4145-12.2013.

106 CASSENAER, S.; LAURENT, G. Corrigendum: Conditional modulation of spike-timingdependent plasticity for olfactory learning, 2012.

107 HUERTA, R.; NOWOTNY, T. Fast and robust learning by reinforcement signals: explorations in the insect brain. Neural computation, v. 21, n. 8, p. 2123-51, 2009. doi: 10.1162/neco.2009.03-08-733.

108 HUERTA, R.; NOWOTNY, T.; GARCÍA-SANCHEZ, M.; ABARBANEL, H. D. I.; RABINOVICH, M. I. Learning classification in the olfactory system of insects. Neural computation, v. 16, n. 8, p. 1601-40, 2004. doi: 10.1162/089976604774201613. 
109 HUERTA, R.; VEMBU, S.; AMIGó, J. M.; NOWOTNY, T.; ELKAN, C. Inhibition in multiclass classification. Neural computation, v. 24, n. 9, p. 2473-507, 2012. doi: 10.1162/NECO_a_00321.

110 STOPFER, M. Central processing in the mushroom bodies. Current Opinion in Insect Science, v. 6, p. 99-103, 2014. doi: 10.1016/j.cois.2014.10.009.

111 HAEHNEL, M.; MENZEL, R. Sensory representation and learning-related plasticity in mushroom body extrinsic feedback neurons of the protocerebral tract. Frontiers in systems neuroscience, v. 4, p. 161, 2010. doi: 10.3389/fnsys.2010.00161.

112 BAZHENOV, M.; STOPFER, M. Forward and back: motifs of inhibition in olfactory processing. Neuron, v. 67, n. 3, p. 357-8, 2010. doi: 10.1016/j.neuron.2010.07.023.

113 PAPADOPOULOU, M.; CASSENAER, S.; NOWOTNY, T.; LAURENT, G. Normalization for sparse encoding of odors by a wide-field interneuron. Science, v. 332, n. 6030, p. 721-725, 2011. doi: 10.1126/science.1201835.

114 MENZEL, R.; GIURFA, M. Cognitive architecture of a mini-brain: the honeybee. Trends in Cognitive Sciences, v. 5, n. 2, p. 62-71, 2001. doi: 10.1016/S1364-6613(00)01601-6.

115 HEISENBERG, M.; BORST, A.; WAGNER, S.; BYERS, D. Drosophila mushroom body mutants are deficient in olfactory learning. Journal of Neurogenetics, v. 2, n. 1, p. 1-30, 1985.

116 PASCUAL, A. Localization of Long-Term Memory Within the Drosophila Mushroom Body. Science, v. 294, n. 5544, p. 1115-1117, 2001. doi: 10.1126/science.1064200.

117 WESSNITZER, J.; YOUNG, J. M.; ARMSTRONG, J. D.; WEBB, B. A model of nonelemental olfactory learning in Drosophila. Journal of Computational Neuroscience, v. 32, n. 2, p. 197-212, 2012. doi: 10.1007/s10827-011-0348-6.

118 COVER, T. M. Geometric and statistical properties of systems of linear in-equalities with applications in pattern recognition. IEEE Transactions on Electronic Computers, v. 14, n. 3, p. 326, 1965. doi: 10.1109/PGEC.1965.264137.

119 BAKER, J. L. Is there a support vector machine hiding in the dentate gyrus? Neurocomputing, v. 52-54, p. 199-207, 2003. doi: 10.1016/S0925-2312(02)00733-6.

120 MONTERO, A.; HUERTA, R.; RODRIGUEZ, F. B. Regulation of specialists and generalists by neural variability improves pattern recognition performance. Neurocomputing, v. 151, p. 69-77, 2015. doi: 10.1016/j.neucom.2014.09.073.

121 LIN, A. C.; BYGRAVE, A. M.; DE CALIGNON, A.; LEE, T.; MIESENBöCK, G. Sparse, decorrelated odor coding in the mushroom body enhances learned odor discrimination. Nature neuroscience, v. 17 , n. 4, p. 559-68, 2014. doi: 10.1038/nn.3660. 
122 GANESHINA, O.; MENZEL, R. GABA-immunoreactive neurons in the mushroom bodies of the honeybee: An electron microscopic study. The Journal of Comparative Neurology, v. 437, n. 3, p. 335-349, 2001. doi: 10.1002/cne.1287.

123 TRINCAVELLI, M.; VERGARA, A.; RULKOV, N.; MURGUIA, J. S.; LILIENTHAL, A.; HUERTA, R.; GOUMA, P. Optimizing the Operating Temperature for an array of MOX Sensors on an Open Sampling System. In: . American Institute of Physics, c2011. p. 225-227.

124 RODRIGUEZ-LUJAN, I.; FONOLLOSA, J.; VERGARA, A.; HOMER, M.; HUERTA, $R$. On the calibration of sensor arrays for pattern recognition using the minimal number of experiments. Chemometrics and Intelligent Laboratory Systems, v. 130, p. 123-134, 2014. doi: 10.1016/j.chemolab.2013.10.012.

125 HUERTA, R.; NOWOTNY, T.; GARCÍA-SANCHEZ, M.; ABARBANEL, H. D. I.; RABINOVICH, M. I. Learning Classification in the Olfactory System of Insects. Neural Computation, v. 16, n. 8, p. 1601-1640, 2004. doi: 10.1162/089976604774201613.

126 RöSSLER, W.; BRILL, M. F. Parallel processing in the honeybee olfactory pathway: structure, function, and evolution. Journal of comparative physiology. A, Neuroethology, sensory, neural, and behavioral physiology, v. 199, n. 11, p. 981-96, 2013. doi: 10.1007/s00359013-0821-y.

127 GEISSER, S. Predictive Inference. London: Chapman \& Hall, 1993.

$128 \mathrm{KOHAVI}, \mathrm{R}$.; OTHERS. A study of cross-validation and bootstrap for accuracy estimation and model selection. In: . c1995 (. p. 1137-1145.

129 HAYKIN, S. Neural Networks: A Comprehensive Foundation. 2th. ed. Prentice Hall, 1999.

130 VAPNIK, V. Pattern recognition using generalized portrait method. Automation and remote control, v. 24, p. 774-780, 1963.

131 VAPNIK, V. The Nature of Statistical Learning Theory. Berlin: Springer, 1999.

132 HUERTA, R. Learning pattern recognition and decision making in the insect brain. AIP Conference Proceedings, v. 101, n. 1, p. 101-119, 2013. doi: 10.1063/1.4776507.

133 IZHIKEVICH, E. M. Dynamical Systems in Neuroscience: The Geometry of Excitability and Bursting. The MIT Press, 2010.

134 KEENER, J. P.; SNEYD, J. Mathematical Physiology. Springer Science \& Business Media, 1998. 
135 BOYD, S.; VANDENBERGHE, L. Convex Optimization. Cambridge: Cambridge University Press, 2004.

136 NOVAK, V.; PERFILIEVA, I.; MOCKOR, J. Mathematical Principles of Fuzzy Logic. Berlin: Springer, 1999.

137 YAGER, R. R.; FILEV, D. P. Essentials of Fuzzy Modeling and Control. New York: Wiley, 1994.

138 NEWMAN, M. E. J.; BARKEMA, G. T. Monte Carlo methods in statistical physics. Gloucestershire: Clarendon Press, 1999.

139 GILKS, W. R.; RICHARDSON, S.; SPIEGELHALTER, D. Markov Chain Monte Carlo in Practice. Atlanta: Chapman and Hall, 1995.

140 SERRANO, E.; NOWOTNY, T.; LEVI, R.; SMITH, B. H.; HUERTA, R. Gain control network conditions in early sensory coding. PLoS computational biology, v. 9, n. 7, p. e1003133, 2013. doi: 10.1371/journal.pcbi.1003133.

141 STROGATZ, S. H. Nonlinear Dynamics and Chaos. Boulder: Westview Press, 2014.

142 WILSON, H. R. Spikes, Decisions, and Actions: The Dynamical Foundations of Neuroscience. Oxford University Press, USA, 1999.

143 IGLESIAS, P. A.; INGALLS, B. P. Control Theory and Systems Biology. Massachusetts: MIT Press, 2009.

144 KATOK, A. Introduction to the Modern Theory of Dynamical Systems. Cambridge: Cambridge University Press, 1996.

145 GUCKENHEIMER, J.; HOLMES, P. Nonlinear oscillations, dynamical systems, and bifurcations of vector fields. Springer. ed. Berlin: Springer, 2002.

146 TAYLOR, T. J.; HARTLEY, C.; SIMON, P. L.; KISS, I. Z.; BERTHOUZE, L. Identification of Criticality in Neuronal Avalanches: I. A Theoretical Investigation of the Non-driven Case. Journal of mathematical neuroscience, v. 3, n. 1, p. 5, 2013. doi: 10.1186/2190-85673-5.

147 MARKOVIć, D.; GROS, C.; SCHUELEIN, A. Criticality in conserved dynamical systems: experimental observation vs. exact properties. Chaos, v. 23, n. 1, p. 13106, 2013. doi: $10.1063 / 1.4773003$.

148 BOTCHAROVA, M.; FARMER, S. F.; BERTHOUZE, L. Power-law distribution of phaselocking intervals does not imply critical interaction. Physical Review E, v. 86, n. 5, p. 51920, 2012. doi: 10.1103/PhysRevE.86.051920. 